\title{
§ 6 Die Feststellungsklage
}

Der gutachterlichen Prüfung der Feststellungsklage liegt die folgende Struktur 1 zugrunde:

A. Zulässigkeit

I. Eröffnung des Verwaltungsrechtswegs (dazu bereits $\S 1$ Rn. 162ff.)

II. Statthafte Klageart (dazu einführend §1 Rn. 222ff. und ausführlich in diesem $\S$ Rn. 2 ff.)

III. Klagebefugnis (dazu Rn. $78 \mathrm{ff}$.)

IV. Beteiligte (dazu Rn. $86 \mathrm{ff}$.)

V. Zuständiges Gericht (dazu Rn. $89 \mathrm{ff}$.)

VI. Feststellungsinteresse (dazu Rn. 93 ff.)

B. Begründetheit

Var. 1: „Klassische“ Feststellungsklage: Bestehen oder Nichtbestehen des Rechtsverhältnisses (dazu Rn. 103ff.)

Var. 2: Nichtigkeitsfeststellungsklage: Nichtigkeit des Verwaltungsakts (dazu Rn. 115ff.)

Zur Feststellungsklage im Polizei- und Ordnungsrecht Rn. 181 ff., im Kommunalrecht Rn. 186 ff. und im Verwaltungsvollstreckungsrecht Rn. 193 ff.

\section{Gliederung}

A. Die Statthaftigkeit der Feststellungsklage - 789

I. Die „klassische“ Feststellungsklage nach § 43 I Alt. 1 VwGO (Katrin Giere) 791

1. Erster Überblick — 792

2. Im Einzelnen: Feststellungsfähiges Rechtsverhältnis, § 43 I Alt. 1 VwGO 793

a) Konkreter Sachverhalt — $\mathbf{7 9 5}$

aa) „Auslöser“ als Verdichtung der abstrakten Rechtsfrage — 795

bb) Die Überprüfung von Normen mittels der allgemeinen Feststellungsklage

797

(1) Untergesetzliche Normen (Rechtsverordnungen und Satzungen) 797

(2) Parlamentsgesetze: Verwaltungsgerichte und BVerfG

799

b) Öffentlich-rechtliche Beziehung

800
aa) Norm - $\mathbf{8 0 1}$
bb) Dem Verwaltungsakt vorgelagerte Situationen - $\mathbf{8 0 1}$
cc) Öffentlich-rechtlicher Vertrag - $\mathbf{8 0 2}$
dd) Realakt $\longrightarrow \mathbf{8 0 2}$

c) Vergangene und zukünftige Rechtsverhältnisse 803

aa) Vergangene Rechtsverhältnisse

803

Ә OpenAccess. () 2019 Nikolas Eisentraut, publiziert von De Gruyter. (cc) BY-SA Dieses Werk ist lizenziert unter der Creative Commons Attribution-ShareAlike 4.0. International. 
bb) Zukünftige Rechtsverhältnisse - $\mathbf{8 0 4}$

d) Verhältnis von Personen zueinander oder einer Person zu einer Sache $-\mathbf{8 0 7}$

e) Rechtsverhältnis mit Drittbeteiligung - $\mathbf{8 0 7}$

3. Im Einzelnen: Die Subsidiarität der Feststellungsklage, § 43 II 1 VwGO 808

a) Ausnahme bei nicht gleichermaßen oder weniger effektivem Rechtsschutz - 809

b) Ausnahme nach der „Ehrenmanntheorie“ - $\mathbf{8 1 0}$

4. Literaturhinweise $\mathbf{8 1 1}$

II. Die Nichtigkeitsfeststellungsklage (Tobias Brings-Wiesen) - $\mathbf{8 1 1}$

B. Weitere Zulässigkeitsvoraussetzungen - 813

I. Klagebefugnis (Hendrik Burbach) $-\mathbf{8 1 3}$

II. (Kein) Vorverfahren (Renana Braun) - $\mathbf{8 1 4}$

III. (Keine) Klagefrist (Patrick Stockebrandt) $-\mathbf{8 1 4}$

IV. Beteiligte (Carola Creemers) - 814

V. Zuständiges Gericht (Katharina Goldberg) — 815

VI. Feststellungsinteresse (Dana-Sophia Valentiner) - $\mathbf{8 1 6}$

1. Berechtigtes Interesse $-\mathbf{8 1 6}$

2. Relevante Fallgruppen $-\mathbf{8 1 7}$

\section{Begründetheit $-\mathbf{8 1 8}$}

I. Begründetheit der „klassischen“ Feststellungsklage (Katrin Giere) - $\mathbf{8 1 8}$

1. Rechtsverhältnis aufgrund einer Norm — 819

2. Rechtsverhältnis aufgrund eines öffentlich-rechtlichen Vertrags $-\mathbf{8 1 9}$

3. Rechtsverhältnis aufgrund eines Realakts - $\mathbf{8 1 9}$

a) Notwendigkeit einer gesetzlichen Ermächtigungsgrundlage (Bernhard Hadank) 819

b) Rechtmäßigkeit der realen Handlung (Katrin Giere) - $\mathbf{8 2 1}$

4. Zusammenfassung $-\mathbf{8 2 2}$

5. Literaturhinweise $-\mathbf{8 2 2}$

II. Begründetheit der Nichtigkeitsfeststellungsklage (Tobias Brings-Wiesen) - 822

1. Das Verhältnis der Absätze des § $44 \mathrm{VwVfG}$ untereinander — 823

2. Besondere Nichtigkeitsgründe, § 44 II VwVfG — 824

a) Unerkennbarkeit der erlassenden Behörde (Nr. 1) -825

b) Fehlen einer Urkunde (Nr. 2) - $\mathbf{8 2 6}$

c) Verstoß gegen die örtliche Zuständigkeit gemäß § 3 I Nr. 1 VwVfG (Nr. 3) - 827

d) Tatsächliche Unmöglichkeit der Befolgung der gesetzten Rechtsfolge (Nr. 4) 828

e) Gebot der Begehung einer rechtswidrigen Tat, die einen Straf- oder Bußgeldtatbestand verwirklicht (Nr. 5) $-\mathbf{8 3 0}$

f) Verstoß gegen die guten Sitten (Nr. 6) -832

3. Allgemeine Nichtigkeitsgründe, § 44 I und III VwVfG

a) Kein Ausschlusstatbestand, § $44 \mathrm{III} \mathrm{VwVfG} 835$

b) Besonders schwerwiegender Fehler — 839

c) Offensichtlichkeit des Fehlers und seiner besonderen Schwere - $\mathbf{8 4 5}$

4. Teilnichtigkeit, § $44 \mathrm{IV} \mathrm{VwVfG} 847$

5. Behördliche Feststellung der Nichtigkeit gemäß § $44 \mathrm{~V} \mathrm{VwVfG} \mathbf{8 4 9}$

6. Literaturhinweise -853

III. Die Feststellungsklage im Polizei- und Ordnungsrecht (Nikolas Eisentraut) $\longrightarrow \mathbf{8 5 4}$ 
IV. Die Feststellungsklage im Kommunalrecht (Sebastian Piecha) $-\mathbf{8 5 4}$

V. Die Feststellungsklage im Verwaltungsvollstreckungsrecht (Mariamo Katharina

Ilal) 856

1. Ermächtigungsgrundlage für die Zwangsmittelanwendung - $\mathbf{8 5 7}$

2. Formelle Rechtmäßigkeit der Zwangsmittelanwendung — 857

3. Materielle Rechtmäßigkeit der Zwangsmittelanwendung — 857

a) Allgemeine Vollstreckungsvoraussetzungen $-\mathbf{8 5 8}$

b) Besondere Vollstreckungsvoraussetzungen - $\mathbf{8 5 8}$

aa) Ordnungsgemäßes Vollstreckungsverfahren $-\mathbf{8 5 8}$

(1) Wirksame Androhung, § 13 VwVG -859

(2) Wirksame Festsetzung, § 14 VwVG -859

bb) Anwendung im Rahmen der Festsetzung

859

\section{A. Die Statthaftigkeit der Feststellungsklage}

Wurde der Verwaltungsrechtsweg für eröffnet erkannt (s. ausführlich zur Prüfung 2 $\S 1$ Rn. 162ff.), so ist im Rahmen der Zulässigkeit als nächstes die statthafte Klagebzw. Antragsart zu untersuchen. Die Klage-/Antragsart ist das zentrale Scharnier für die gesamte restliche Klausur. Nach ihr richten sich sowohl die weiteren Zulässigkeitsvoraussetzungen als auch die Struktur der Begründetheitsprüfung. Entsprechend wichtig ist die saubere Prüfung, welche Klage- bzw. Antragsart einschlägig ist (eine erste Übersicht über die Klage- und Antragsarten der VwGO findet sich in $\S 1 \mathrm{Rn}$. 222ff.).

Die allgemeine Feststellungsklage ist in $§ 43$ VwGO geregelt. Hat die Kläger^in 3 ein berechtigtes Interesse, kann sie mit der Feststellungklage i. S.d. § 43 I VwGO die Feststellung des Bestehens oder Nichtbestehens eines Rechtsverhältnisses (§ 43 I Alt. 1 VwGO) oder der Nichtigkeit eines Verwaltungsakts (§ 43 I Alt. 2 VwGO) verlangen.

Neben den anderen Klagearten der VwGO ist die Feststellungsklage als eine 4 der schwierigsten zu betrachten. Dies liegt nicht allein an der Subsidiarität dieser gegenüber anderen Klagearten, § 43 II 1 VwGO (dazu sogleich Rn. 63 ff.), sondern insbesondere an den weiten und abstrakten Voraussetzungen und den unterschiedlichen Ausformungen der Feststellungsklage.

$\mathrm{Zu}$ nennen sind:

- die „klassische“ Feststellungsklage, § 43 I Alt. 1 VwGO

- die vorbeugende Feststellungsklage

- die Nichtigkeitsfeststellungsklage, § 43 I Alt. 2 VwGO

- die Fortsetzungsfeststellungsklage, § 113 I 4 VwGO (hierzu bereits ausführlich $\S 4)$ und

- die Zwischenfeststellungsklage, § 173 VwGO i.V.m. § 256 II ZPO. 
6 Die Klagen nach $\S 43$ VwGO werden als allgemeine Feststellungklagen bezeichnet. Dies dient der Abgrenzung zur „besonderen“ Feststellungsklage, der Fortsetzungsfeststellungsklage i.S.d. § 113 I 4 VwGO. Wenn im Folgenden von der Feststellungsklage gesprochen wird, ist hiermit die allgemeine Feststellungsklage nach $\S 43$ I VwGO gemeint. ${ }^{1}$

Bei der Nichtigkeitsfeststellungsklage (und auch der Fortsetzungsfeststellungsklage) steht im Gegensatz zur „klassischen“ Feststellungsklage ein Verwaltungsakt im Mittelpunkt der Prüfung (s. zur Fortsetzungsfeststellungsklage §4 und zur Nichtigkeitsfeststellungsklage Rn. 73ff.). Demgegenüber verlangt die „klassische“ Feststellungsklage, § 43 I Alt. 1 VwGO das Vorliegen eines feststellungsfähigen Rechtsverhältnisses.

7 Examenswissen: Die Feststellungsklage i.S.d. §43 VwGO unterscheidet sich insoweit von den anderen Klagearten, als sie mangels Leistungsbefehl im Urteilstenor - anders als Anfechtungsund Leistungsklagen - nicht der unmittelbaren Durchsetzung eines materiell-rechtlichen Anspruchs dient. Sie begründet vielmehr einen Rechtsschutzanspruch der Klägerin gegen das Gericht auf Feststellung des streitigen Rechtsverhältnisses. Die Feststellungsklage ist mithin - mit Ausnahme der Kosten ${ }^{2}$ - nicht vollstreckbar. ${ }^{3}$ Sie dient daher als Auffangrechtsbehelf, der der Rechtsschutzgarantie des Art. 19 IV GG und der VwGO Rechnung trägt. Nach dieser Rechtsschutzgarantie muss jeder Streitigkeit, der der Verwaltungsrechtsweg offensteht, eine Klageart zur Verfügung stehen. ${ }^{4}$

8 Die allgemeine Feststellungsklage lässt zwar eine geringe Prüfungsrelevanz vermuten. Sie gewinnt in der Praxis und damit auch in der Theorie für Studierende und Referendare jedoch zunehmend an Bedeutung: Das liegt zum einen daran, dass die Rspr. den Grundsatz der Subsidiarität (§ 43 II 1 VwGO) mehr und mehr relativiert, sodass die Feststellungsklage einen größeren Anwendungsbereich gewinnt. ${ }^{5}$ Da die Rechtssatzverfassungsbeschwerde nach der Rechtsprechung des BVerfG $^{6}$ gegenüber den verwaltungsgerichtlichen Feststellungsklagen subsidiär ist (s. näher sogleich Rn. 30), kommt der Feststellungsklage eine hohe Relevanz auch im Rahmen der Überprüfung von Normen zu. Zum anderen findet die allgemeine Feststellungsklage dann Anwendung, wenn die Rechtslage mit Blick

1 So auch Gersdorf, Verwaltungsprozessrecht, 6. Aufl. 2019, Rn. 117.

2 Bosch/Schmidt/Vondung, Praktische Einführung in das verwaltungsgerichtliche Verfahren, 10. Aufl. 2019, Rn. 857.

3 Pietzcker, in: Schoch/Schneider/Bier, VwGO, 36. EL Februar 2019, § 43 Rn. 1; Würtenberger/ Heckmann, Verwaltungsprozessrecht, 4. Aufl. 2018, Rn. 463.

4 Möstl, in: Posser/Wolf, VwGO, 50. Ed., Stand: 1.4.2019, § 43 Einl.

5 S. etwa BVerfG, Beschl. v. 16.7.2015, Az.: 1 BvR 1014/13 = NVwZ-RR 2016, 1.

6 BVerfG, Beschl. v. 22.3.2000, Az.: 1 BvR 1500/93 = NVwZ-RR 2000, 473 ff.

Katrin Giere 
auf eine Vielzahl von Pflichten - anders als bei Gestaltungsklagen - geklärt werden soll.

Die gutachterliche Prüfung einer Klausuraufgabe, in der die Feststellungs- 9 klage als statthafte Klageart erkannt wurde, ist mit einem Obersatz zu beginnen (allgemein dazu $§ 1$ Rn. 42).

Formulierungsvorschlag: „Die Klage hat Aussicht auf Erfolg, wenn sie zulässig und begründet ist.“

Die Statthaftigkeit der Klage richtet sich nach dem Klagebegehren (§ 88 VwGO). 10 Begehrt die Kläger^in die Feststellung des Bestehens oder Nichtbestehens eines Rechtsverhältnisses oder die Feststellung der Nichtigkeit eines Verwaltungsakts, ist die allgemeine Feststellungsklage i.S.d. § 43 I VwGO statthaft.

Die Feststellungsklage i.S.d. § 43 I VwGO erfasst mithin drei Klagebegehren:

- die Feststellung des Bestehens eines Rechtsverhältnisses (sog. positive Feststellungsklage nach § 43 I Var. 1 VwGO) (sogleich Rn. 16ff.).

Beispiel: Feststellung des Bestehens eines Beamtenverhältnisses; Feststellung des Vorliegens einer Mitgliedschaft in einer öffentlich-rechtlichen Körperschaft.

- die Feststellung des Nichtbestehens eines Rechtsverhältnisses (sog. negative Feststellungsklage nach §43 I Var. 2 VwGO) (ebenfalls sogleich Rn. 16 ff.).

Beispiel: Feststellung des Nichtunterliegens einer Genehmigungspflicht; das Nichtbestehen einer der Rechtspflicht zum Tragen einer Robe.

- $\quad$ oder die Feststellung der Nichtigkeit eines Verwaltungsakts (sog. Nichtigkeitsfeststellungsklage nach § 43 I Var. 3 VwGO) (näher Rn. 73 ff.).

\section{Die „klassische“ Feststellungsklage nach § 43 I Alt. 1 VwGO (Katrin Giere)}

Die „klassische“ Feststellungsklage nach § 43 I Alt. 1 VwGO ist unter zwei Vor- 12 aussetzungen statthaft:

- es liegt ein feststellungsfähiges Rechtsverhältnis vor 
- $\quad$ und es greift nicht die Subsidiarität der Feststellungsklage gegenüber Gestaltungs- $^{7}$ oder Leistungsklagen, § 43 II 1 VwGO.

Dies gilt gleichermaßen für die positive als auch für die negative Feststellungsklage.

\section{Erster Überblick}

13 Der folgende Abschnitt soll einen ersten Überblick über die Voraussetzungen der „klassischen“ Feststellungsklage geben. Bei der allgemeinen Feststellungsklage müssen neben den allgemeinen Sachentscheidungsvoraussetzungen folgende besondere Voraussetzungen vorliegen:

1. Ein feststellungsfähiges Rechtsverhältnis, § 43 I Alt. 1 VwG0: Das feststellungsfähige Rechtsverhältnis ist eine sich aus einem konkreten Sachverhalt ergebende öffentlich-rechtliche Beziehung einer Person zu einer anderen Person oder zu einer Sache. ${ }^{8}$

- Konkreter Sachverhalt (Rn. 20 ff.): Um dem weiten Verständnis des verwaltungsrechtlichen Rechtsverhältnisses Einhalt zu gebieten und den Anwendungsbereich der Feststellungsklage aufgrund der Fülle an Rechten und Pflichten, die aus Verträgen, Normen und Realakten hervorgehen können, nicht übermäßig auszudehnen (allgemeine „Auskunftsklage“99), setzt die Statthaftigkeit der Feststellungsklage einen konkreten Sachverhalt voraus. ${ }^{10}$ Davon ist auszugehen, wenn eine Rechtsfrage mit Blick auf einen Einzelfall vorliegt, also dann, wenn das Geschehen zeitlich und örtlich festgelegt ist und die Beteiligten individualisiert sind. ${ }^{11}$

Notwendig ist somit ein „Auslöser“, der die abstrakte Rechtsfrage durch tatsächliches Geschehen oder Verhalten der Beteiligten verdichtet. ${ }^{12}$

- öffentlich-rechtliche Beziehung (Rn. $36 \mathrm{ff}$.): Das Rechtsverhältnis muss öffentlich-rechtlicher Natur sein. Ist dies nicht der Fall, wäre bereits der Verwaltungsrechtsweg i.S.d. § 40 I 1 VwGO nicht eröffnet (Erinnerung an den Wortlaut der Norm: „öffentlich-rechtliche Streitigkeit“).

7 Anfechtungs- oder Verpflichtungsklagen gem. § 42 VwGO.

8 BVerwG, Urt. v. 26.1.1996, Az.: 8 C 19/94 = BVerwGE 100, 262 (264).

9 Hufen, Verwaltungsprozessrecht, 11. Aufl. 2019, § 18 Rn. 11.

10 A. A. Ehlers, JURA 2007, 179 (182): Diese Voraussetzung sei nicht notwendig, sie ergebe sich bereits aus $\S 40$ I 1 VwGO.

11 Sodan/Kluckert, GewArch 2003, 3 (8).

12 Hufen, Verwaltungsprozessrecht, 11. Aufl. 2019, § 18 Rn. 11.

Katrin Giere 
Öffentlich-rechtliche Beziehungen können nur auf Grundlage des Rechts bestehen. Das Rechtsverhältnis muss folglich durch eine öffentlich-rechtliche Regelung begründet werden.

Möglichkeiten: durch eine Norm, durch eine dem Verwaltungsakt vorgelagerte Situation, durch einen öffentlich-rechtlichen Vertrag oder durch Realakt.

- Verhältnis von Personen zueinander oder einer Person zu einer Sache (Rn. 60 ff.): Die oben beschriebenen rechtlichen Beziehungen sind als solche zwischen zwei Personen oder zwischen einer Person zu einer Sache zu verstehen. ${ }^{13}$

2. Keine Subsidiarität der Feststellungsklage, § 43 II 1 VwG0: Ergänzend zum 15 o. g. Obersatz bleibt bzgl. der Statthaftigkeit der Feststellungsklage hinzuzufügen, dass aufgrund der Subsidiarität nach §43 II 1 VwGO zunächst alle anderen möglichen Klagearten aufgrund fehlender Statthaftigkeit ausgeschlossen werden müssen, bevor mit der Prüfung der Feststellungsklage begonnen werden kann. Der Grundsatz der Subsidiarität i. S. d. § 43 II 1 VwGO schreibt vor, dass eine Feststellung dann nicht begehrt werden kann, soweit die Klägerin ihre Rechte durch Gestaltungs- oder Leistungsklage verfolgen kann oder hätte verfolgen können.

\section{Im Einzelnen: Feststellungsfähiges Rechtsverhältnis, § 43 I Alt. 1 VwG0}

Das feststellungsfähige Rechtsverhältnis wird (sehr abstrakt und weit) als die sich 16 aus einem konkreten Sachverhalt ergebende öffentlich-rechtliche Beziehung einer Person zu einer anderen Person oder zu einer Sache definiert. ${ }^{14}$

Beachte in der Klausur: An dieser Stelle ist freilich noch nicht festzustellen, 17 ob ein solches Rechtsverhältnis bereits tatsächlich vorliegt bzw. nicht vorliegt. Im Rahmen der Zulässigkeit kommt es nur auf das entsprechende Klagebegehren i.S.d. $§ 88$ VwGO an. Aus dem - als wahr unterstellten - Vortrag der Klägerin muss sich ein feststellungsfähiges Rechtsverhältnis ergeben. ${ }^{15}$ Die tatsächliche Überprüfung erfolgt erst in der Begründetheit.

Ein verwaltungsrechtliches Rechtsverhältnis und damit Gegenstand dieser 18 Klageart kann ein Rechtsverhältnis als Ganzes (Bündel von Rechten und Pflichten, etwa das gesamte Beamtenverhältnis) oder einzelne Rechte und

13 St. Rspr. BVerwG, Urt. v. 26.1.1996, Az.: 8 C 19/94 = BVerwGE 100, 262 (264) m.w. N.

14 BVerwG, Urt. v. 26.1.1996, Az.: 8 C 19/94 = BVerwGE 100, 262 (264).

15 Wöckel, JA 2015, 205. 
Pflichten (etwa ein Gehaltsanspruch einer Beamt*in gegenüber der Dienstherr`in) sein. ${ }^{16}$ Darüber hinaus kann zwischen einem Dauerrechtsverhältnis (langfristig: Gewährung von Arbeitslosengeld, Sozialversicherung, Rentenversicherung) und einem kurzfristigen Rechtsverhältnis (polizeiliche Maßnahme, wie eine Identitätsfeststellung oder die Aufforderung des Finanzamts bzgl. einer Steuererklärung) differenziert werden. ${ }^{17}$ Es kommt nicht darauf an, ob es sich um ein Außenrechtsverhältnis zwischen Bürger und Staat oder ein Innenrechtsverhältnis als intraverwaltungsrechtliche Streitigkeit zwischen Organen oder Organwaltern sowie Ämtern handelt. ${ }^{18}$

19 Nicht feststellungsfähig sind dagegen:

- Unselbstständige Teile oder Vorfragen eines Rechtsverhältnisses, die lediglich Voraussetzungen von Rechten und Pflichten sind: Streit um die allgemeine Gültigkeit einer Frauenförderungsrichtlinie außerhalb eines konkreten Bewerbungsverfahrens ${ }^{19}$

- Abstrakte Rechtsfragen wie die Gültigkeit oder Auslegung einer bestimmten Norm (näher Rn. 27 ff.): Bebaubarkeit eines Grundstücks; Arzneimitteleigenschaft eines Stoffes ${ }^{20}$ Wichtig: Eine Regelung kann niemals selbst ein Rechtsverhältnis sein. Sie muss ein solches begründen, verändern oder beenden. ${ }^{21}$

- Tatbestandsmerkmale, von denen das Vorliegen des Rechtsverhältnisses abhängig ist: Erfüllen bestimmte Arzneimittel die tatbestandlichen Voraussetzungen einer gesetzlichen Definition, die die Apothekenpflicht regelt? ${ }^{22}$

- Rechtserhebliche Eigenschaften einer Person: Abstrakte Eignung oder Zuverlässigkeit für die Ausübung eines Gewerbes

- Rechtserhebliche Eigenschaften einer Sache: Abstrakte Eigenschaft eines Raumes als Werkswohnung oder Feststellung der Verkehrsfähigkeit von Lebensmitteln

- oder der Inhalt eines Gesetzes. ${ }^{23}$

16 Bosch/Schmidt/Vondung, Einführung in die Praxis des verwaltungsgerichtlichen Verfahrens, 10. Aufl. 2019, Rn. 857; Schenke, Verwaltungsprozessrecht, 16. Aufl. 2019, Rn. 380.

17 Erbguth/Guckelberger, Allgemeines Verwaltungsrecht, 9. Aufl. 2018, § 10 Rn. 2.

18 Ehlers, JURA 2007, 179 (181).

19 Hufen, Verwaltungsprozessrecht, 11. Aufl. 2019, § 18 Rn. 11.

20 S. hierzu auch Schenke, in: Kopp/Schenke, VwGO, 25. Aufl. 2019, § 43 Rn. 13.

21 Ehlers, JURA 2007, 179 (181).

22 BVerwG, Urt. v. 20.11.2003, Az.: 3 C 44/02 = NVwZ-RR 2004, 253 (254).

23 BVerwG, Urt. v. 8.6.1962, Az.: VII C 78.61 = BVerwGE 14, 235 (236).

Katrin Giere 


\section{a) Konkreter Sachverhalt}

Um dem weiten Verständnis des verwaltungsrechtlichen Rechtsverhältnis- 20 ses Einhalt zu gebieten und den Anwendungsbereich der Feststellungsklage aufgrund der Fülle an Rechten und Pflichten, die aus Verträgen, Normen und Realakten hervorgehen können, nicht übermäßig auszudehnen (allgemeine „Auskunftsklage“24), ist für die Statthaftigkeit der Feststellungsklage ein konkreter Sachverhalt Voraussetzung. ${ }^{25}$ Davon ist auszugehen, wenn eine Rechtsfrage mit Blick auf einen Einzelfall vorliegt, also dann, wenn das Geschehen zeitlich und örtlich festgelegt ist und die Beteiligten individualisiert sind. ${ }^{26}$

\section{aa) „Auslöser“ als Verdichtung der abstrakten Rechtsfrage}

Notwendig ist ein „Auslöser“, der die abstrakte Rechtsfrage durch tatsächliches 21 Geschehen oder Verhalten der Beteiligten verdichtet. ${ }^{27}$

Examenswissen: Das BVerwG definiert wie folgt: „Ein feststellungsfähiges Rechtsverhältnis setzt voraus, daß zwischen den Beteiligten dieses Rechtsverhältnisses ein Meinungsstreit besteht, aus dem heraus sich eine Seite berühmt, ein bestimmtes Tun oder Unterlassen der anderen Seite verlangen zu können. “28 Dem BVerwG ist beizupflichten, dass ein Meinungsstreit als Verhalten der Beteiligten einen abstrakten Sachverhalt zu einem konkreten verdichten kann. Daneben kann jedoch ein tatsächliches Geschehen als weitere Möglichkeit vorliegen, das einen solchen konkreten Sachverhalt hervorruft. ${ }^{29}$ Anzumerken bleibt außerdem, dass nicht immer eine Seite „ein Tun oder Unterlassen der anderen Seite“ verlangt bzw. verlangen kann. Darüber hinaus ist dem Wortlaut des § 43 I Alt. 1 VwGO zu entnehmen, dass ein streitiges Rechtsverhältnis nicht unmittelbar zwischen den Beteiligten, d. h. Kläger ${ }^{\star}$ in oder Beklagte ${ }^{\star}$, bestehen muss. ${ }^{30}$ Nach der hier vertretenen Ansicht liegt ein konkreter Sachverhalt nicht erst dann vor, wenn „ein Meinungsstreit“ zwischen den Parteien nachweisbar ist. ${ }^{31}$ Es genügt eine formlose Verdichtung des Sachverhalts.

24 Hufen, Verwaltungsprozessrecht, 11. Aufl. 2019, § 18 Rn. 11.

25 A. A. Ehlers, JURA 2007, 179 (182): Diese Voraussetzung sei nicht notwendig, sie ergebe sich bereits aus $\S 40$ I 1 VwGO.

26 Sodan/Kluckert, GewArch 2003, 3 (8).

27 Hufen, Verwaltungsprozessrecht, 11. Aufl. 2019, § 18 Rn. 11.

28 BVerwG, Urt. v. 8.9.1972, Az.: IV C 17/71 = BVerwGE 40, 323 (325).

29 Z.B. durch Kampfflugzeug aufgenommene Bilder, s. dazu sogleich Rn. 23; vgl. auch Möstl, in: Posser/Wolf, VwGO, 50. Ed., Stand: 1.4.2019, § 43 Rn. 5.

30 Schenke, in: Kopp/Schenke, VwGO, 25. Aufl. 2019, § 43 Rn. 19; zu Rechtsverhältnissen mit Drittbeteiligung s. in diesem $\S$ Rn. $61 \mathrm{ff}$.

31 Möstl, in: Posser/Wolf, VwGO, 50. Ed., Stand: 1.4.2019, § 43 Rn. 5. 
23 „Auslöser“ für einen konkreten Sachverhalt können sein:

- Beanstandung, warnender Hinweis oder Drohung mit Straf- oder Bußgeldverfahren durch eine Behörde: Gesetzlich nicht geregelte sog. mündliche Gefährderansprache an eine Person aufgrund vergangenen (auch strafbaren) Verhaltens; ${ }^{32}$ Stadionverbot auf „Anregung“33 der Polizei: Polizei regt gegenüber einem Verein an, er solle ein bundesweites Stadionverbot für den F nach den Richtlinien des DFB zur einheitlichen Behandlung von Stadionverboten erlassen ${ }^{34}$

- Berühmen einer Behörde, bestimmte belastende Maßnahmen erlassen zu dürfen ${ }^{35}$

- Drohung mit gerichtlicher Klage oder Strafanzeige ${ }^{36}$

- Meinungsverschiedenheiten über eine Berechtigung oder Befugnis: Innehaben eines öffentlich-rechtlichen Status, wie Mitgliedschaft in einer Industrie- und Handelskammer; Genehmigungsfreiheit eines tatsächlich ausgeübten Gewerbes

- Eingriff in Grundrechte: Kenntnisnahme, Aufzeichnung und Verwertung von Kommunikationsdaten einer konkreten Person durch den Staat (Art. 10 I GG), ${ }^{37}$ durch Kampfflugzeug aufgenommene Bilder von betroffenen Personengruppen in einem Demonstranten-Camp (Art. 8 I GG ${ }^{38}$ oder der Aufruf einer Bürgermeister*in, der sich unmittelbar gegen die von einer konkreten Person angemeldete Demonstration richtet (Art. 8 I und 5 I GG) (s. hierzu auch den Beispielsfall in Rn. 205ff.) $)^{39}$

24 Von den konkreten Rechtsfragen abzugrenzen sind abstrakte Rechtsfragen, welche nicht Gegenstand einer allgemeinen Feststellungsklage i.S.d. § 43 I VwGO sein können. Nicht ausreichend ist damit ein nur erdachter oder ein solcher Sachverhalt, dessen Eintritt noch ungewiss, insbesondere von einer in ihren tatsächlichen und rechtlichen Auswirkungen noch nicht übersehbaren künftigen Entwicklung abhängig ist. ${ }^{40}$

32 OVG NRW, Beschl. v. 22.8.2016, Az.: 5 A 2532/14.

33 Aufgrund fehlender Regelung liegt kein Verwaltungsakt vor.

34 Tomerius, JURA 2018, 822f.

35 Sodan, in: Sodan/Ziekow, VwGO, 5. Aufl. 2018, § 43 Rn. 46.

36 Schenke, in: Kopp/Schenke, VwGO, 25. Aufl. 2019, § 43 Rn. 19.

37 BVerwG, Urt. v. 28.5.2014, Az.: 6 A 1/13 = NVwZ 2014, 1666 (1668 Rn. 20 ff.).

38 BVerwG, Urt. v. 25.10.2017, Az.: 6 C 46/16 = BVerwGE 160, 169.

39 BVerwG, Urt. v. 13.9.2017, Az.: 10 C 6/16 = BVerwGE 159, 327 (327 Rn. 12).

40 BVerwG, Urt. v. 8.6.1962, Az.: VII C 78.61 = BVerwGE 14, 235 (236).

Katrin Giere 
Ein „Auslöser“ fehlt dementsprechend regelmäßig dann, wenn noch kein 25 „Kommunikationsakt“ o. Ä. zwischen den Parteien vorlag: Also etwa dann, wenn keine Drohung oder Beanstandung der Behörde vorliegt ${ }^{41}$ oder die Klägerin im Vorfeld keine Anfragen oder Anträge an die Behörde gerichtet hat, ergo erstmals mit der Klage ihr Begehren geltend macht. ${ }^{42}$

Beispiel: Genehmigungsfreiheit eines nicht ausgeübten Gewerbes; die reine Möglichkeit, dass der persönliche oder berufliche E-Mail-Verkehr Gegenstand einer strategischen Überwachung des BND wird ${ }^{43}$

Problematisch ist dies insbesondere bei der Überprüfung von Normen mittels der 26 allgemeinen Feststellungsklage:

\section{bb) Die Überprüfung von Normen mittels der allgemeinen Feststellungsklage}

Bei der Überprüfung von Normen ${ }^{44}$ ist in der Klausurbearbeitung zunächst zu 27 unterscheiden, ob eine untergesetzliche Norm (Rechtsverordnung oder Satzung) oder ein Parlamentsgesetz vorliegt. Diese Unterscheidung macht sich in der Klausur wie folgt bemerkbar:

\section{(1) Untergesetzliche Normen (Rechtsverordnungen und Satzungen)}

Grundsätzlich gilt, dass die prinzipale Feststellung der Gültigkeit untergesetzlicher 28 Normen nicht mit einer Feststellungsklage i.S.d. § 43 I Alt. 1 VwGO erwirkt werden kann. Die abstrakte Ungültigkeit einer untergesetzlichen Norm betrifft zum einen kein konkretes feststellungsfähiges Rechtsverhältnis und ist in der Regel ${ }^{45}$ Gegenstand einer verwaltungsgerichtlichen Normenkontrolle i.S.d. § $47 \mathrm{VwGO}$ (näher zum Verfahren nach § $47 \mathrm{VwGO} \S 7$ ). ${ }^{46}$ Letzteres gilt freilich nur, sofern das jeweilige Land von der bundesrechtlichen Regelungsermächtigung des § 47 I Nr. 2 VwGO Gebrauch gemacht hat (hierzu § 7 Rn. 19ff.).

41 BVerwG, Urt. v. 7.5.1987, Az.: 3 C 53.85 = BVerwGE 77, 207 (211).

42 BVerwG, Urt. v. 20.11.2014, Az.: 3 C 26/13 = NVwZ-RR 2015, 420 (421).

43 BVerwG, Urt. v. 28.5.2014, Az.: 6 A 1/13 = NVwZ 2014, 1666 (1668 Rn. 20 ff.).

44 S. zur Überprüfung von Normen im Rahmen der allgemeinen Feststellungsklage auch Geis, in: Festschrift Schenke, 2001, S. 709 ff.; Hufen, in: Festschrift Schenke, 2001, S. 803 ff.; Seiler, DVBl 2007, $538 \mathrm{ff}$.

$45 \S 47$ I Nr. 1 VwGO: Satzungen, die nach BauGB erlassen wurden sowie Rechtsverordnungen, die aufgrund des § 246 II BauGB entstanden sind; § 47 I Nr. 2 VwGO: Rechtsverordnungen und Satzungen nach Landesrecht, nicht nach Bundesrecht.

46 S. auch Schenke, in: Kopp/Schenke, VwGO, 25. Aufl. 2019, § 43 Rn. 8m. 
Umstritten ist, ob die inzidente Überprüfung einer untergesetzlichen Norm Gegenstand der Feststellungsklage sein kann. Eine inzidente Überprüfung wird dann vorgenommen, wenn die Entscheidung durch ein Gericht von der Gültigkeit einer Norm abhängt. Geht es beispielsweise um das Bestehen eines Rechtsverhältnisses, dass auf einer Norm beruht (etwa Zwangsmitgliedschaft in der Industrie- und Handelskammer nach § 2 I IHKG) muss zunächst (inzident) überprüft werden, ob die Norm rechtmäßig ist, um in einem weiteren Schritt das Bestehen oder Nichtbestehen des Rechtsverhältnisses anhand der Voraussetzungen dieser Norm feststellen zu können.

Dagegen wird angeführt, dass dies eine verkappte Einführung des Normenkontrollverfahrens in denjenigen Ländern darstelle, die sich gegen ein solches Verfahren i.S.d. § 47 I Nr. 2 VwGO entschieden haben. ${ }^{47}$

Richtig ist zwar, dass die Normenkontrolle nach § 47 VwGO nicht unzulässig umgangen werden darf. Nimmt man jedoch eine klare Abgrenzung der Streitgegenstände der beiden infrage stehenden Verfahrensarten (§§ 43 I und 47 VwGO) vor, so entfaltet die Normenkontrolle nach \$ 47 VwGO keine Sperrwirkung gegenüber der inzidenten Prüfung untergesetzlicher Normen im Rahmen einer Feststellungsklage. ${ }^{48}$ Beruht ein feststellungsfähiges Rechtsverhältnis auf einer (untergesetzlichen) Norm, ${ }^{49}$ ist die Feststellungsklage unproblematisch zu bejahen, da es der Kläger^in um die Feststellung konkreter Rechte oder Pflichten geht, die aus einem Rechtsverhältnis resultieren..$^{50}$

Hinzuzufügen bleibt, dass $\S 47 \mathrm{VwGO}$ einen so geringen Anwendungsbereich aufweist, ${ }^{51}$ dass Rechtsschutzlücken etwa im Bereich von Bundesrechtsverordnungen entstehen, die mit der Rechtsschutzgarantie des Art. 19 IV GG nicht vereinbar sind. ${ }^{52}$ Selbstredend ist auch hier der richtige Streitgegenstand, ein Rechtsverhältnis auf das es ankommen muss, vonnöten.

47 BVerwG, Beschl. v. 2.4.1993, Az.: 7 B 38/93 = NVwZ-RR, 1993, 513 (514); BVerwG, Urt. v. 23.8. 2007, Az.: 7 C 2/07 = BVerwGE 129, 199 (204f.).

48 Hufen, Verwaltungsprozessrecht, 11. Aufl. 2019, § 18 Rn. 8.

49 BVerwG, Urt.v. 26.3. 2015, Az.: 7 C 17/12 = NVwZ 2015, 1215; Gersdorf, Verwaltungsprozessrecht, 6. Aufl. 2019, Rn. 118.

50 Vgl. BVerfG, Beschl.v. 2.12.1986, Az.: 1 BvR 1509/83 = BVerfGE 74, 69 (76); BVerwG, Urt. v. 9.12. 1982, Az.: 5 C 103/81 = NJW 1983, 2208; außerdem Pietzcker, in: Schoch/Schneider/Bier, VwGO, 36. EL Feburar 2019, § 43 Rn. 25 m.w. N.; anders Schenke, in: Kopp/Schenke, VwGO, 25. Aufl. 2019, $\S 43 \mathrm{Rn} .8 \mathrm{~b}$.

$51 \S 47$ I Nr. 1 VwGO: Satzungen, die nach BauGB erlassen wurden sowie Rechtsverordnungen, die aufgrund des § 246 II BauGB entstanden sind; § 47 I Nr. 2 VwGO: Rechtsverordnungen und Satzungen nach Landesrecht, nicht nach Bundesrecht.

52 Möstl, in: Posser/Wolf, VwGO, 50. Ed., Stand: 1.4.2019, § 43 Rn. 29.

Katrin Giere 
Hausarbeitswissen: Die vorangegangene Problematik der sog. „Normnichtigkeitsfeststellungs- 30 klage“ beruht auf der Rspr. des BVerfG zur Subsidiarität der Rechtssatzverfassungsbeschwerde, mittels welcher auch untergesetzliche Normen überprüft werden können. Danach stellt die allgemeine Feststellungsklage ein Rechtsmittel i.S.d. Subsidiaritätsgrundsatzes dar, da die Feststellungsklage aufgrund der Unanwendbarkeit des Art. 100 I GG („Gesetz“) denselben Rechtsschutz gewährt wie das BVerfG. ${ }^{53}$ Dieses Rechtskonstrukt dient der Entlastung des BVerfG. Eine Verfassungsbeschwerde zur Überprüfung einer untergesetzlichen Norm kann also erst dann zulässig sein, wenn zunächst im Wege der Feststellungsklage die Belastung aufgrund einer rechtswidrigen Norm festgestellt wurde. ${ }^{54}$ Ausnahmen davon können sich nur aus $\S 90$ II 2 BVerfGG ergeben. Ein Äußerungsrecht der Kläger*in des Ausgangsverfahrens steht ihr nach § 82 III BVerfGG zu.

\title{
(Echte) Beispiele für eine inzidente Überprüfung einer untergesetzlichen 31 Norm im Rahmen einer Feststellungsklage:
}

\begin{abstract}
„Ob der Kl. Fluglaternen des Typs „Glühwürmchen“ voraussetzungslos aufsteigen lassen darf, hängt von der Rechtswirksamkeit der FluglaternenVO der früheren Landesdirektion Leipzig vom 27.8.2009ab. “55

„Eine Klage auf Feststellung, dass die strategische Beschränkung des Telekommunikationsverkehrs durch den Bundesnachrichtendienst nach $\$ 5 \mathrm{G} 10$ in einem bestimmten Jahr rechtswidrig gewesen ist, ist nur zulässig, wenn zur Überzeugung des Gerichts festgestellt werden kann, dass der Telekommunikationsverkehr des Kl. im Zuge dieser strategischen Beschränkung tatsächlich erfasst worden ist. “ 56
\end{abstract}

Examenswissen: Der (lückenfüllende) Rechtsschutz der Feststellungsklage kommt auch im Be- 32 reich des EU-Rechts zum Tragen. Die Feststellungsklage ist in dem Bereich immer dann statthaft, wenn eine unmittelbar beschwerende, d.h. keinen Vollzugsakt voraussetzende EU-Verordnung Gegenstand der Klage ist. ${ }^{57}$

\section{(2) Parlamentsgesetze: Verwaltungsgerichte und BVerfG}

Die Feststellungsklage kann ebenso bei der Überprüfung von Parlamentsgeset- 33 zen statthaft sein. Kommt eine Rechtssatzverfassungsbeschwerde i.S.d. Art. 93 I Nr. 4a GG, §§ 13 Nr. 8a BVerfGG in Betracht, ist auch bei der Überprüfung von Parlamentsgesetzen aufgrund der Subsidiarität zunächst die Möglichkeit der Erhebung einer verwaltungsgerichtlichen Klage zu erörtern. Ist die Feststellungsklage wegen des Vorliegens eines feststellungsfähigen Rechtsverhältnisses

53 Gersdorf, Verwaltungsprozessrecht, 6. Aufl. 2019, Rn. 118.

54 Bsp. BVerfG, Beschl. v. 17.1.2006, Az.: 1 BvR 541/02, 1 BvR 542/02 = BVerfGE 115, 81 (91).

55 BVerwG, Urt. v. 25.10.2017, Az.: 6 C 44/16 = BVerwGE 160, 157 = NJW 2018, 325 (325 Rn. 12).

56 BVerwG, Urt.v. 28.5.2014, Az.: 6 A 1/13 = NVwZ 2014, 1666 Ls. 2.; vgl. auch BVerwG, Urt.v. 14.12. 2016, Az.: 6 A 2.15 = ZD 2017, 396 Ls. der Red.

57 Möstl, in: Posser/Wolf, VwGO, 50. Ed., Stand:1.4.2019, § 43 Rn. 32; s. auch Schenke, in: Kopp/ Schenke, VwGO, 25. Aufl. 2019, § 43 Rn. 8g. 
statthaft und kommt das Gericht bzw. die Klausurbearbeitenden bei der inzidenten Prüfung der Norm zu der Überzeugung, die Norm sei verfassungswidrig, muss das Verfahren ausgesetzt werden und die jeweilige Norm nach Art. 100 I GG im Wege der konkreten Normenkontrolle zur Klärung dem BVerfG vorgelegt werden.

34 Examenswissen: Dies führt $\mathrm{zu}$ enormen zeitlichen Verzögerungen, wodurch ein effektiver Rechtsschutz teilweise nur noch schwer gewährleistet werden kann. Deshalb ist in der Klausur immer darauf zu achten, ob eine Rechtssatzverfassungsbeschwerde nicht doch aufgrund der Unzumutbarkeit eines langwierigen fachgerichtlichen Rechtsschutzes ausnahmsweise zulässig sein kann..$^{58}$

35 Praktische Relevanz erlangt die inzidente Überprüfung von Parlamentsgesetzen mittels der allgemeinen Feststellungsklage im Bereich der sog. self-executingNormen. Dies sind solche Normen, die „sich selbst“ vollziehen, mithin keines Vollzugsakts durch die Verwaltung bedürfen. Eine Anfechtungsklage scheidet mangels Verwaltungsakt in diesen Fällen aus.

Beispiele: Gesetzlich begründete Zwangsmitgliedschaft in einer Körperschaft des öffentlichen Rechts, wie der Industrie- und Handelskammer nach \& 2 I IHKG; Bindung an die Speicherpflicht von Kommunikationsdaten nach § 113 a I i. V.m. § 113 b I und III TKG ${ }^{59}$

\section{b) Öffentlich-rechtliche Beziehung}

36 Das Rechtsverhältnis muss darüber hinaus öffentlich-rechtlicher Natur sein. Ist dies nicht der Fall, wäre bereits der Verwaltungsrechtsweg i.S.d. § 40 I 1 VwGO nicht eröffnet.

Öffentlich-rechtliche Beziehungen können nur auf Grundlage des öffentlichen Rechts bestehen. Das Rechtsverhältnis - genauer: der konkrete Sachverhalt - muss folglich durch eine öffentlich-rechtliche Regelung begründet werden. Neben Normen (Rn. 38f.), können öffentlich-rechtliche Rechtsverhältnisse durch den Verwaltungsakt vorgelagerte Situationen (Rn. $40 \mathrm{ff}$.), durch öffentlichrechtlichen Vertrag (Rn. 43) oder durch Realakt (Rn. 44) begründet werden.

58 Gersdorf, Verwaltungsprozessrecht, 6. Aufl. 2019, Rn. 118; vgl. dazu ausführlich Schenke, in: Kopp/Schenke, VwGO, 25. Aufl. 2019, § 43 Rn. 8f.

59 S. hierzu OVG Münster, Beschl. v. 22.6.2017, Az.: 13 B 238/17 = NVwZ-RR 2018, 43 ff. - Vorratsdatenspeicherung.

Katrin Giere 


\section{aa) Norm}

Öffentlich-rechtliche Beziehungen können also auf Grundlage einer Norm be- 38 stehen, deren Tatbestandsvoraussetzungen bereits vorliegen müssen. Hierzu gehören alle rechtswirksamen Normen wie Vorschriften des EU-Rechts, Verfassungsnormen, Parlamentsgesetze, untergesetzliche Normen und auch Gewohnheitsrecht. ${ }^{60}$

Zur Begründung eines Rechtsverhältnisses i.S.d. § 43 I Alt. 1 VwGO kommen zu einem großen Teil die oben bereits genannten sog. self-executing Normen in Betracht (s. Rn. 35). Ein Rechtsverhältnis begründet sich bei solchen Normen bereits ohne Vollzugsakt, da sie auch ohne einen solchen eine Regelungswirkung entfalten.

Sich selbst vollziehende Normen sind beispielsweise $\S 18$ I SGB XII (Sozialhilfeanspruch mit der Kenntnis des Sozialhilfeträgers vom Hilfefall) oder § 4 I StAG (Erwerb der Staatsangehörigkeit durch Gesetz).

Fallbeispiele: Eine Landesnorm (öffentlich-rechtl. Norm) schreibt eine Studiengebühr vor. S zahlt nicht. Darüber besteht zwischen der Behörde und S Streit, es ergeht aber (noch) kein Bescheid. S kann die Pflicht aus der landesrechtlichen Norm feststellen lassen.

Meister M züchtigt seinen Lehrling L. Das zuständige Organ der Handwerkskammer H droht ihm deshalb mit Ausschluss aus der Handwerkskammer. $M$ möchte feststellen lassen, dass er wegen der Züchtigung des L nicht aus der Kammer ausgeschlossen werden kann.

Wiederholung (fehlender konkreter Sachverhalt): Die Feststellungsklage ist jedoch nicht statthaft, wenn $M$ hätte feststellen lassen wollen, dass und ob er den L grundsätzlich züchtigen darf.

\section{bb) Dem Verwaltungsakt vorgelagerte Situationen}

Zwar kann die Überprüfung der Rechtmäßigkeit eines Verwaltungsakts (hierzu 40 ausführlich $\S 2 \mathrm{Rn}$. 553ff.) im Rahmen der allgemeinen Feststellungsklage aufgrund der Subsidiaritätsklausel des § 42 II 1 VwGO nicht überprüft werden; hierfür ist die Anfechtungsklage statthafte Klageart (hierzu § 2 Rn. 2ff.).

Gleichwohl können Verwaltungsakte im Bereich der allgemeinen Feststellungsklage mittelbar eine Rolle spielen. Dies ist der Fall, wenn das Rechtsverhältnis durch eine dem Verwaltungsakt vorgelagerte Situation begründet wird, etwa dann wenn eine Bürger`in einen Antrag auf Erlass eines Verwaltungsakts stellt, da so das Verwaltungsverfahren nach § 9 VwVfG beginnt. ${ }^{61}$ Weiterhin kann

60 Ehlers, JURA 2007, 179 (181).

61 Erbguth/Guckelberger, Allgemeines Verwaltungsrecht, 9. Aufl. 2018, § 10 Rn. 6. 
der Verwaltungsakt relevant sein, wenn festgestellt werden soll, ob dieser eine bestimmte Rechtsstellung vermittelt. ${ }^{62}$

Beispiel: Drohung einer Behörde gegenüber der Bürger*in A mit einem Bußgeldbescheid

41 Examenswissen: Die allgemeine Feststellungsklage kann ebenso statthaft sein, wenn es um die Auslegung oder Reichweite der Bindungswirkung eines Verwaltungsakts geht. Ist diese und nicht die Rechtmäßigkeit des Verwaltungsakts - umstritten und damit der Umfang eines staatlichen Leistungsanspruchs oder die Befolgung einer der Bürger`in durch einen Verwaltungsakt auferlegten Pflichten unklar, kann eine Klärung durch allgemeine Feststellungsklage erfolgen. ${ }^{63}$

42 Um eine Abgrenzung eines vorliegenden Verwaltungsakts $\mathrm{zu}$ Vorbereitungshandlungen vorzunehmen, kann das Tatbestandsmerkmal des Verwaltungsakts, die Regelung i. S. d. § 351 VwVfG, herangezogen werden. Liegt in der Formulierung einer Behörde keine einseitige, zielgerichtete, unmittelbare und verbindliche Anordnung einer Rechtsfolge, kann noch kein Verwaltungsakt vorliegen. ${ }^{64}$

\section{cc) Öffentlich-rechtlicher Vertrag}

43 Darüber hinaus kann ein öffentlich-rechtlicher Vertrag i.S.d. §§ $54 \mathrm{ff}$. VwVfG ein öffentlich-rechtliches Rechtsverhältnis begründen.

\section{dd) Realakt}

44 Schließlich ist die Begründung eines Rechtsverhältnisses auch durch einen Realakt möglich (zum Realakt als Handlungsform der Verwaltung näher $\S 5$ Rn. $6 \mathrm{ff}$.), wobei im Auge behalten werden muss, dass ein Realakt regelmäßig auf einer Norm beruht (zum Vorbehalt des Gesetzes bei Realakten näher Rn. 109f.). ${ }^{65}$ Darüber hinaus können auch dem Verwaltungsakt vorgelagerte Situationen einen Realakt darstellen.

Beispiele für Realakte: durch Kampfflugzeug aufgenommene Bilder von betroffenen Personengruppen in einem Demonstranten-Camp; ${ }^{66}$ Gefährderansprache bzw. Gefährderanschrei-

62 BVerwG, Urt. v. 29.08.1986, Az.: 7 C 5/85 = NVwZ 1987, 216.

63 Schenke, in: Kopp/Schenke, VwGO, 25. Aufl. 2019, § 43 Rn. 11; Ehlers, JURA 2007, 179 (185).

64 Tomerius, JURA 2018, 822 (823); zur Regelung i.S.d. § 35 S. 1 VwVfG Detterbeck, Allgemeines Verwaltungsrecht, 17. Aufl. 2019, Rn. $445 \mathrm{ff}$.

65 Wöckel, JA 2015, 205 (205).

66 BVerwG, Urt. v. 25.10.2017, Az.: 6 C 46/16 = BVerwGE 160, 169.

\section{Katrin Giere}


ben; ${ }^{67}$ der Aufruf einer Bürgermeister*in, der sich unmittelbar gegen die von einer konkreten Person angemeldete Demonstration richtet (s. hierzu den Fall 11 in: Eisentraut, Fälle zum Verwaltungsrecht, 2020).

\section{c) Vergangene und zukünftige Rechtsverhältnisse}

Im Rahmen der Feststellungsklage können auch vergangene und zukünftige 45 Rechtsverhältnisse relevant sein.

\section{aa) Vergangene Rechtsverhältnisse}

Feststellungsfähig sind nach heute einhelliger Auffassung auch vergangene 46 Rechtsverhältnisse, d.h. solche, die sich zum Zeitpunkt der gerichtlichen Entscheidung bereits erledigt haben. Unerheblich ist, ob sich das Rechtsverhältnis vor der Klageerhebung oder erst währenddessen erledigt hat. ${ }^{68}$

Die Feststellungsklage bezüglich vergangener Rechtsverhältnisse kann man sich als Fortsetzungsfeststellungsklage (hierzu ausführlich §4) ohne Verwaltungsaktcharakter vorstellen. Die Fortsetzungsfeststellungklage i. S.d. § 113 I 4 VwGO (analog) kommt dann in Frage, wenn die Anfechtungsklage nicht mehr statthaft ist. Der Verwaltungsakt als Gegenstand der Anfechtungsklage besteht in diesen Fällen aufgrund von Erledigung nicht mehr, er liegt mithin in der Vergangenheit. Genauso liegt es bei der Feststellungsklage mit dem Klagegenstand eines vergangenen Rechtsverhältnisses, sie kommt (auch) dann in Frage, wenn sich das Rechtsverhältnis bereits erledigt hat.

Da eine rechtliche oder sachliche Beschwer dann aktuell nicht mehr gegeben ist, wird sowohl bei der Fortsetzungsfeststellungsklage gem. § 113 I 4 VwGO als auch bei der Feststellungsklage bezüglich eines vergangenen Rechtsverhältnisses ein „besonderes“ (qualifiziertes) Feststellungsinteresse (Wiederholungsgefahr, Rehabilitationsinteresse etc.) gefordert (zum Feststellungsinteresse im Rahmen der Fortsetzungsfeststellungsklage s. § 4 Rn. 50 ff., zur Feststellungsklage s. Rn. 93 ff.). ${ }^{69}$

Entgegen der Auffassung in der Literatur ${ }^{70}$ fordert das BVerwG, dass das 48 vergangene Rechtsverhältnis über seine Beendigung hinaus anhaltende Wir-

67 Götz/Geis, Allgemeines Polizei- und Ordnungsrecht, 16. Aufl. 2017, § 12 Rn. 5.

68 Sodan, in: Sodan/Ziekow, VwGO, 5. Aufl. 2018, § 43 Rn. 15; Möstl, in: Posser/Wolf, VwGO, 50. Ed., Stand: 1.4.2019, § 43 Rn. 6-8.1.

69 Zur Fortsetzungsfeststellungsklage Decker, in: Posser/Wolf, VwGO, 50. Ed., Stand: 1.4.2019, $\S 113$ Rn. 86; zur Feststellungsklage bzgl. vergangener Rechtsverhältnisse Möstl, in: Posser/Wolf, VwGO, 49. Ed., Stand: 1.4.2019, § 43 Rn. 6-8.1.

70 Happ, in: Eyermann, VwGO, 15. Aufl. 2019, § 43 Rn. 18; Sodan, in: Sodan/Ziekow, VwGO, 5. Aufl. 2018, § 43 Rn. 18f. 
kung äußern muss, um überhaupt als Klagegegenstand der Feststellungsklage in Betracht $\mathrm{zu}$ kommen. ${ }^{71}$ Diese Einordnung ist jedoch problematisch, da die anhaltende Wirkung kein Element des Klagegenstandes darstellt und damit nicht im Rahmen der Statthaftigkeit der Klage relevant sein kann. Vielmehr ist die anhaltende Wirkung des vergangenen Rechtsverhältnisses im berechtigten (qualifizierten) Feststellungsinteresse zu erörtern. In diesem Rahmen muss festgestellt werden, ob die Kläger^in trotz des in der Vergangenheit liegenden Rechtsverhältnisses immer noch ein schutzwürdiges Interesse rechtlicher, wirtschaftlicher oder ideeller Art hat. ${ }^{72}$

Beispiele: Feststellung der Besoldungsgruppe einer früheren Beamt*in, da diese Bedeutung für die Höhe des Ruhegehaltes hat; ${ }^{73}$ Feststellung, ob die heimliche polizeiliche Observation aus dem Jahr zuvor rechtmäßig war

\section{bb) Zukünftige Rechtsverhältnisse}

49 Nach ebenso einhelliger Auffassung ist die allgemeine Feststellungsklage bei zukünftigen Rechtsverhältnissen statthaft. Das zukünftige Rechtsverhältnis kann anders als das gegenwärtige und vergangene Rechtsverhältnis noch nicht an einem bereits bestehenden bzw. geschehenen überschaubaren Sachverhalt festgemacht werden.

50 Daher sind folgende Anforderungen an das zukünftige Rechtsverhältnis zu stellen: ${ }^{74}$

- $\quad$ in der Zukunft liegender aber dennoch konkreter, überschaubarer Sachverhalt, der gewiss und überwiegend wahrscheinlich ist,

- der den Tatbestand einer Regelung (bereits) erfüllt

- und dadurch Rechtsfolgen auslöst.

51 Nicht feststellungsfähig ist ein zukünftiges Rechtsverhältnis - genau wie gegenwärtige Rechtsverhältnisse - daher dann, wenn der (in der Zukunft liegende)

71 BVerwG, Urt. v. 7.10.1955, Az.: II C 27.54 = BVerwGE 2, 229 (230) = NJW 1956, 36 (36); BVerwG, Urt. v. 10.5.1984, Az.: 3 C 68/82 = NJW 1985, 1302 (1303); BVerwG, Urt. v. 21.11.1980, Az.: 7 C 18/79= BVerwGE 61, 164 (169); BVerwG, Urt.v. 8.12.1995, Az.: 8 C 37/93 = BVerwGE 100, 83 (90) = NJW 1997, 71 (72).

72 BVerwG, Urt. v. 30.1.1990, Az.: 1A 36/86 = BVerwGE 84, 306.

$73 \mathrm{Bosch} / \mathrm{Schmidt} /$ Vondung, Einführung in die Praxis des verwaltungsgerichtlichen Verfahrens, 10. Aufl. 2019, Rn. 868.

74 Sodan/Kluckert, GewArch 2003, 3 (16); Ehlers, JURA 2007, 179 (187).

Katrin Giere 
Sachverhalt nicht hinreichend konkretisiert, mithin theoretischer Natur, ausgedacht oder unwahrscheinlich ist.

Beispiele für zukünftige Rechtsverhältnisse, die feststellungsfähig sind:

Studentin S möchte feststellen lassen, ob sie ihr Examen im kommenden Jahr noch nach der alten Prüfungsordnung absolvieren kann;

Beamter B möchte feststellen lassen, ob seine Frau nach seinem Tod (Zukunft) Ansprüche auf Versorgungsbezüge (Tatbestand und dadurch hervorgerufene Rechtsfolge) besitzt. ${ }^{75}$

Ein Unternehmer möchte feststellen lassen, ob ein bestimmtes Produkt, dessen Verkehrsfähigkeit zwischen ihm und der Behörde streitig ist, vertrieben werden darf, wenn er demnächst mit dessen Herstellung, Import, Vermarkung beginnen möchte ${ }^{76}$

Ein potenzieller Käufer möchte feststellen lassen, als künftiger Eigentümer nicht sanierungsverantwortlich für zukünftig auftretende Altlasten zu sein. ${ }^{77}$

Das BVerwG hat sich bis heute noch nicht ausdrücklich zu zukünftigen Rechtsverhältnissen geäußert. Faktisch erkennt es aber auch solche Rechtsverhältnisse als feststellungsfähig an. ${ }^{78}$

Examenswissen: Die vorbeugende Feststellungsklage

Der Grundsatz des repressiven Rechtsschutzes in der VwGO sieht es vor, dass Verwaltungshandeln nachträglich kontrolliert wird. Grund hierfür ist die Gewaltenteilung. Die Judikative soll so nicht (vorläufig) den Bereich der Exekutive berühren, in dem ein (Gerichts-)Verfahren in ein noch laufendes Verwaltungsverfahren eingreift. Dennoch soll es im Rahmen der VwGO vorbeugenden Rechtsschutz - wie die vorbeugende Feststellungsklage - geben.

Klarzustellen ist der Unterschied zwischen vorläufigem und vorbeugendem Rechts- 54 schutz. Während sich der vorläufige Rechtsschutz die Sicherung oder Regelung einer bereits eingetretenen Belastung kümmert, richtet sich der vorbeugende Rechtsschutz gegen nicht zumutbare zukünftig eintretende Belastungen.

Uneinigkeit herrscht über die Voraussetzungen der Statthaftigkeit der vorbeugenden Feststellungsklage:

Einige Stimmen sehen die vorbeugende Feststellungsklage dann als statthaft an, wenn ein zukünftiges Rechtsverhältnis (hierzu ausführlich Rn. $49 \mathrm{ff}$.) vorliegt, ${ }^{79}$ folglich dann, wenn eine (unmittelbar bevorstehende) Verwaltungsmaßnahme wie ein Verwaltungsakt oder eine Sanktion angedroht wird. ${ }^{80}$ Andere Stimmen betonen hingegen explizit, dass die vorbeugende Feststel-

75 BVerwG, Urt. v. 13.10.1971; Az.: VI C 57/66 = BVerwGE 38, $346 \mathrm{ff}$.

76 Sodan, in: Sodan/Ziekow, VwGO, 5. Aufl. 2018, § 43 Rn. 22.

77 VG Gera, Urt. v. 14.10.1997, Az.: 2 K 350/96 = ThürVBl. 1998, 109.

78 BVerwG, Urt. v. 9.5.2001, Az.: 3 C 2/01 = BVerwGE 114, 226 (228) = NVwZ-RR 2001, $664 \mathrm{ff}$.

79 Happ, in: Eyermann, VwGO, 15. Aufl. 2019, § 43 Rn. 32; Gersdorf, Verwaltungsprozessrecht, 6. Aufl. 2019, Rn. 125.

80 Vgl. etwa Bosch/Schmidt/Vondung, Einführung in die Praxis des verwaltungsgerichtlichen Verfahrens, 10. Aufl. 2019, Rn. 900; Hufen, Verwaltungsprozessrecht, 11. Aufl. 2019, § 18 Rn. 23. 
lungsklage und die Überprüfung zukünftiger Rechtsverhältnisse klar zu differenzieren sind. Die vorbeugende Feststellungsklage ist danach nur bei gegenwärtigen Rechtsverhältnissen statthaft. ${ }^{81}$ Letztlich bleibt zu sagen, dass es sich bei der vorbeugenden Feststellungsklage um ein (rein) begriffliches Problem handelt:

Die Konstellation des gegenwärtigen Rechtsverhältnisses fällt nach hier vertretener Ansicht bereits in den Anwendungsbereich der allgemeinen Feststellungsklage i.S.d. § 43 I VwGO. Ein konkretes gegenwärtiges Rechtsverhältnis reicht neben der Subsidiarität als Voraussetzung für die Statthaftigkeit der allgemeinen Feststellungsklage aus. Genauso liegt es bei zukünftigen Rechtsverhältnissen. Bei solchen handelt es sich ebenso um konkrete Rechtsverhältnisse. Da in diesen Fällen ein subjektives Recht (noch) nicht besteht, ${ }^{82}$ ist ein qualifiziertes Rechtsschutzinteresse (s. hierzu Rn. 99) gefordert. ${ }^{83}$

Daher ist ein Anwendungsbereich der vorbeugenden Feststellungsklage nach hier vertretener Ansicht nicht ersichtlich bzw. findet mit Blick auf die ohnehin vorrangige vorbeugende Unterlassungsklage (s. hierzu $\S 5 \mathrm{Rn}$. 22ff.) nahezu keinen Anwendungsbereich. ${ }^{84}$ Die sog. vorbeugende Feststellungsklage und die allgemeine Feststellungsklage unterscheiden sich mithin nur begrifflich. ${ }^{85}$ Dies wird durch die uneinheitliche Rechtsprechung, in der die vorbeugende Feststellungsklage mit der vorbeugenden Unterlassungsklage teilweise sogar gleichgesetzt wird, umso deutlicher. ${ }^{86}$ Materiell-rechtlich hat die unterschiedliche Bezeichnung allerdings keine Konsequenzen. ${ }^{87}$

58 Begründung für das oben Gesagte ist der Sinn und Zweck der allgemeinen Feststellungsklage. Sie dient dazu, die (Rechts-)Schutzlücke zu schließen, die besteht, wenn eine Verwaltungsmaßnahme angedroht wird, diese jedoch noch nicht vorgenommen wurde. In diesen Fällen, in denen oft ein Verwaltungsakt die Verwaltungsmaßnahme darstellt, können Anfechtungs- oder Verpflichtungsklage noch nicht statthaft sein. Die Person ist jedoch durch diese Androhung bereits konkret betroffen, sodass mithin ein gegenwärtiges Rechtsverhältnis besteht und die allgemeine Feststellungsklage bereits statthaft ist. Dieser speziell für diese Konstellation geschaffene Auffangrechtsbehelf, entspricht damit dem Rechtsstaatsgebot nach Art. 19 IV GG. Für jede Streitigkeit, die besteht, muss eine statthafte Klageart zur Verfügung stehen. ${ }^{88}$

Beispiel: Nach hier vertretener Ansicht liegt somit auch in der Entscheidung zur Vorratsdatenspeicherung des OVG Münster ${ }^{89}$ keine vorbeugende, sondern eine allgemeine Feststel-

81 Sodan, in: Sodan/Ziekow, VwGO, 5. Aufl. 2018, § 43 Rn. 20; Schenke, Verwaltungsprozessrecht, 16. Aufl. 2019, Rn. 408.

82 Schenke, Verwaltungsprozessrecht, 16. Aufl. 2019, Rn. 406.

83 Gersdorf, Verwaltungsprozessrecht, 6. Aufl. 2019, Rn. 125.

84 Hufen, Verwaltungsprozessrecht, 11. Aufl. 2019, § 18 Rn. 22.

85 So auch Sodan/Kluckert, GewArch 2003, 3 (16f.); vgl. auch Detterbeck, Allgemeines Verwaltungsrecht, 17. Aufl. 2019, Rn. 1446.

86 Vgl. zur Rspr. exemplarisch BVerwG, Urt. v. 8.9.1972, Az.: IV C 17/71 = BVerwGE 40, 323 (327); kritisch auch Hufen, Verwaltungsprozessrecht, 11. Aufl. 2019, § 18 Rn. 22; Schenke, in: Kopp/ Schenke, VwGO, 25. Aufl. 2019, § 43 Rn. 29.

87 Detterbeck, Allgemeines Verwaltungsrecht, 17. Aufl. 2019, Rn. 1446.

88 Möstl, in: Posser/Wolf, VwGO, 50. Ed., Stand: 1.4.2019, § 43 Einl.

89 OVG Münster, Beschl. v. 22.6.2017, Az.: 13 B 238/17 = NVwZ-RR 2018, 43 ff.

Katrin Giere 
lungsklage vor. Mit der Klage wollte ein Telekommunikationsunternehmen mittels einstweiligen Rechtsschutzes nach § 123 VwGO feststellen lassen, dass sie als Erbringerin öffentlich zugänglicher Internetzugangsdienste an die durch die Regelungen des TKG angeordnete Speicherpflicht von Telekommunikationsverkehrsdaten ihrer Kunden nicht gebunden ist. ${ }^{90}$

Grund: Da es zwischen der Antragstellerin und der Bundesnetzagentur bereits Kontakt bzgl. des in Frage stehenden Themas gab, lag bereits ein konkretes, gegenwärtiges Rechtsverhältnis vor. In diesen Fällen ist die allgemeine Feststellungsklage statthaft. Einer „vorbeugenden" Feststellungsklage bedarf es nicht.

Nimmt man in diesen Fällen - entgegen der hier vertretenen Ansicht - eine vorbeugende Feststellungsklage an, sind aufgrund des „präventiven“ Rechtsschutzes besondere Voraussetzungen an das Feststellungsinteresse zu stellen. Der Kläger`in kann es nicht zugemutet werden, die konkrete Rechtsverletzung abzuwarten (s. zum Feststellungsinteresse ausführlich Rn. 93 ff.).

\section{d) Verhältnis von Personen zueinander oder einer Person zu einer Sache}

Die oben beschriebenen rechtlichen Beziehungen sind als solche zwischen zwei 60

Personen oder von einer Person zu einer Sache zu verstehen. ${ }^{91}$ Dabei ist begrifflich zu beachten, dass eine Rechtsbeziehung zu einer Sache an sich nicht bestehen kann. Vielmehr ist damit die durch die Sache vermittelte Rechtsbeziehung zu einer „dritten“ Person gemeint. ${ }^{92} \mathrm{Zu}$ vergleichen ist dies etwa mit dem Sachenrecht des zivilrechtlichen Bereichs, in dem rechtliche Beziehungen auch zwischen zwei Personen in Ansehung einer Sache bestehen. In Bezug auf eine Sache können im Zivilrecht Eigentümer und Besitzer oder Nießbraucher in einer rechtlichen Beziehung stehen. ${ }^{93}$

Beispiel für eine rechtliche Beziehung zwischen einer Person und „einer Sache“ im Verwaltungsrecht: Widmung einer öffentlich-rechtlichen Einrichtung. Das Rechtsverhältnis besteht hier zwischen der betroffenen Person und der Rechtskörperschaft, die hinter der Sache steht.

\section{e) Rechtsverhältnis mit Drittbeteiligung}

Das Rechtsverhältnis besteht regelmäßig zwischen der beklagten Person und der $\mathbf{6 1}$ Kläger^in. Unproblematisch ist dennoch ein Rechtsverhältnis mit Drittbeteiligung, also ein solches zwischen der Beklagte ${ }^{\star} n$ und einer Dritten, an dem die

90 Nach dem OVG Münster, Beschl.v. 22.6.2017, Az.: 13 B 238/17 = NVwZ-RR 2018, 43ff. stellt dies sogar vorläufigen vorbeugenden Rechtsschutz dar. S. auch OVG Münster, Beschl.v. 2.3.2001, Az.: 5 B 273/01 = NVwZ 2001, $1315 \mathrm{ff}$.

91 St. Rspr. BVerwG, Urt. v. 26.1.1996, Az.: 8 C 19/94 = BVerwGE 100, 262 (264) m.w. N.

92 Schenke, in: Kopp/Schenke, VwGO, 25. Aufl. 2019, § 43 Rn. 11.

93 Schenke, Verwaltungsprozessrecht, 16. Aufl. 2019, Rn. 379. 
Kläger ${ }^{\star}$ in nicht beteiligt ist. ${ }^{94}$ Ein starres Zweiergefüge wird durch den Wortlaut des $§ 43$ I Alt. 1 VwGO nicht vorgegeben.

Zwingende Voraussetzung bleibt jedoch, dass von dem fremden Rechtsverhältnis konkrete subjektive Rechte für die dritte Person abhängen müssen, da alle Klagearten der VwGO Popularklagen ausschließen.

Beispiel: Es gibt Unklarheiten im Rahmen der Verbeamtung des A. B als sein Konkurrent möchte feststellen lassen, dass das Rechtsverhältnis zwischen A und seinem Dienstherrn nicht besteht. Dieses Verhältnis betrifft den B in seinen subjektiven Rechten, sodass es sich hierbei um ein feststellungsfähiges Rechtsverhältnis mit Drittbeteiligung handelt.

\section{Im Einzelnen: Die Subsidiarität der Feststellungsklage, § 43 II 1 VwG0}

作 Statthaftigkeit der Feststellungsklage. Weiterhin müssen aufgrund der Subsidiaritätsklausel nach $\S 43$ II 1 VwGO alle anderen möglichen Klagearten ausgeschlossen werden.

64 Der Grundsatz der Subsidiarität i.S.d. § 43 II 1 VwGO schreibt vor, dass eine Feststellung dann nicht begehrt werden kann, soweit die Kläger^in ihre Rechte durch Gestaltungs- oder Leistungsklage verfolgen kann oder hätte verfolgen können. ${ }^{95}$

65 Gestaltungsklagen sind Anfechtungs- oder Verpflichtungsklagen nach § 42 I VwGO (zur Anfechtungsklage § 2, zur Verpflichtungsklage § 3), mit denen die Aufhebung eines Verwaltungsakts (Anfechtung) oder der Erlass eines abgelehnten oder unterlassenen Verwaltungsakts (Verpflichtung) erreicht werden kann. Ist eine Anfechtungs- oder Verpflichtungsklage deshalb nicht mehr zulässig, weil etwa das Vorverfahren nicht eingehalten oder die Klagefrist verpasst wurde, kann in der Folge nicht etwa die Feststellungsklage statthaft sein. Dies widerspräche dem Subsidiaritätsgrundsatz des § 43 II 1 VwGO. ${ }^{96}$

Die allgemeine Leistungsklage (dazu §5) ist von der VwGO nicht ausdrücklich vorgesehen, sie wird aber in den $\S \S 43$ II, 111, 113 IV VwGO vorausgesetzt. Die allgemeine Feststellungsklage ist auch gegenüber der allgemeinen Leistungsklage subsidiär. Darüber kann nicht hinweghelfen, dass eine juristische Person des öffentlichen Rechts diese Leistungsklage erhebt. ${ }^{97}$ Nach dem BVerwG soll dies aufgrund von Art. 20 III GG eine Ausnahme des Subsidiaritätsgrundsatzes darstellen (s. hierzu näher Rn. 71). Gleiches gilt für die vorbeu-

94 BVerwG, Urt. v. 27.6.1997, Az.: 8 C 23/96 = NJW 1997, 3257 (3257f.).

95 Nach § 43 II 2 VwGO gilt die Subsidiarität nicht für die Nichtigkeitsfeststellungsklage.

96 Sodan, in: Sodan/Ziekow, VwGO, 5. Aufl. 2018, § 43 Rn. 116.

97 So die h. M. Schenke, in: Kopp/Schenke, VwGO, 25. Aufl. 2019, § 43 Rn. 28 m.w. N.

Katrin Giere 
gende Unterlassungsklage (zur vorbeugenden Unterlassungsklage $§ 5 \mathrm{Rn}$. $22 \mathrm{ff}$., s. auch den Fall 10 in: Eisentraut, Fälle zum Verwaltungsrecht, 2020), die ein Unterfall der allgemeinen Leistungsklage darstellt.

Funktion der Subsidiarität im Bereich der Feststellungsklage ist es

- ein Umgehen der engeren Sachentscheidungsvoraussetzungen der Anfechtungs- und Verpflichtungsklage wie das Vorverfahren i.S.d. § 68 VwGO und die Klagefristen nach $\S 74$ VwGO durch die Feststellungsklage zu verhindern. ${ }^{98}$ (Konzentrationsziel)

- das allgemeine Rechtsschutzbedürfnis zu wahren, sodass die Subsidiaritätsklausel auch aus prozessökonomischer Sicht von Bedeutung ist. Für die Kläger^in besteht nämlich dann kein Rechtsschutzbedürfnis, wenn sie durch Anfechtungs-, Verpflichtungs- oder Leistungsklage einen vollstreckungsfähigen Leistungstitel - mithin eine weiterreichende effektivere Rechtsschutzmöglichkeit - erreichen kann. Die Feststellungsklage ist demgegenüber - mit Ausnahme der Kosten - nicht vollstreckbar.

Die Feststellungsklage bleibt aber dann zulässig, wenn sich erst nachträglich die 68 Möglichkeit einer Gestaltungs- oder Leistungsklage ergibt. In diesen Fällen kann das Konzentrationsziel, eine effektivere Rechtsschutzmöglichkeit durch die Gestaltungswirkung bzw. vollstreckungsfähigen Leistungstitel zu erreichen, nicht mehr eingehalten werden kann. ${ }^{99}$ Eine Ausnahme hiervon ergibt sich wiederum dann, wenn die Feststellungsklage zwar eingelegt, jedoch noch nicht begründet wurde. ${ }^{100}$

Examenswissen: Es gilt prinzipiell die Gleichwertigkeit der Rechtswege. Aufgrund dessen ist die Subsidiaritätsklausel als rechtswegübergreifend anzusehen. Sie kommt also auch dann zum Tragen, wenn eine konkurrierende Leistungs- oder Unterlassungsklage vor dem Zivilgericht bereits erhoben wurde oder zu erheben ist. ${ }^{101}$

\section{a) Ausnahme bei nicht gleichermaßen oder weniger effektivem Rechtsschutz} Die Subsidiaritätsklausel i. S.d. § 43 II 1 VwGO gilt ausnahmsweise dann nicht, 70 wenn im Vergleich zu den Leistungs- oder Gestaltungsklagen ein nicht gleicher-

98 Würtenberger/Heckmann, Verwaltungsprozessrecht, 4. Aufl. 2018, Rn. 477.

99 Sodan, in: Sodan/Ziekow, VwGO, 5. Aufl. 2018, § 43 Rn. 117.

100 Sodan, in: Sodan/Ziekow, VwGO, 5. Aufl. 2018, § 43 Rn. 117.

$101 \mathrm{Bosch} /$ Schmidt/Vondung, Einführung in die Praxis des verwaltungsgerichtlichen Verfahrens, 10. Aufl. 2019, Rn. 888. 
maßen oder gar weniger effektiver Rechtsschutz erreicht werden kann. Dies ist insbesondere der Fall, wenn die Klagewege nicht dem Rechtsschutzziel der Kläger ${ }^{\star}$ in entsprechen, etwa wenn anstatt eines Einzelaktes ein ganzes Bündel von Rechten oder Pflichten in Rede steht. ${ }^{102}$

\begin{abstract}
Beispiele: Effektiverer Rechtsschutz für eine Beamt*in die Grundlage und damit die Höhe ihrer Besoldung mittels Feststellungsklage feststellen zu lassen, anstatt das beanspruchte Gehalt monatlich einzuklagen. ${ }^{103}$

Die Kläger*in hält ein beabsichtigtes Gewerbe für erlaubnisfrei oder die Erlaubnisvorschrift für verfassungswidrig. Eine Verpflichtungsklage auf Erlaubnis entspricht hier nicht dem Klageziel. ${ }^{104}$
\end{abstract}

\title{
b) Ausnahme nach der „Ehrenmanntheorie“
}

71 Der Grundsatz der Subsidiarität i.S.d. § 43 II 1 VwGO soll nach der Rspr. - analog zu den im Zivilprozess entwickelten Grundsätzen - auch dann nicht zur Anwendung kommen, wenn die Feststellungsklage gegen den Bund, ein Land oder andere Körperschaften des öffentlichen Rechts gerichtet ist. Begründet wird dies damit, dass die aufgezählten Beklagten das Urteil auch ohne Vollstreckungsfähigkeit akzeptieren würden (sog. „Ehrenmanntheorie“, s. dazu auch $\S 5$ Rn. 317, 319). ${ }^{105}$

Zuzustimmen ist dem insoweit, als dass die genannten juristischen Personen des öffentlichen Rechts aufgrund der Bindung der Verwaltung an Recht und Gesetz gebunden sind, sie also auch an ein nicht vollstreckbares Feststellungsurteil gebunden sind, Art. 20 III GG.

Die triftigeren Gründe ${ }^{106}$ sprechen aber gegen die oben beschriebene Ausnahme vom Grundsatz der Subsidiarität. Zunächst lässt der Wortlaut des § 43 II 1 VwGO eine solche Ausnahme nicht zu. Darüber hinaus widerspricht diese Ausnahme dem Willen des Gesetzgebers, nämlich den effektiven Rechtsschutz durch die Subsidiaritätsklausel zu sichern, indem ein vollstreckbarer Leistungstitel, der auf eine konkrete Handlung bezogen ist, angestrengt und erreicht wird. In der

102 Ehlers, JURA 2007, 179 (185); vgl. auch BVerwG, Urt. v. 24.6.2004, Az.: 4 C 11/03 = BVerwGE 121, 152 (156).

103 BVerwG, Urt. v. 18.7.1969, Az.: VII C 56.68 = BVerwGE 32, 333 (335); BVerwG, Urt. v. 17.2.1971, Az.: V C 68.69 = BVerwGE 37, 243 (247).

104 BVerwG, Urt. v. 17.1.1972, Az.: I C 33.68 = BVerwGE 39, 247 (249).

105 BVerwG, Urt. v. 27.10.1970, Az.: VI C 8.69 = BVerwGE 36, 179; Urt. v. 8.9.1972, Az.: IV C 17.71 = BVerwGE 40, 323; BVerwG, Urt. v. 22.2.2001, Az.: 5 C 34/00 = BVerwGE 114, 61; a. A. Sodan, in: Sodan/Ziekow, VwGO, 5. Aufl. 2018, § 43 Rn. 121.

106 S. dazu auch $\S 172$ VwGO.

Katrin Giere 
Konsequenz ist eine Feststellungsklage auch gegenüber öffentlichen Entscheidungsträgern subsidiär (s. bereits $§ 5 \mathrm{Rn} .319){ }^{107}$

\section{Literaturhinweise}

s. Rn. 113

\section{Die Nichtigkeitsfeststellungsklage (Tobias Brings-Wiesen)}

Der Bundesgesetzgeber hat auf gerichtlicher ${ }^{108}$ Ebene einen besonderen Rechts- 73 behelf wider den Rechtsschein der Wirksamkeit eines Verwaltungsakts vorgesehen: die Nichtigkeitsfeststellungsklage gemäß § 43 I Var. 3 VwGO. ${ }^{109}$ Angesichts der Tatsache, dass die herrschende Meinung eine Anfechtungsklage gemäß § 42 I Var. 1 VwGO auch gegen nichtige Verwaltungsakte zulässt (s. dazu bereits in $\S 2$ Rn. 197 ff.), spielt die Nichtigkeitsfeststellungsklage in der Praxis tatsächlich nur eine nachgeordnete Rolle. ${ }^{110}$ In der Ausbildung sollten die wenigen Besonderheiten, die sich hinsichtlich der Prüfung ihrer Statthaftigkeit ergeben, gleichwohl beherrscht werden.

Die Klage nach $\S 43$ I Var. 3 VwGO ist statthaft, wenn das Begehren des 74 Klägers auf die Feststellung der (teilweisen) Nichtigkeit eines Verwaltungsakts gerichtet ist. Im Rahmen der Prüfung der Statthaftigkeit der Klageart sollten vertiefte Ausführungen zur Frage der Nichtigkeit unterbleiben ${ }^{111}$ - diese erfolgen erst im Rahmen der Begründetheitsprüfung. Es genügen Ausführungen zum Vorliegen eines Verwaltungsakts ${ }^{112}$ - sprich zur Verwaltungsaktqualität und zur

107 So auch die h. M.: u. a. Hufen, Verwaltungsprozessrecht, 11. Aufl. 2019, § 18 Rn. 6; Schenke, in: Kopp/Schenke, VwGO, 25. Aufl. 2019, § 43 Rn. 28; Schenke, Verwaltungsprozessrecht, 16. Aufl. 2019, Rn. 420, 565; Sodan, in: Sodan/Ziekow, VwGO, 5. Aufl. 2018, § 43 Rn. 121; Ehlers, JURA 2007, 179 (186).

108 S. zur behördlichen Feststellung der Nichtigkeit gemäß § 44 V VwVfG noch Rn. 166 ff.

109 Zum Mehrwert dieser besonderen Feststellungsklage nur Möstl, in: Posser/Wolff, VwGO, 50. Ed., Stand: 1.4.2019, § 43 Rn. 35.

110 So wird die Feststellung der Nichtigkeit zumeist hilfsweise oder auf Hinweis des Gerichts (§ 86 III VwGO) beantragt, Hufen, Verwaltungsprozessrecht, 11. Aufl. 2019, § 18 Rn. 28.

111 Schenke, JuS 2016, 97 (99).

112 BVerwG, Urt. v. 6.2.1986, Az.: 5 C 40.84 = BVerwGE 74, 1 (3f.); Pietzcker, in: Schoch/ Schneider/Bier, VwGO, 36. EL Februar 2019, § 43 Rn. 27; Sodan, in: Sodan/Ziekow, VwGO, 5. Aufl. 2018, § 43 Rn. 64; Möstl, in: Posser/Wolff, VwGO, 50. Ed., Stand: 1.4.2019, § 43 Rn. 37. 
wirksamen Bekanntgabe - sowie zum auf die Feststellung der Nichtigkeit gerichteten Vorbringen des Klägers ${ }^{113}$.

75 Examenswissen: Wie hinsichtlich anderer Wirksamkeitsprobleme (s. dazu $§ 2$ Rn. 177) und im Rahmen von $\S 44$ V VwVfG (s. dazu Rn. 169) stellt sich die Frage des Umgangs mit dem Klagebegehren der positiven Feststellung der Wirksamkeit eines Verwaltungsakts auch hinsichtlich des Fehlens von Nichtigkeitsgründen. Anders als auf behördlicher Ebene hält die ganz herrschende Meinung ein entsprechendes Klagebegehren für grundsätzlich zulässig. Umstritten ist lediglich die statthafte Klageart. Eine Ansicht votiert für die analoge Anwendung von §43 I Var. 3 VwGO. ${ }^{114}$ Begründet wird dies damit, dass ein gleichwertiges Interesse an der positiven Feststellung der Wirksamkeit bestehen könne und außerdem die gerichtliche Ablehnung der Nichtigkeitsfeststellung mangels Begründetheit kehrseitig die positive Feststellung der Wirksamkeit enthalte. Dem werden von der Gegenansicht zu Recht der klare Wortlaut sowie methodisch entgegengehalten, dass eine Analogie bereits mangels planwidriger Regelungslücke ausscheide. ${ }^{115}$ Die wohl herrschende Meinung bejaht sodann auch die Statthaftigkeit der allgemeinen Feststellungsklage gemäß § 43 I Var. 1 VwGO gerichtet auf die Feststellung des Bestehens eines durch wirksamen Verwaltungsakt begründeten Rechtsverhältnisses. ${ }^{116}$

76 Anders als die allgemeine Feststellungsklage gemäß § 43 I Var. 1 und 2 VwGO ist die Nichtigkeitsfeststellungsklage nicht subsidiär gegenüber Gestaltungs- oder Leistungsklagen, § 43 II 2 VwGO. Dies führt dazu, dass der Kläger ein Wahlrecht zwischen der Nichtigkeitsfeststellungsklage und der - nach herrschender Ansicht gleichsam statthaften - Anfechtungsklage hat (s. dazu ausführlich unter $\S 2$ Rn. 197 ff.). Dies bedeutet insbesondere auch, dass der Kläger mit einem Hauptantrag die Feststellung der Nichtigkeit eines Verwaltungsakts und hilfsweise seine Aufhebung beantragen kann. ${ }^{117}$

113 Der Vortrag des Klägers muss auf einen Nichtigkeitsgrund schließen lassen Hufen, Verwaltungsprozessrecht, 11. Aufl. 2019, § 18 Rn. 28, Sodan, in: Sodan/Ziekow, VwGO, 5. Aufl. 2018, § 43 Rn. 64. Diese Erwägungen ordnet Möstl, in: Posser/Wolff, VwGO, 50. Ed., Stand: 1.4.2019, § 43 Rn. 37, der Prüfung des Feststellungsinteresses bzw. der Klagebefugnis zu.

114 Schenke, JuS 2016, 97 (98f.).

115 Sodan, in: Sodan/Ziekow, VwGO, 5. Aufl. 2018, § 43 Rn. 63; s. auch Geis/Schmidt, JuS 2012, 599 (601); Will/Rathgeber, JuS 2012, 1057 (1062f.).

116 Hufen, Verwaltungsprozessrecht, 11. Aufl. 2019, § 18 Rn. 30; Würtenberger/Heckmann, Verwaltungsprozessrecht, 4. Aufl. 2018, Rn. 474f.; Schmitt-Glaeser/Horn, Verwaltungsprozessrecht, 15. Aufl. 2000, Rn. 336; Sodan, in: Sodan/Ziekow, VwGO, 5. Aufl. 2018, § 43 Rn. 63; Möstl, in: Posser/Wolff, VwGO, 50. Ed., Stand: 1.4. 2019, § 43 Rn. 36; Will/Rathgeber, JuS 2012, 1057 (1062). 117 BVerwG, Beschl.v. 7.1.2013, Az.: 8 B 57.12 = BeckRS 2013, 46061, Rn. 5; Pietzcker, in: Schoch/ Schneider/Bier, VwGO, 36. EL Februar 2019, § 43 Rn. 27; Sennekamp, in: Fehling/Kastner/Störmer, Verwaltungsrecht, 4. Aufl. 2016, § 42 VwGO Rn. 12; vgl. auch BSG, Urt. v. 21.6.1960, Az.: 3 RK 72/ 55 = NJW 1960, 2308; Urt. v. 23.2.1989, Az.: 11/7 RAr 103/87 = NVwZ 1989, 902.

Tobias Brings-Wiesen 


\section{B. Weitere Zulässigkeitsvoraussetzungen}

Nach der Prüfung der Eröffnung des Verwaltungsrechtswegs und der Prüfung der 77 statthaften Klageart sind im Falle der Feststellungsklage regelmäßig die folgenden weiteren Zulässigkeitsvoraussetzungen anzusprechen, wobei es auch hierbei auf problembewusstes Arbeiten ankommt (dazu § 1 Rn. 52, 123).

\section{Klagebefugnis (Hendrik Burbach)}

Ob der Kläger bei Feststellungsklagen die Klagebefugnis im Sinne des § 42 II 78 VwGO darlegen muss, ist umstritten. Nach der Rechtsprechung des BVerwG ist eine Feststellungsklage nur dann zulässig, wenn der Kläger analog § 42 II VwGO klagebefugt ist. ${ }^{118}$ Dies soll vor allem der Vorbeugung von Popularklagen dienen. Dem Kläger muss es auch bei der Feststellungsklage um die Verwirklichung eigener Rechte gehen. Er muss daher an dem Rechtsverhältnis beteiligt sein oder eigene Rechte müssen von diesem abhängen. ${ }^{119}$

Gegen die analoge Anwendung des § 42 II VwGO auf die Feststellungsklage 79 spricht dagegen der strenge Wortlaut des § 43 I VwGO. Dieser spricht ausdrücklich nur von einem besonderen Interesse (zum Feststellungsinteresse sogleich näher Rn. 93 ff.). Somit enthält § 43 I VwGO eine eigene, wenn auch weniger strenge, jedoch funktional ähnliche Zugangsbegrenzung. ${ }^{120}$ Somit fehlt es bereits an einer die analoge Anwendung des $\S 42$ II VwGO rechtfertigenden Regelungslücke. ${ }^{121}$ Aufgrund des konkretisierten Rechtsverhältnisses und des qualifizierten Rechtschutzbedürfnisses besteht nach dieser Auffassung kein weiterer Anlass, zusätzlich die Klagebefugnis nach $\S 42$ II VwGO zu prüfen. ${ }^{122}$

In der Klausur ist dieser Streit zumeist nicht zu entscheiden, da der Kläger 80 sowohl ein berechtigtes Interesse haben als auch die Anforderungen des § 42 II VwGO erfüllen dürfte. Trotzdem sollten die Auffassungen kurz dargelegt und die Kernargumente genannt werden. Sodann kann darauf hingewiesen werden, dass der Streit dahinstehen kann, da der Kläger jedenfalls klagebefugt ist. Es muss dafür natürlich dargelegt werden, warum dies der Fall ist.

Sollte der Kläger hingegen ausnahmsweise einmal nicht klagebefugt sein, 81 aber ein Feststellungsinteresse haben, muss der Streit entschieden werden.

118 BVerwG, Urt. v. 28.11.2007, Az.: 9 C 10.07 = BVerwGE 130, 52 Rn. 14.

119 Glaser, in: Gärditz, VwGO, 2. Aufl. 2018, § 43 Rn. 84.

120 Glaser, in: Gärditz, VwGO, 2. Aufl. 2018, § 43 Rn. 84.

121 Württemberger/Heckmann, Verwaltungsprozessrecht, 4. Aufl. 2018, § 25 Rn. 489.

122 Hufen, Verwaltungsprozessrecht, 11. Aufl. 2019, § 18 Rn. 17.

Hendrik Burbach 


\section{II. (Kein) Vorverfahren (Renana Braun)}

82 Grundsätzlich ist die Durchführung eines Vorverfahrens im Rahmen der Feststellungsklage nicht erforderlich. Für einige Ausnahmefälle ist es allerdings ausdrücklich angeordnet (Bsp.: § 54 II 1 BeamtStG, § 126 II 1 BBG). ${ }^{123}$ Der Prüfungspunkt ist daher in der Regel nicht anzusprechen.

\section{III. (Keine) Klagefrist (Patrick Stockebrandt)}

83 Für die Feststellungsklage gemäß $\S 43$ VwGO gilt grundsätzlich keine Klagefrist. ${ }^{124}$ Der Prüfungspunkt ist daher in der Regel nicht anzusprechen. Eine Ausnahme besteht nur dann, wenn eine Frist spezialgesetzlich angeordnet wird. ${ }^{125}$

84 Eine unredliche, gegen Treu und Glauben verstoßende Verzögerung der Klageerhebung führt zur Verwirkung des Klagerechts (s. § 2 Rn. $399 \mathrm{ff}$.). ${ }^{126}$

85 Im Hinblick auf die Fristberechnung und die Rechtsbehelfsbelehrung (s. § 2 Rn. $361 \mathrm{ff}$.) und die Wiedereinsetzung in den vorigen Stand (s. $\S 2$ Rn. 394 ff.) wird auf die entsprechenden Ausführungen im Rahmen der Anfechtungsklage verwiesen.

Weiterführende Literaturhinweise finden sich in $\S 2$ Rn. 402.

\section{Beteiligte (Carola Creemers)}

86 Die Ausführungen zu den Beteiligten im Rahmen der Anfechtungsklage gelten mit Ausnahme von $\S 78$ VwGO entsprechend für die Feststellungsklage. Die Beteiligungs- und Prozessfähigkeit richtet sich also nach den $\S \S 61$ und 62 VwGO (s. ausführlich § 2 Rn. $403 \mathrm{ff}$.).

87 Für die Bestimmung des richtigen Klagegegners gelten im Wesentlichen die gleichen Grundsätze wie für die allgemeine Leistungsklage (s. § 5 Rn. 37). Auch bei der Feststellungsklage ist der richtige Beklagte nach dem Rechtsträgerprinzip zu

123 S. Hufen, Verwaltungsprozessrecht, 11. Aufl. 2019, Teil 2 § 6 Rn. 16.

124 Schenke, Verwaltungsprozessrecht, 16. Aufl. 2019, Rn. 704.

125 Z.B. § 54 II 1 BeamtStG und § 126 II 1 BBG, s. hierzu Schenke, Verwaltungsprozessrecht, 16. Aufl. 2019, Rn. 704.

126 Schenke, Verwaltungsprozessrecht, 16. Aufl. 2019, Rn. 704.

Renana Braun/Patrick Stockebrandt/Carola Creemers 
bestimmen. ${ }^{127}$ Richtiger Klagegegner ist folglich der Rechtsträger, dem gegenüber das streitige Rechtsverhältnis positiv oder negativ festgestellt werden soll.

Ausnahmsweise ist $\S 78$ I Nr. 1 VwGO analog auf die Nichtigkeitsfeststel- 88 lungsklage anwendbar, da bei dieser, wie bei Anfechtungs- und Verpflichtungsklagen, um einen Verwaltungsakt gestritten wird. ${ }^{128}$

\section{Zuständiges Gericht (Katharina Goldberg)}

Die allgemeine Leistungsklage ist nur zulässig, wenn das zuständige Gericht 89 angerufen wurde (zur Verweisung bei fehlerhafter Zuständigkeit s. näher $\S 1$ Rn. 49, 163 und § 2 Rn. 468). Bei der Frage des zuständigen Gerichts liegt häufig kein Schwerpunkt der Klausurlösung. Dennoch müssen die sachliche und örtliche Zuständigkeit in jeder Klausur zumindest angesprochen und die relevanten Normen benannt werden.

Formulierungsvorschlag: „Das angerufene Gericht müsste sachlich gem. $\S 4590$ VwGO und örtlich gem. $§ 52$ VwGO zuständig sein.“

Das Verwaltungsgericht ist sachlich in der ersten Instanz für alle Streitig- 91 keiten zuständig, für die der Verwaltungsrechtsweg gem. § 40 VwGO eröffnet ist, $\S 45 \mathrm{VwGO}^{129}$ (zur ausnahmsweise abweichenden Zuständigkeit von OVG und BVerwG s. § 2 Rn. 466f.).

Die örtliche Zuständigkeit richtet sich bei allen Klagearten nach $\S 52$ VwGO. 92 Sie muss bestimmt werden, wenn verschiedene Gerichte sachlich zuständig sind. In den meisten Klausuren wird die örtliche Zuständigkeit durch den Klausursteller vorgegeben. Wenn dies nicht gegeben ist müssen die einzelnen Nummern des $\S 52$ VwGO gründlich gelesen werden. Sie geben eine Reihenfolge vor, nach der die örtliche Zuständigkeit bestimmt werden muss. Bei der Feststellungsklage sind folgende Nummern des $\S 52$ VwGO in folgender Reihenfolge relevant: Nr. 1, Nr. 4, Nr. 5 (ein Überblick über die Nummern des $\S 52$ VwGO findet sich in $\S 2$ Rn. 473).

127 Meissner/Schenk, in: Schoch/Schneider/Bier, VwGO, 36. EL Februar 2019, § 78 Rn. 53.

128 Meissner/Schenk, in: Schoch/Schneider/Bier, VwGO, 36. EL Februar 2019, § 78 Rn. 53; Brenner, in: Sodan/Ziekow, VwGO, 5. Aufl. 2018, §78 Rn. 12; a. A. Schenke, in: Kopp/Schenke, VwGO, 25. Aufl. 2019, § 78 Rn. 2.

129 Berstermann, in: Posser/Wolf, VwGO, 49. Ed., Stand: 1.10.2018, § 45 Rn. 2. 


\section{Feststellungsinteresse (Dana-Sophia Valentiner)}

93 Für die Feststellungsklage muss ein berechtigtes Interesse der klagenden Person vorliegen (s. einleitend zum Erfordernis des allgemeinen und besonderen Rechtsschutzbedürfnisses bereits $\S 2$ Rn. 483f.).

\section{Berechtigtes Interesse}

$94 \S 43$ I VwGO verlangt ein berechtigtes Interesse des Klägers an der baldigen Feststellung des Bestehens oder Nichtbestehens eines Rechtsverhältnisses bzw. an der Nichtigkeit eines Verwaltungsakts. Während bei der Feststellungsklage im Zivilprozess (§ $256 \mathrm{ZPO}$ ) ein rechtliches Interesse gefordert ist, genügt im Verwaltungsprozess als berechtigtes Interesse jedes nach vernünftigen Erwägungen gerechtfertigte schutzwürdige öffentliche oder private Interesse rechtlicher, wirtschaftlicher oder ideeller Natur. ${ }^{130}$

95 Das Interesse an einer „baldigen“ Feststellung des Rechtsverhältnisses liegt vor, wenn die begründete Besorgnis einer Gefährdung der klägerischen Rechtspositionen besteht. ${ }^{131}$ Mit dem Interesse an der „baldigen“ Feststellung gehen die Anforderungen an das besondere Rechtsschutzbedürfnis aus § 43 I VwGO über jene des § 113 I 4 VwGO hinaus.

Das berechtigte Feststellungsinteresse ist aufgrund der besonderen Missbrauchsgefahr der gerichtlichen Rechtsverfolgung mit der Feststellungsklage positiv festzustellen. ${ }^{132}$ Lässt sich das qualifizierte Rechtsschutzinteresse nicht positiv nachweisen, geht dies zu Lasten der rechtsschutzsuchenden Person. ${ }^{133}$

Das Feststellungsinteresse muss gegenüber dem Klage- bzw. Antragsgegner bestehen, ${ }^{134}$ ein Feststellungsinteresse gegenüber einer beigeladenen Person reicht nicht aus. ${ }^{135}$

97 Das gemäß $\S 43$ I VwGO bei der Feststellungsklage nachzuweisende Rechtsschutzinteresse ist als besondere Sachentscheidungsvoraussetzung unter einem eigenständigen Gliederungspunkt ,(berechtigtes) Feststellungsinteresse“ zu prüfen. So zeigt der Bearbeiter der Korrektorin, dass er das gegenüber dem allgemeinen Rechtsschutzbedürfnis besondere Erfordernis der positiven Feststellung des Rechtsschutzinteresses verstanden hat. Das allgemeine Rechts-

130 BVerwG, Urt. v. 28.10.1970, Az.: VI C 55.68 = BVerwGE 36, 218 (226).

131 Mann/Wahrendorf, Verwaltungsprozessrecht, 4. Aufl. 2015, § 19 Rn. 311.

132 Ehlers, in: Schoch/Schneider/Bier, VwGO, 36. EL Februar 2019, Vorbem. § 40 Rn. 79.

133 Ehlers, in: Schoch/Schneider/Bier, VwGO, 36. EL Februar 2019, Vorbem. § 40 Rn. 79.

134 Engels, NVwZ 2018, 1001 (1005).

135 Brüning, JuS 2004, 882 (885).

Dana-Sophia Valentiner 
schutzbedürfnis ist daneben bei Feststellungsklagen nicht noch gesondert anzusprechen. $^{136}$

\section{Relevante Fallgruppen}

Die Anforderungen an das berechtigte Feststellungsinteresse richten sich da- 98 nach, ob die Feststellung vergangener oder künftiger Rechtsverhältnisse begehrt wird. ${ }^{137}$ Bezieht sich die Feststellungsklage auf ein vergangenes Rechtsverhältnis, z.B. auf einen erledigten Realakt, liegt das Feststellungsinteresse bei Wiederholungsgefahr, Rehabilitationsinteresse, typischerweise kurzfristiger Erledigung einer Grundrechtsbeeinträchtigung oder Präjudizität vor (s. dazu $\S 4$ Rn. $53 \mathrm{ff}.)^{138}$

Examenswissen: Bei einer vorbeugenden allgemeinen Feststellungsklage (s. dazu § 6 Rn. 52ff.) 99 ist - vergleichbar der vorbeugenden Unterlassungsklage - ein besonderes Feststellungsinteresse nachzuweisen. ${ }^{139}$ Dieses fehlt, wenn die klagende Person in zumutbarer Weise auf andere Rechtsschutzmöglichkeiten der Verwaltungsgerichtsordnung verwiesen werden darf.

Umstritten ist die Frage, ob einer auf Feststellung der Nichtigkeit eines Verwal- 100 tungsakts gerichteten Feststellungsklage ein erfolgloser Antrag auf behördliche Feststellung der Nichtigkeit gemäß § 44 V Hs. 2 VwVfG vorausgehen muss. Dafür spricht, dass der Antrag auf behördliche Feststellung grundsätzlich einen einfacheren und kostengünstigeren Weg darstellt, um die begehrte Feststellung zu erreichen. ${ }^{140}$ Dagegen spricht jedoch, dass die Annahme einer solchen Erfordernis über den Rückgriff auf das allgemeine Institut des Rechtsschutzbedürfnisses ein Vorverfahren etablieren würde, welches der Gesetzgeber in den $\S \S 68 \mathrm{ff}$. VwGO nicht vorgesehen hat. ${ }^{141}$ Dementsprechend sind beide Rechtsbehelfe nebeneinander anwendbar. ${ }^{142}$ Eine Feststellungsinteresse fehlt jedoch, wenn einem Antrag nach $\S 44 \mathrm{~V}$ Hs. 2 VwVfG bereits entsprochen wurde. ${ }^{143}$ Wegen der Identität des

136 Ehlers, in: Schoch/Schneider/Bier, VwGO, 36. EL Februar 2019, Vorbem. § 40 Rn. 79.

137 Gersdorf, Verwaltungsprozessrecht, 6. Aufl. 2019, Rn. 125.

138 Gersdorf, Verwaltungsprozessrecht, 6. Aufl. 2019, Rn. 125.

139 Möstl, in: Posser/Wolff, VwGO, 49. Ed., Stand: 1.4.2019, § 43 Rn. $26 \mathrm{f}$.

140 Schmitt Glaeser/Horn, Verwaltungsprozessrecht, 15. Aufl. 2000, Rn. 342.

141 Schenke, JuS 2016, 97 (99); Schenke, Verwaltungsprozessrecht, 16. Aufl. 2019, Rn. 576.

142 Ramsauer, in: Kopp/Ramsauer, VwVfG, 20. Aufl. 2019, § 44 Rn. 69.

143 Schenke, Verwaltungsprozessrecht, 16. Aufl. 2019, Rn. 577; Hufen, Verwaltungsprozessrecht, 11. Aufl. 2019, § 18 Rn. 32; Sodan, in: Sodan/Ziekow, VwGO, 5. Aufl. 2018, § 43 Rn. 109; Möstl, in: Posser/Wolff, VwGO, 50. Ed., Stand: 1.4.2019, § 43 Rn. 39; noch vor der Entscheidung der Behörde ansetzend W.-R. Schenke, in: Kopp/Schenke, VwGO, 25. Aufl. 2019, § 43 Rn. 20. 
Streitgegenstandes ist es ebenfalls unzulässig, eine Nichtigkeitsfeststellungsklage zu erheben, wenn bereits eine Anfechtungsklage erhoben bzw. gar rechtskräftig zum Abschluss gebracht worden ist. ${ }^{144}$

101 Bei der Feststellungsklage einer Behörde gegenüber einer Privatperson ist umstritten, ob ein berechtigtes Feststellungsinteresse der Behörde vorliegt, wenn sie die Möglichkeit hätte, einen Verwaltungsakt zu erlassen. In der Literatur wird vereinzelter Rechtsprechung dahingehend zugestimmt, dass eine solche Feststellung im Grundsatz möglich sei. ${ }^{145}$

\section{Begründetheit}

102 Die Prüfung der Begründetheit der Feststellungsklage ist danach auszurichten, ob die „klassische“ Feststellungsklage (dazu I.) oder die Nichtigkeitsfeststellungsklage (dazu II.) für statthaft befunden wurde.

\section{Begründetheit der „klassischen“ Feststellungsklage (Katrin Giere)}

103 Formulierungsvorschlag: „Die allgemeine Feststellungsklage i.S.d. § 43 I Alt. 1 VwGO ist begründet, wenn das von der Kläger*in geltend gemachte Rechtsverhältnis besteht (positive Feststellungsklage) bzw. das von ihr verneinte Rechtsverhältnis nicht besteht (negative Feststellungsklage).“

104 Wenden die Klausurbearbeitenden § 42 II VwGO (Klagebefugnis) analog an (hierzu Rn. 78ff.), sollte dem Obersatz Folgendes hinzugefügt werden: „... und die Kläger*in dadurch in ihren Rechten verletzt ist. “ 146

105 In der Begründetheit werden die konkreten Voraussetzungen des infrage stehenden Rechtsverhältnisses geprüft. Im Rahmen der Begründetheit kommt es mithin auf die Art des Rechtsverhältnisses an.

144 So ausdrücklich das BVerwG, Beschl. v. 7.1.2013, Az.: 8 B 57.12 = BeckRS 2013, 46061, Rn. 5, m.w. N.; so auch W.-R. Schenke, in: Kopp/Schenke, VwGO, 25. Aufl. 2019, § 43 Rn. 32.

145 Pietzcker, in: Schoch/Schneider/Bier, VwGO, 36. EL Februar 2019, § 43 Rn. 37 m.w. N.

146 Gersdorf, Verwaltungsprozessrecht, 6. Aufl. 2019, Rn. 127; sollte dieser Zusatz nicht beigefügt werden, darf dies nicht als Fehler gelten.

Dana-Sophia Valentiner/Katrin Giere 


\section{Rechtsverhältnis aufgrund einer Norm}

Begründet sich das Rechtsverhältnis durch eine Norm (s. hierzu ausführlich 106 Rn. 38f.) und wird diese für nichtig gehalten, so sind folgende Szenarien vorstellbar:

a) (Inzidente) Prüfung der Verfassungsmäßigkeit eines formellen Gesetzes auf dem das Rechtsverhältnis beruht (in Bezug auf die „klassische“ Feststellungsklage ausführlich Rn. $33 \mathrm{ff}$.). An dieser Stelle ist die gewohnte Prüfung der Verfassungsmäßigkeit eines Gesetzes durchzuführen (formelle und materielle Verfassungsmäßigkeit).

b) (Inzidente) Prüfung der Rechtmäßigkeit einer Satzung oder Rechtsverordnung auf der das Rechtsverhältnis beruht (in Bezug auf die „klassische“ Feststellungsklage ausführlich Rn. 28ff.), etwa Satzungen nach dem BauGB oder Rechtsverordnungen nach § 246 II BauGB (zur Prüfung s. ausführlich § 8 Rn. 72 ff.).

\section{Rechtsverhältnis aufgrund eines öffentlich-rechtlichen Vertrags}

Folgt die Begründung des Rechtsverhältnisses aus einem öffentlich-rechtlichen 107 Vertrag i.S.d. $\$ \S 54 \mathrm{ff}$. VwVfG, sind die genauen Voraussetzungen eines öffentlichen-rechtlichen Vertrages zu prüfen (s. zum öffentlich-rechtlichen Vertrag näher $\S 5$ Rn. $65 \mathrm{ff}$.$) :$

a) Vorliegen eines öffentlich-rechtlichen Vertrages, §54 VwVfG

b) Wirksamkeit des Vertrags, 62 S. 2 VwVfG i.V.m. den einschlägigen Vorschriften des BGB

c) Nichtigkeitsgründe (formell und materiell), $\S \S 57 \mathrm{ff}$. VwVfG

\section{Rechtsverhältnis aufgrund eines Realakts}

Begründet sich das Rechtsverhältnis durch einen Realakt, muss geprüft werden, 108 ob der Realakt rechtmäßig war (s. hierzu Fall 11 in: Eisentraut, Fälle zum Verwaltungsrecht, 2020). Die Rechtmäßigkeit eines Realakts ist wie folgt zu prüfen.

\section{a) Notwendigkeit einer gesetzlichen Ermächtigungsgrundlage (Bernhard Hadank)}

Zunächst ist zu überlegen, ob und unter welchen Umständen auch für Realakte 109 eine gesetzliche Ermächtigungsgrundlage notwendig ist. Rechtsbindungen bestehen selbstverständlich auch bei schlichtem Verwaltungshandeln, für dessen vielfältige Möglichkeiten allerdings keine einheitlichen Determinanten beste- 
hen. ${ }^{147}$ Es wäre sicherlich überzogen, für jedes Realhandeln der Verwaltung eine gesetzliche Ermächtigung zu fordern. Aber insbesondere dann, wenn schlichtes Verwaltungshandeln erhebliche Grundrechtsrelevanz hat, ist zu diskutieren, den Vorbehalt des Gesetzes (s. einführend bereits Rn. 554 ff.) auch auf Realakte zu erstrecken.

Besondere Klausurrelevanz hat in diesem Zusammenhang die staatliche Informationstätigkeit, etwa Warnungen oder (unverbindliche) Informationen. Gerade in diesem Bereich driften die Auffassungen, ob der Vorbehalt des Gesetzes eingreift oder nicht, besonders auseinander. Während etwa für Arzneimitteltransparenzlisten ${ }^{148}$ oder für die Veröffentlichung von Warentests im landwirtschaftlichen Bereich ${ }^{149}$ der Vorbehalt des Gesetzes Anwendung finden soll, hat sich das BVerfG in seiner jüngeren Rechtsprechung von der generellen Anwendung des Vorbehalts des Gesetzes auf staatliches Informationshandeln distanziert: Bei der Warnung vor sogenannten Jugendsekten ${ }^{150}$ sowie der Veröffentlichung einer Liste diethylenglykolhaltiger Weine unter Nennung der Abfüllbetriebe ${ }^{151}$ hat das Gericht den Vorbehalt des Gesetzes für die informelle Tätigkeit der Bundesregierung verneint. Sofern die Informationstätigkeit in den (verfassungsrechtlich) zugewiesenen Aufgabenbereich des Staates falle, bedürfe es keiner gesonderten Ermächtigungsgrundlage, weil diese keinen Gewinn an „Messbarkeit und Berechenbarkeit staatlichen Handelns“ nach sich zöge. Da gesetzliche Ermächtigungen für staatliches Informationshandeln zwangsläufig weit und unbestimmt seien, sei ohnehin fraglich, ob überhaupt von einer eigenen Entscheidung des Parlaments gesprochen werden könnte. ${ }^{152}$ Im Ergebnis lässt die Rechtsprechung die Legitimierung der staatlichen Informationstätigkeit durch die Zuständigkeitszuweisung für die jeweilige Sachaufgabe trotz nicht unerheblicher mittelbar-faktischer Grundrechtseingriffe genügen. Etwas anderes soll nur dann gelten, wenn die staatliche Maßnahme nach ihrer Zielrichtung und Wirkung ein „funktionales Äquivalent“ zu einem Grundrechtseingriff im klassischen Sinne darstellt. ${ }^{153}$ Die Anwendung des Vorbehalts des Gesetzes auf staatliches Infor-

147 Remmert, in: Ehlers/Pünder, Allgemeines Verwaltungsrecht, 15. Aufl. 2015, § 36 Rn. 2.

148 BVerfG (Kammerbeschl.), Beschl. v. 25.2.1999, Az.: 1 BvR 1472/91, 1 BvR 1510/91 = NJW 1999, 3404 (3405).

149 BVerwG, Urt. v. 7.12.1995, Az.: 3 C 23/94 = NJW 1996, 3161 (3162).

150 BVerfG, Beschl.v. 26.6.2002, Az.: 1 BvR 670/91 = BVerfGE 105, 279 (303ff.) - Osho.

151 BVerfG, Beschl. v. 26.6.2002, Az.: 1 BvR 558/91 = BVerfGE 105, 252 (268) - Glykol.

152 BVerfG, Beschl. v. 26.6.2002, Az.: 1 BvR 670/91 = BVerfGE 105, 279 (305) - Osho.

153 BVerfG, Beschl. v. 26.6.2002, Az.: 1 BvR 670/91 = BVerfGE 105, 279 (303) - Osho. Zu den genauen Anforderungen an das „funktionale Äquivalent“ äußert sich das BVerfG in der Entscheidung allerdings nicht. Es wird aber zu verlangen sein, dass die staatliche Tätigkeit nach 
mationshandeln bleibt deshalb die Ausnahme. Zu Recht ist diese Auffassung auf Kritik gestoßen. Wegen der nicht unerheblichen Grundrechtsrelevanz staatlicher Informationstätigkeit ist eine gesetzliche Vorzeichnung geboten. Selbst wenn normative Ermächtigungen nur mit geringer Regelungsdichte ausgestaltet werden können, wird der Handlungsfreiheit des Staates wirksam Grenzen gesetzt. ${ }^{154}$

In der Klausur ist es ratsam, die Beantwortung der Frage, ob Realakte dem 111 Vorbehalt des Gesetzes unterliegen, daran zu orientieren, wie grundrechtssensibel das schlichte Verwaltungshandeln ist. Zwar führen Realakte und damit nicht-regelndes Verwaltungshandeln mangels unmittelbaren Zugriffs auf bestimmte Rechtsgüter durch Ge- oder Verbote regelmäßig nur zu mittelbar-faktischen Grundrechtsbeeinträchtigungen. ${ }^{155}$ Doch gilt der Vorbehalt des Gesetzes für jedes staatliche Eingriffshandeln, unabhängig von der Handlungsform und der Art des Grundrechtseingriffs. ${ }^{156}$ Anstatt die Wesentlichkeitstheorie (s. hierzu Rn. 567 f.) in Fällen mittelbar-faktischer Grundrechtseingriffe zurückzudrängen ${ }^{157}$, kann sie herangezogen werden, um die notwendige Regelungsdichte etwaiger gesetzlicher Ermächtigungen zu klären.

\section{b) Rechtmäßigkeit der realen Handlung (Katrin Giere)}

Im Rahmen der Überprüfung der Rechtmäßigkeit der realen Handlung sind ver- 112 schiedene Punkte zu beachten. Zunächst gilt der Vorrang des Gesetzes. Der Realakt darf mithin nicht gegen geltende Gesetze verstoßen. In der Klausur werden dann in der Regel die Tatbestandsvoraussetzungen der Ermächtigungsgrundlage wie die Zuständigkeit und Weitere geprüft (s. hierzu den Fall 11 in: Eisentraut, Fälle zum Verwaltungsrecht, 2020). Des Weiteren ist die Vereinbarkeit mit höherrangigem Recht in die Prüfung einzubeziehen. Hierbei ist insbesondere auf die Vereinbarkeit mit den Grundrechten und den Verhältnismäßigkeitsgrundsatz $\mathrm{zu}$ achten.

ihren Zielsetzungen und Wirkungen einem klassischen Grundrechtseingriff gleichkommt. Dazu Murswiek, NVwZ 2003, 1 (6); Schoch, NVwZ 2011, 193 (195).

154 Hebeler, NVwZ 2011, 1364 (1365f.); Schulze-Fielitz, in: Dreier, GG, Band II, 3. Aufl. 2015, Art. 20 (Rechtsstaat) Rn. 116; Remmert, in: Ehlers/Pünder, Allgemeines Verwaltungsrecht, 15. Aufl. 2015, § 37 Rn. 3. Vgl. auch Schoch, NVwZ 2011, 193 (195f.).

155 Remmert, in: Ehlers/Pünder, Allgemeines Verwaltungsrecht, 15. Aufl. 2015, § 36 Rn. 4.

156 S. auch Schoch, NVwZ 2011, 193 (195) m.w. N.; Lerche, in: Merten/Papier, Handbuch der Grundrechte, Band III, 2009, § 62 Rn. 27. Folgerichtig wird für die grundrechtsrelevante Gefährderansprache eine gesetzliche Ermächtigung verlangt, s. hierzu OVG Lüneburg, Urt. v. 22.9. 2005, Az.: 11 LC 51/04 = NJW 2006, 391 (393); vgl. auch Hebeler, NVwZ 2011, 1364 ff.

157 Lerche, in: Merten/Papier, Handbuch der Grundrechte, Band III, 2009, § 62 Rn. 27. 


\section{Zusammenfassung}

113 Zusammenfassend muss sich die Prüfung der Begründetheit im Rahmen der allgemeinen Feststellungsklage gem. § 43 I Alt. 1 VwGO immer nach dem Gegenstand des Rechtsverhältnisses richten. Ein grundsätzliches Schema wie es etwa bei der Anfechtungsklage gegeben ist (s. hierzu $§ 2$ Rn. 507 ff.), kann nicht vorgehalten werden. Die Begründetheit einer Feststellungsklage kann somit von einer verfassungsrechtlichen Prüfung bis hin $\mathrm{zu}$ einer rein verwaltungsrechtlichen Prüfung reichen und ist damit vielseitig gestaltbar.

\section{Literaturhinweise}

114 Boch/Schmidt/Vondung, Einführung in die Praxis des verwaltungsgerichtlichen Verfahrens, 10. Aufl. 2019, S. $211 \mathrm{ff}$; Ehlers, Verwaltungsgerichtliche Feststellungsklage, JURA 2007, 179ff.; Geis/Schmidt, Grundfälle zur verwaltungsprozessualen Feststellungsklage ( $\$ 43$ VwGO), JuS 2012, 599 ff.; Hufen, Verwaltungsprozessrecht, 11. Aufl. 2019, § 18; Schwabe/Finkel, Lernen mit Fällen - Allgemeines Verwaltungsrecht und Verwaltungsprozessrecht, 9. Aufl. 2017, S. 76ff.; Wöckel, Das Rechtsverhältnis im Sinne von § 43 I VwGO, JA 2015, 205 ff.

Falllösung: Fall 11 in: Eisentraut, Fälle zum Verwaltungsrecht, 2020

\section{Begründetheit der Nichtigkeitsfeststellungsklage (Tobias Brings-Wiesen)}

115 Die Nichtigkeitsfeststellungsklage ist begründet, wenn der Verwaltungsakt (teilweise) nichtig ist. ${ }^{158}$ Soweit keine spezialgesetzlichen Nichtigkeitsvorschriften existieren, ${ }^{159}$ richtet sich dies nach § 44 VwVfG, ${ }^{160}$ auf den im Folgenden genau einzugehen ist.

116 Soweit bereits im Rahmen der Zulässigkeit das Vorliegen einer Klagebefugnis gemäß § 42 II VwGO analog gefordert wurde, bedarf es für die Annahme der Begründetheit darüber hinaus auch der Feststellung einer Betroffenheit ${ }^{161}$ des

158 Umstritten ist der maßgebliche Beurteilungszeitpunkt: für den Zeitpunkt der letzten behördlichen Entscheidung, Hufen, Verwaltungsprozessrecht, 11. Aufl. 2019, § 24 Rn. 16; Wienbracke, Verwaltungsprozessrecht, 3. Aufl. 2019, Rn. 484; demgegenüber für den Zeitpunkt der letzten mündlichen Verhandlung, Schenke, Verwaltungsprozessrecht, 16. Aufl. 2019, Rn. 870.

159 So bspw. für das Abgabenrecht in § 125 AO oder für das Sozialrecht in § 40 SGB X.

160 Bzw. nach den entsprechenden Vorschriften der VwVfGe der Länder.

161 Eine Verletzung wird mangels rechtlicher Wirkungen des nichtigen Verwaltungsakts aber zu Recht nicht verlangt, Hufen, Verwaltungsprozessrecht, 11. Aufl. 2019, § 29 Rn. 12. 
Klägers in einem subjektiven Recht gemäß § 113 I 1 VwGO analog. ${ }^{162}$ Insofern kann auf den Rechtsschein der Wirksamkeit und die aus ihm resultierenden tatsächlichen Auswirkungen für einen Betroffenen abgestellt werden.

\section{Das Verhältnis der Absätze des $§ 44$ VwVfG untereinander}

Das Verhältnis der Absätze 1 bis 3 des $\S 44$ VwVfG untereinander ist norm- 117 strukturell „umstritten“. ${ }^{163}$ Die Klärung dieses Verhältnisses hat jedoch Auswirkungen auf den Prüfungsaufbau und soll daher vorab erfolgen.

Die Tatbestände der Abs. 1 und 2 begründen erst die Nichtigkeit eines Verwaltungsakts. Abs. 3 hingegen bestimmt Rückausnahmen für den Fall, dass nach Abs. 1 oder 2 grundsätzlich von einer Nichtigkeit auszugehen wäre (,nicht schon deshalb nichtig“). Normlogisch bedarf es also einer Prüfung von Abs. 3 gar nicht, wenn sich bereits keine Nichtigkeit über die Abs. 1 und 2 begründen lässt.

Im Verhältnis von Abs. 1 zu Abs. 2 gebührt Abs. 2 der Vorrang. Zwar 119 handelt es sich nicht um eine Spezialregelung, da nach herrschender Meinung die von Abs. 2 erfassten Konstellationen auch unabhängig von der Offensichtlichkeit zur Nichtigkeit führen (s. dazu Rn 121) ${ }^{\mathbf{1 6 4}}$ und die Absätze somit auch voneinander unabhängige Konstellationen erfassen. ${ }^{165}$ Der Gesetzgeber hat jedoch durch die Bestimmung der besonderen ${ }^{166}$ Nichtigkeitsgründe die im Rahmen von Abs. 1 im Einzelfall zu treffende Wertentscheidung der Nichtigkeit eines Rechtsfehlers bereits selbst getroffen. ${ }^{167}$ Die Begründung der Nichtigkeit über Abs. 2 ist vor

162 Hufen, Verwaltungsprozessrecht, 11. Aufl. 2019, § 29 Rn. 12; Würtenberger/Heckmann, Verwaltungsprozessrecht, 4. Aufl. 2018, Rn. 494; a. A. indes Wienbracke, Verwaltungsprozessrecht, 3. Aufl. 2019, Rn. 484.

163 S. dazu auch Ipsen, Allgemeines Verwaltungsrecht, 11. Aufl. 2019, Rn. 686; Sachs, in: Stelkens/Bonk/Sachs, VwVfG, 9. Aufl. 2018, § 44 Rn. 99 ff.; Peuker, in: Knack/Henneke, VwVfG, 10. Aufl. 2014, § 44 Rn. 12; Schladebach, VerwArch 2013, 188 (195f.).

164 Peuker, in: Knack/Henneke, VwVfG, 10. Aufl. 2014, § 44 Rn. 12, erwägt gar, dass die Fehler den Grad der besonderen Schwere nach Abs. 1 verfehlen könnten - dies ist angesichts der maßstabsbildenden Wirkung von Abs. 2 für die Bestimmung der besonderen Schwere, s. dazu noch Rn. 155, nicht überzeugend.

165 Sachs, in: Stelkens/Bonk/Sachs, VwVfG, 9. Aufl. 2018, § 44 Rn. 100. S. zur Konstellation der bloßen Überschneidung der Anwendungsbereiche zweier Rechtsnormen Zippelius, Juristische Methodenlehre, 11. Aufl. 2012, S. $31 \mathrm{f}$.

166 Vielerorts wird terminologisch auch zwischen „absoluten“ und „relativen“ Nichtigkeitsgründen unterschieden, Detterbeck, Allgemeines Verwaltungsrecht, 17. Aufl. 2019, Rn. 614, 616; Maurer/Waldhoff, Allgemeines Verwaltungsrecht, 19. Aufl. 2017, § 10 Rn. 87; Peuker, in: Knack/ Henneke, VwVfG, 10. Aufl. 2014, § 44 Rn. 12.

167 Schemmer, in: Bader/Ronellenfitsch, VwVfG, 44. Ed., Stand: 1.7.2019, § 44 Rn. 40. 
diesem Hintergrund schlicht der einfachere Weg, ${ }^{168}$ sodass Abs. 2 aus verfahrensökonomischen Gründen stets vorzuziehen ist. Im Verhältnis von Abs. 1 und $3^{169}$ gilt Folgendes: $\S 44$ III VwVfG vermag selbst keine Nichtigkeit zu begründen, sondern setzt deren Vorliegen voraus („nicht schon deshalb“). Es handelt sich daher um einen Ausnahmetatbestand, dessen Anwendungsbereich normlogisch erst dann eröffnet wäre, wenn eine Nichtigkeit nach Abs. 1 in Frage käme. Da jedoch ein Ausschluss der Nichtigkeit über Abs. 3 leichter zu begründen ist, besteht wie von Sachs treffend festgestellt zumindest ein anwendungspraktischer Nachrang von Abs. 1. ${ }^{170}$

120 Daraus ergeben sich folgende Vorgaben für das Vorgehen in der Prüfung: Gedanklich erfolgt die Beurteilung in der Reihenfolge Abs. 2 - Abs. 3 - Abs. $1^{171}$. Innerhalb des Prüfungsaufbaus sollte dementsprechend mit der Bewertung einer möglichen Nichtigkeit gemäß § 44 II VwVfG begonnen werden. Wird diese verneint, ist indes sodann eine mögliche Nichtigkeit gemäß § 44 I VwVfG zu prüfen, deren erster Gliederungspunkt jedoch das Vorliegen eines Ausschlusstatbestands gemäß § 44 III VwVfG ist. ${ }^{172}$

\section{Besondere Nichtigkeitsgründe, § 44 II VwVfG}

121 Die Enumeration der besonderen Nichtigkeitsgründe in $\S 44$ II VwVfG ist abschließend. ${ }^{173}$ Aufgrund ihres Ausnahmecharakters bedarf es ihrer restriktiven Handhabung und einer entsprechend genauen Kenntnis ihrer Anwendungsbereiche ${ }^{174}$. Stets ist jedoch $\mathrm{zu}$ beachten, dass diesen Gründen verwandte Sachverhaltskonstellationen im Einzelfall durchaus noch eine Nichtigkeit nach §44 I

168 Sachs, in: Stelkens/Bonk/Sachs, VwVfG, 9. Aufl. 2018, § 44 Rn. 100.

169 Normstrukturell spricht nichts gegen eine Anwendung von Abs. 3 auf Abs. 2, allerdings bestehen zwischen beiden Vorschriften schlicht keine anwendungspraktischen Überschneidungen.

170 Sachs, in: Stelkens/Bonk/Sachs, VwVfG, 9. Aufl. 2018, § 44 Rn. 101.

171 So bspw. auch Maurer/Waldhoff, Allgemeines Verwaltungsrecht, 19. Aufl. 2017, § 10 Rn. 87; Peine/Siegel, Allgemeines Verwaltungsrecht, 12. Aufl. 2018, Rn. 547; Ipsen, Allgemeines Verwaltungsrecht, 11. Aufl. 2019, Rn. 685f.; a. A. Detterbeck, Allgemeines Verwaltungsrecht, 17. Aufl. 2019, Rn. 618; Will/Rathgeber, JuS 2012, 1057 (1058).

172 S. für ein Beispiel des Aufbaus und Formulierungshilfen den Fall 12 in: Eisentraut, Fälle zum Verwaltungsrecht, 2020.

173 Ganz h.M., s. nur Ramsauer, in: Kopp/Ramsauer, VwVfG, 20. Aufl. 2019, § 44 Rn. 31; Beaucamp, JA 2007, 704 (705); Will/Rathgeber, JuS 2012, 1057 (1059); Schladebach, VerwArch 2013, 188 (196). Konsequent gegen eine analoge Anwendung daher Peine/Siegel, Allgemeines Verwaltungsrecht, 12. Aufl. 2018, Rn. 548; Sachs, in: Stelkens/Bonk/Sachs, VwVfG, 9. Aufl. 2018, § 44 Rn. 129.

174 S. zu den einzelnen Tatbeständen auch Will/Rathgeber, JuS 2012, 1057 (1059ff.).

Tobias Brings-Wiesen 
VwVfG begründen können. Danach bedarf es indes neben der durchaus anspruchsvollen Feststellung der besonderen Schwere des Fehlers auch der Feststellung seiner Offensichtlichkeit, die im Rahmen von Abs. 2 keine Rolle spielt. ${ }^{175}$

\section{a) Unerkennbarkeit der erlassenden Behörde (Nr. 1)}

Gemäß § 44 II Nr. 1 VwVfG ist ein schriftlich oder elektronisch erlassener Ver- 122 waltungsakt nichtig, wenn er die erlassende Behörde nicht erkennen lässt. Die Vorschrift knüpft an § 37 III 1 Hs. 1 VwVfG an, der u.a. diese Mindestangabe fordert. Der Erkennbarkeit wird so eine herausgehobene Bedeutung beigemessen, weil die Betroffenen nur auf diesem Wege sichere Kenntnis darüber erlangen können, mit wem durch den Verwaltungsakt ein Rechtsverhältnis etabliert worden und wer entsprechend Gegner von Rechtsbehelfen ist. ${ }^{176}$ Weiterhin ermöglicht erst sie es, zu beurteilen, ob es sich überhaupt um einen Verwaltungsakt handelt (Begriffsmerkmal: „Behörde“; s. dazu in $\S 2$ Rn. 52ff.) und dieser von der zuständigen Behörde erlassen wurde. ${ }^{177}$

Gleichwohl sind an die Erkennbarkeit keine überhöhten Anforderungen

zu stellen. Zwar ist es in der Praxis üblich und sinnvoll, dass sich aus einem Briefkopf oder einem Dienstsiegel, ${ }^{178}$ einem Rubrum oder einem Zusatz bei der Unterschrift $^{179}$ klar auf die erlassende Behörde ${ }^{180}$ schließen lässt. Nach wohl herrschender Meinung ist jedoch auch dann nicht von einer Nichtigkeit auszugehen, wenn der Betroffene anderweitig aus dem textlich fixierten Verwaltungs-

175 S. nur BVerwG, Beschl. v. 11.2.1987, Az.: 1 B 129.86 = NVwZ 1987, 411; Urt. v. 30.1.1990, Az.: 1 C $26.87=$ BVerwGE 84, 314 (315).

176 Maurer/Waldhoff, Allgemeines Verwaltungsrecht, 19. Aufl. 2017, § 10 Rn. 88; Peine/Siegel, Allgemeines Verwaltungsrecht, 12. Aufl. 2018, Rn. 549. So bereits die Gesetzesmaterialien BTDrucks. 7/910, S. 64.

177 Ramsauer, in: Kopp/Ramsauer, VwVfG, 20. Aufl. 2019, § 44 Rn. 32; Schemmer, in: Bader/ Ronellenfitsch, VwVfG, 44. Ed., Stand: 1.7.2019, § 44 Rn. 41.

$178 \mathrm{Zu}$ entsprechenden landesrechtlichen Vorschriften OVG Weimar, Beschl. v. 29.3.1994, Az.: 2 EO 18/93 = NVwZ-RR 1995, 253. Nicht notwendig aus dem Briefkopf, vgl. VGH München, Beschl. 27.4.2010, Az.: 7 ZB 08.2577= BeckRS 2010, 49187, Rn. 11. Eine schlichte Ungültigstempelung ohne weitere Informationen genügt nicht, vgl. VGH Mannheim, Beschl. v. 27.1.1992, Az.: 1 S 2993/91 = juris, Rn. 12.

179 Ramsauer, in: Kopp/Ramsauer, VwVfG, 20. Aufl. 2019, § 44 Rn. 33.

180 Im Wege einer teleologischen Reduktion kann auch die korrekte Bezeichnung des Rechtsträgers ausreichen, sofern dieser nur über eine einzige Behörde verfügt, für die intern lediglich unterschiedlich gegliederte Organe oder Dienststellen agieren, s. OVG Münster, Beschl. v. 7.10. 2009, Az.: 15 A 3141/07 = juris, Rn. 14, mit beispielhafter Nennung des Bürgermeisters bei Gemeinden und des Rektors bei Universitäten. 
akt ${ }^{181}$ - auch im Wege der Auslegung ${ }^{182}$ - oder gar aus den mit ihm (unmittelbar) zusammenhängenden Dokumenten und Informationen ${ }^{183}$ (einem Briefumschlag, einem Poststempel, einer Zustellungsurkunde, ${ }^{184}$ einem Begleitschreiben ${ }^{185}$ oder auch einer elektronischen Signatur, vgl. § 37 III 2 VwVfG) die erlassende Behörde zweifelsfrei feststellen kann. Eine zweifelsfreie Feststellung scheitert demgegenüber, wenn die Angaben sachlich schlicht falsch, nicht spezifisch genug oder wie im Falle der Angabe mehrerer Behörden - widersprüchlich sind. ${ }^{186}$ Gleichsam wird es mehrheitlich als nicht ausreichend erachtet, dass der Betroffene lediglich aus dem Sachzusammenhang die erlassende Behörde erkennen kann. ${ }^{187}$

Nach herrschender Meinung findet die Vorschrift keine (analoge) Anwendung auf die Inhaltsvorgaben in $\S 37$ III 1 Hs. 2 VwVfG (Unterschrift und Namenswiedergabe). ${ }^{188}$ Vertreten wird bisweilen eine analoge Anwendung auf in anderer Form erlassene Verwaltungsakte. ${ }^{189}$

\section{b) Fehlen einer Urkunde (Nr. 2)}

125 Gemäß § 44 II Nr. 2 VwVfG ist ein Verwaltungsakt nichtig, der nach einer Rechtsvorschrift nur durch die Aushändigung einer Urkunde erlassen werden kann, aber dieser Form nicht genügt. Die Worte „Urkunde“ und „Form“ verleiten gerade Anfänger^innen zu der Annahme eines Sachzusammenhangs mit den im Rahmen der formellen Rechtmäßigkeit zu prüfenden Formvorgaben (§37 II-VI VwVfG). Träfe dies zu, führte jeder Formfehler automatisch zur Nichtigkeit des Verwaltungsakts. Nach ganz herrschender Meinung findet die Vorschrift jedoch

181 VGH München, Beschl. v. 27.4.2010, Az.: 7 ZB 08.2577 = BeckRS 2010, 49187, Rn. 11.

182 Nicht ausreichend ist, dass die erlassende Behörde erst in der Rechtsmittelbelehrung als Widerspruchsbehörde genannt ist, OVG Schleswig, Urt. v. 24.10.2001, Az.: 2 L 29/00 = BeckRS 2001, 13051, Rn. 39.

183 VGH Mannheim, Urt. v. 25.2.1988, Az.: 2 S 2543/87 = VBlBW 1988, 439 (Ls. 2).

184 Ramsauer, in: Kopp/Ramsauer, VwVfG, 20. Aufl. 2019, § 44 Rn. 33; Beaucamp, JA 2007, 704 (705).

185 Schemmer, in: Bader/Ronellenfitsch, VwVfG, 44. Ed., Stand: 1.7.2019, § 44 Rn. 44.

186 Ramsauer, in: Kopp/Ramsauer, VwVfG, 20. Aufl. 2019, § 44 Rn. 34.

187 So Ramsauer, in: Kopp/Ramsauer, VwVfG, 20. Aufl. 2019, § 44 Rn. 33; Schwarz, in: Fehling/ Kastner/Störmer, Verwaltungsrecht, 4. Aufl. 2016, § 44 VwVfG Rn. 15, die das Beispiel vorangegangener Gespräche nennen.

188 VGH München, Urt. v. 22. 8.1986, Az.: 23 B 85 A. 446 = NVwZ 1987, 729; OVG Weimar, Beschl.v. 29.3.1994, Az.: 2 EO 18/93 = NVwZ-RR 1995, 253; Peuker, in: Knack/Henneke, VwVfG, 10. Aufl. 2014, $\S 44$ Rn. 35.

189 Ramsauer, in: Kopp/Ramsauer, VwVfG, 20. Aufl. 2019, § 44 Rn. 35; wohl auch Peuker, in: Knack/Henneke, VwVfG, 10. Aufl. 2014, §44 Rn. 36. Zu Recht dagegen jedoch Schemmer, in: Bader/Ronellenfitsch, VwVfG, 44. Ed., Stand: 1.7.2019, § 44 Rn. 43.

Tobias Brings-Wiesen 
nur auf solche Fälle Anwendung, in denen die Aushändigung einer Urkunde konstitutiver Bestandteil des Erlassvorgangs eines Verwaltungsakts ist. ${ }^{190}$ Dies bedarf einer Auslegung des im Einzelfall einschlägigen Fachrechts. Davon konsequent abzugrenzen sind mithin Schriftstücke, die von der Verwaltung nur zu Legitimations- und Beweiszwecken ausgestellt werden. ${ }^{191}$

Beispiele für solch konstitutive Urkunden i. S.v. § 44 II Nr. 2 VwVfG sind: die Einbürgerungsurkunde (§ 16 S. 1 StAG) $)^{192}$ sowie deren Gegenstücke - die Urkunden über die Entlassung aus der (§23 StAG) und über den Verzicht auf die Staatsangehörigkeit (§ 26 III StAG); die Ernennungsurkunde im Beamtenverhältnis (§ 10 II 1 BBG; $§ 8$ II 1 BeamtStG) $)^{193}$.

\section{c) Verstoß gegen die örtliche Zuständigkeit gemäß § 3 I Nr. 1 VwVfG (Nr. 3)}

Gemäß § 44 II Nr. 3 VwVfG ist ein Verwaltungsakt nichtig, den eine Behörde au- 127 Berhalb ihrer durch § 3 I Nr. 1 begründeten Zuständigkeit erlassen hat, ohne dazu ermächtigt zu sein. Der Anwendungsbereich dieses Tatbestands ist bereits durch den Verweis auf $\S 3$ VwVfG auf die örtliche Zuständigkeit beschränkt. Zwar soll die Nichteinhaltung der Vorschriften über die örtliche Zuständigkeit gemäß $\S 44$ III Nr. 1 VwVfG grundsätzlich nicht zur Nichtigkeit eines Verwaltungsakts führen (s. dazu Rn. 145). Davon ausdrücklich ausgenommen wird jedoch gemäß $\S 44$ II Nr. 3, III Nr. 1 Hs. 2 VwVfG der „qualifizierte[n] Fall örtlicher Unzuständigkeit“"194 in Angelegenheiten, die sich auf unbewegliches Vermögen oder ein ortsgebundenes Recht oder Rechtsverhältnis beziehen, § 3 I Nr. 1 VwVfG. Diese Sonderbehandlung ist der Annahme geschuldet, dass in den Fällen der besonderen Ortsgebundenheit ein besonderes räumliches Näheverhältnis und besondere Ortskenntnis bestehen.

Eine Nichtigkeit gemäß § 44 II Nr. 3 VwVfG kommt jedoch nur in Frage, wenn 128 die gemäß § 3 I Nr. 1 VwVfG örtlich unzuständige Behörde auch nicht anderweitig zum Erlass des Verwaltungsakts ermächtigt ist. Kommt es zu einer abweichen-

190 Ramsauer, in: Kopp/Ramsauer, VwVfG, 20. Aufl. 2019, § 44 Rn. 36; Sachs, in: Stelkens/Bonk/ Sachs, VwVfG, 9. Aufl. 2018, § 44 Rn. 133; Will/Rathgeber, JuS 2012, 1057 (1060).

191 Ramsauer, in: Kopp/Ramsauer, VwVfG, 20. Aufl. 2019, § 44 Rn. 37.

192 BVerwG, Urt. v. 9.9.2014, Az.: 1 C 10.14 = NVwZ 2014, 1679 (1680, Rn. 15).

193 Wobei zu beachten ist, dass das Beamtenrecht für diese Konstellation spezialgesetzliche Nichtigkeitsregelungen (§ 13 I Nr. 1 BBG; § 11 I Nr. 1 BeamtStG) vorsieht, die entsprechend vorgehen, BVerwG, Urt. v. 23.2.1989, Az.: 2 C 25.87 = BVerwGE 81, 282 (284f.); Sachs, in: Stelkens/ Bonk/Sachs, VwVfG, 9. Aufl. 2018, § 44 Rn. 134. Diskutiert wird - zumindest im Kontext des Beamtenrechts - jedoch zu Recht, ob bei Fehlen der Aushändigung nicht gar eine „Nichternennung“, sprich ein „Nichtakt“ (s. dazu bereits in $\S 2$ Rn. 20) vorliegt, s. dazu m.w. N. Sachs, a.a.O. 194 So die Gesetzesmaterialien, BT-Drucks. 7/910, S. 64. 
den Ermächtigung durch ein spezielleres Gesetz handelt es sich um eine grundsätzlich neue Zuständigkeitsregelung und daher bereits nicht mehr um eine durch $\S 3$ I Nr. 1 VwVfG begründete Zuständigkeit. ${ }^{195}$ Eine entsprechende Ermächtigung kann aber auf Grundlage eines Gesetzes im Falle von Mehrfachzuständigkeiten (vgl. § 3 II VwVfG), im Falle eines Zuständigkeitswechsels (§ 3 III VwVfG) ${ }^{196}$ oder im Falle sog. (Einzel- oder General-)Delegationen ${ }^{197}$, vorliegen.

Obgleich die Vorschrift ausdrücklich auf die Begründung einer örtlichen Zuständigkeit durch $\S 3$ I Nr. 1 VwVfG abstellt, ${ }^{198}$ will die herrschende Meinung den Nichtigkeitsgrund auch auf weitere, die Zuständigkeitszuweisung nach materiell vergleichbaren Maßstäben vornehmende Vorschriften anwenden. ${ }^{199}$ Eine darüber hinausgehende (analoge) Anwendung der Vorschrift auf andere Konstellationen fehlender örtlicher oder sonstiger Zuständigkeit wird indes von einer deutlichen Mehrheit abgelehnt. ${ }^{200}$ Insofern kann jedoch in bestimmten Konstellationen eine Nichtigkeit nach § 44 I VwVfG in Frage kommen.

\section{d) Tatsächliche Unmöglichkeit der Befolgung der gesetzten Rechtsfolge (Nr. 4)}

130 Gemäß § 44 II Nr. 4 VwVfG ist ein Verwaltungsakt nichtig, den aus tatsächlichen Gründen niemand ausführen kann. ${ }^{201}$

131 Der Terminus ,ausführen“ legt auf den ersten Blick sprachlich nahe, die Norm lediglich auf befehlende Verwaltungsakte anzuwenden, die ein bestimmtes Verhalten einfordern. Ganz überwiegend wird der Begriff jedoch ,in einem weiten Sinne verstanden, der jede denkbare Art der Verwirklichung des Verwaltungsakts

195 Sachs, in: Stelkens/Bonk/Sachs, VwVfG, 9. Aufl. 2018, § 44 Rn. 138.

196 Peuker, in: Knack/Henneke, VwVfG, 10. Aufl. 2014, § 44 Rn. 39.

197 Delegationen sind von „Botenschaften“ und „Mandaten“ abzugrenzen, vgl. dazu Sachs, in: Stelkens/Bonk/Sachs, VwVfG, 9. Aufl. 2018, § 44 Rn. 140f. S. auch Sachs, a.a. O., Rn. 138f., zur Frage der Wirksamkeit der Delegation.

198 Art. 44 II Nr. 3 BayVwVfG verzichtet auf einen Verweis und setzt auf § 3 I Nr. 1 VwVfG entsprechende materielle Maßstäbe.

199 S. nur Ramsauer, in: Kopp/Ramsauer, VwVfG, 20. Aufl. 2019, § 44 Rn. 38; Sachs, in: Stelkens/ Bonk/Sachs, VwVfG, 9. Aufl. 2018, § 44 Rn. 137; a. A. wohl Schladebach, VerwArch 2013, 188 (197). 200 Ramsauer, in: Kopp/Ramsauer, VwVfG, 20. Aufl. 2019, § 44 Rn. 38; Sachs, in: Stelkens/Bonk/ Sachs, VwVfG, 9. Aufl. 2018, § 44 Rn. 137; noch für die entsprechende Norm des VwVfG LSA a.F. OVG Magdeburg, Beschl.v. 16.11.2006, Az.: 4 L 191/06 = LKV 2008, 139; für das VwVfG NRW OVG Münster, Beschl. v. 27.9.2018, Az.: 13 A 1547/16 = juris, Rn. 16.

201 BVerwG, Beschl.v. 8.5.1995, Az.: 7 B 223.94 = juris, Rn. 2: „Der Vorschrift liegt die Erwägung zugrunde, daß ein Verwaltungsakt der auf einen unmöglichen Erfolg gerichtet ist, keine Rechtsgeltung beanspruchen kann $[. .$.$] “.$

Tobias Brings-Wiesen 
einschließt“202 und somit der Anwendungsbereich auch auf feststellende und gestaltende Verwaltungsakte erstreckt ${ }^{203}$.

Der Terminus „aus tatsächlichen Gründen“ beschränkt den Anwendungsbereich auf Konstellationen, in denen ein Verwaltungsakt aus naturgesetzlichen Gründen (entsprechend des jeweils aktuellen Erkenntnisstandes ${ }^{204}$ ) von niemandem ausgeführt werden kann. Dies kann beispielsweise der Tatsache geschuldet sein, dass das sachliche Bezugsobjekt eines Verwaltungsakts nicht (mehr) existiert oder es bereits unumkehrbar verändert wurde. ${ }^{205}$ Dasselbe gilt, wenn ein Verhalten verlangt wird, dass nach aktuellem Stand von Wissenschaft und Technik ${ }^{206}$ oder in einer vorgegebenen Zeit $^{207}$ schlicht nicht zu leisten ist. Gestritten wird um die analoge Anwendung der Vorschrift auf Konstellationen, in denen die Ausführung objektiv mit einem völlig unverhältnismäßigen Aufwand verbunden wäre. ${ }^{208}$

Nach herrschender Meinung ist die Norm nicht anwendbar auf Konstellationen rechtlicher Unmöglichkeit. ${ }^{209}$ Die Differenzierung erfolgt über die Ana-

202 BVerwG, Beschl. v. 8.5.1995, Az.: 7 B 223.94 = juris, Rn. 2.

203 Ramsauer, in: Kopp/Ramsauer, VwVfG, 20. Aufl. 2019, § 44 Rn. 41; Sachs, in: Stelkens/Bonk/ Sachs, VwVfG, 9. Aufl. 2018, § 44 Rn. 149; a. A. wohl Leisner-Egensperger, in: Mann/Sennekamp/ Uechtritz, VwVfG, 2. Aufl. 2019, § 44 Rn. 35.

204 S. auch Ramsauer, in: Kopp/Ramsauer, VwVfG, 20. Aufl. 2019, § 44 Rn. 39: entsprechend des gegenwärtigen Kenntnisstands von Wissenschaft und Technik.

205 Bspw. bei einer Abrissverfügung betreffend ein (nach bereits erfolgtem Abriss) leeres Grundstück, Maurer/Waldhoff, Allgemeines Verwaltungsrecht, 19. Aufl. 2017, § 10 Rn. 88; Peine/ Siegel, Allgemeines Verwaltungsrecht, 12. Aufl. 2018, Rn. 552. Ungewöhnlich vor diesem Hintergrund OVG Münster, Urt. v. 14.9.1989, Az.: 7 A 889/87 = NVwZ-RR 1990, 341, das die Nichtigkeit einer denkmalrechtlichen Unterschutzstellung eines nicht mehr existierenden Gebäudes auf $\S 44$ I VwVfG NRW stützt. Vgl. auch KreisG Dresden, Urt. v. 24.6.1992, Az.: III K 400/91 = LKV 1993, 143 (144), wo das Gericht von der tatsächlichen Unverfügbarkeit von DDR-Mark als Zahlungsmittel ausging.

206 Zur entsprechenden Vorschrift des hessischen VwVfG VGH Kassel, Beschl.v. 29.10.2007, Az.: 7 TG 2891/06 = juris, Rn. 13. Vgl. auch das Beispiel bei Peine/Siegel, Allgemeines Verwaltungsrecht, 12. Aufl. 2018, Rn. 552, das sich beliebig abwandeln lässt.

207 Sachs, in: Stelkens/Bonk/Sachs, VwVfG, 9. Aufl. 2018, § 44 Rn. 143; Leisner-Egensperger, in: Mann/Sennekamp/Uechtritz, VwVfG, 2. Aufl. 2019, § 44 Rn. 36; in diese Richtung auch VGH Kassel, Beschl. v. 30.4.1982, Az.: III TG 119/82 = NVwZ 1982, 514 (515). Vgl. entsprechend auch BVerwG, Beschl. v. 10.5.1988, Az.: 2 WDB 6/87 = BVerwGE 86, 18 (20).

208 Dafür Ramsauer, in: Kopp/Ramsauer, VwVfG, 20. Aufl. 2019, § 44 Rn. 39; Peuker, in: Knack/ Henneke, VwVfG, 10. Aufl. 2014, § 44 Rn. 40; a. A. jedoch Peine/Siegel, Allgemeines Verwaltungsrecht, 12. Aufl. 2018, Rn. 552; Sachs, in: Stelkens/Bonk/Sachs, VwVfG, 9. Aufl. 2018, § 44 Rn. 145.

209 Sachs, in: Stelkens/Bonk/Sachs, VwVfG, 9. Aufl. 2018, § 44 Rn. 146; Schemmer, in: Bader/ Ronellenfitsch, VwVfG, 44. Ed., Stand: 1.7.2019, § 44 Rn. 52; a. A. aber Ramsauer, in: Kopp/Ram-

Tobias Brings-Wiesen 
lyse der Gründe für die Unmöglichkeit: Genehmigt die Behörde ein Bauvorhaben unter fehlerhafter Angabe der Größe eines Baugrundstücks, bleibt dieses bautechnisch und damit tatsächlich durchführbar, auch wenn es und damit die erteilte Baugenehmigung gegen (bau-)rechtliche Vorgaben verstößt. ${ }^{210}$ Ein Widerspruch der Verwirklichung eines Verwaltungsakts zur geltenden Rechtsordnung führt nur unter den Voraussetzungen von § 44 II Nr. 5 oder I VwVfG zur Nichtigkeit.

Der Terminus „niemand“ verdeutlicht, dass die Vorschrift nur Konstellationen objektiver Unmöglichkeit erfasst. Subjektives Unvermögen wegen mit dem Adressaten oder sonst Betroffenen verbundener Gründe ${ }^{211}$ kann allein nach $\S 44$ I VwVfG zur Nichtigkeit führen. ${ }^{212}$ Die Abgrenzungen zwischen objektiver und subjektiver, tatsächlicher und rechtlicher Unmöglichkeit sind in der (Klausur-) Praxis oft mit Schwierigkeiten verbunden. ${ }^{213}$ Oftmals sind sie jedoch bloß der Tatsache geschuldet, dass subjektiven bzw. rechtlichen Erwägungen im Einzelfall doch Relevanz beigemessen wird. ${ }^{214}$

\section{e) Gebot der Begehung einer rechtswidrigen Tat, die einen Straf- oder Bußgeldtatbestand verwirklicht (Nr. 5)}

135 Gemäß $§ 44$ II Nr. 5 VwVfG ist ein Verwaltungsakt nichtig, der die Begehung einer rechtswidrigen Tat verlangt, die einen Straf- oder Bußgeldtatbestand verwirklicht. ${ }^{215}$ Auf diesem Wege sollen die Einheit der Rechtsordnung gewahrt und die Betroffenen vor Repressalien geschützt werden. ${ }^{216}$

sauer, VwVfG, 20. Aufl. 2019, § 44 Rn. 40; Schwarz, in: Fehling/Kastner/Störmer, Verwaltungsrecht, 4. Aufl. 2016, § 44 VwVfG Rn. 19.

210 BVerwG, Urt.v. 26.9.1991, Az.: 4 C 36.88 = NVwZ 1992, 564 (564f.); a. A. in der Vorinstanz noch das OVG Münster, Urt. v. 23.2.1988, Az.: 7 A 1261/86 = DÖV 1989, 685.

211 Bspw. wegen des Fehlens finanzieller Mittel oder wegen gesundheitlicher Einschränkungen. 212 Ramsauer, in: Kopp/Ramsauer, VwVfG, 20. Aufl. 2019, § 44 Rn. 42; Sachs, in: Stelkens/Bonk/ Sachs, VwVfG, 9. Aufl. 2018, § 44 Rn. 144.

213 Vgl. für ein Beispiel den Fall 12 in: Eisentraut, Fälle zum Verwaltungsrecht, 2020.

214 Vgl. insofern das VGH Kassel, Beschl. v. 24.11.1999, Az.: 8 UZ 993/99 = juris, Rn. 23 ff. (insbesondere 26), das neben der objektiven Unmöglichkeit der Erreichung einer - dem aktuellen technischen Kenntnisstand entsprechenden - Mindestverbrennungstemperatur auch die subjektive Unmöglichkeit hinsichtlich einer konkreten Verbrennungsanlage berücksichtigen will, allerdings allenfalls wenn mit ihr „wegen ihrer Bauart oder Betriebsweise oder nach ihrer Auslegung etc. die Einhaltung einer solchen Mindesttemperatur grundsätzlich und auch unter Einbeziehung technisch möglicher und rechtlich genehmigungsfähiger sowie vernünftigerweise noch in Betracht zu ziehender Auf- oder Umrüchtungsmaßnahmen nicht erreichbar ist“.

215 Beide Bedingungen müssen kumulativ erfüllt sein, da selbstredend rechtswidriges Verhalten denkbar ist, dass der Gesetzgeber nicht mit den Mitteln des Straf- oder Ordnungswidrigkeitenrechts sanktionieren möchte.

Tobias Brings-Wiesen 
Materieller Bezugspunkt des Verwaltungsakts muss eine rechtswidrige 136 Tat sein, die einen Straf- oder Bußgeldtatbestand verwirklicht. Um einen Straftatbestand handelt es sich, wenn die rechtswidrige Tat im StGB oder den Normen des Fachrechts mit einer Strafe i.S.v. § 12 StGB bedroht ist; um einen Bußgeldtatbestand handelt es sich bei entsprechender Drohung mit einer Geldbuße i.S.v. $§ 1$ OWiG. ${ }^{217}$ Erforderlich ist damit eine Inzidentprüfung der einschlägigen Vorschriften. Diese kann jedoch beschränkt werden auf die objektiven Tatbestandsmerkmale und die Rechtswidrigkeit; Ausführungen zu subjektiven Tatbestandsmerkmalen und zur Schuld können unterbleiben. ${ }^{218}$ Soweit Rechtsfertigungsgründe greifen, ist nicht von einer rechtswidrigen Tat auszugehen und der Verwaltungsakt damit zumindest wirksam; ${ }^{219}$ von dem jeweiligen Verwaltungsakt kann jedoch auch selbst eine Legalisierungswirkung ${ }^{220}$ ausgehen - deren Voraussetzungen sind jedoch umstritten ${ }^{221}$.

Der Verwaltungsakt muss die Begehung einer eben solchen Tat „verlan- 137 gen“.222 Sprachlich ist die Vorschrift somit auf befehlende Verwaltungsakte beschränkt, die ein Gebot aussprechen. Dies kann auch das Gebot eines tatbestandlich relevanten Unterlassens sein. ${ }^{223}$ Auf Verwaltungsakte, die ein entsprechendes Verhalten bloß erlauben, ist die Norm nach wohl herrschender Meinung nicht anwendbar. ${ }^{224}$

216 Ramsauer, in: Kopp/Ramsauer, VwVfG, 20. Aufl. 2019, § 44 Rn. 43.

217 Peuker, in: Knack/Henneke, VwVfG, 10. Aufl. 2014, § 44 Rn. 42. Auf andere Konstellationen der Rechtswidrigkeit ist die Norm nach h.M. nicht anwendbar, s. nur Ramsauer, in: Kopp/Ramsauer, VwVfG, 20. Aufl. 2019, § 44 Rn. 45 f.

218 Ramsauer, in: Kopp/Ramsauer, VwVfG, 20. Aufl. 2019, § 44 Rn. 43; Sachs, in: Stelkens/Bonk/ Sachs, VwVfG, 9. Aufl. 2018, § 44 Rn. 150.

219 Peuker, in: Knack/Henneke, VwVfG, 10. Aufl. 2014, § 44 Rn. 42.

220 Ramsauer, in: Kopp/Ramsauer, VwVfG, 20. Aufl. 2019, § 44 Rn. 43; Schemmer, in: Bader/ Ronellenfitsch, VwVfG, 44. Ed., Stand: 1.7.2019, § 44 Rn. 56.

221 S. zu diesen komplexen Fragestellungen ausführlich Sachs, in: Stelkens/Bonk/Sachs, VwVfG, 9. Aufl. 2018, § 43 Rn. 72, 149 ff.

222 Zur Auslegung dieses Begriffs ausführlich Gmeiner/Lorenz, VR 2017, 371.

223 So auch Will/Rathgeber, JuS 2012, 1057 (1060); a. A. aber Schemmer, in: Bader/Ronellenfitsch, VwVfG, 44. Ed., Stand: 1.7.2019, § 44 Rn. 55.

224 VG Saarlouis Urt. v. 23.5.2018, 5 K 1418/17 = BeckRS 2018, 10335; Peine/Siegel, Allgemeines Verwaltungsrecht, 12. Aufl. 2018, Rn. 553; Sachs, in: Stelkens/Bonk/Sachs, VwVfG, 9. Aufl. 2018, $\S 44$ Rn. 150; a.A. aber Ramsauer, in: Kopp/Ramsauer, VwVfG, 20. Aufl. 2019, § 44 Rn. 44; ausführlich Gmeiner/Lorenz, VR 2017, 371. 


\section{f) Verstoß gegen die guten Sitten (Nr. 6)}

138 Gemäß § 44 II Nr. 6 VwVfG ist ein Verwaltungsakt nichtig, der gegen die guten Sitten verstößt. Die Idee der Nichtigkeit von Rechtshandlungen wegen Verstoßes gegen die guten Sitten ist ein allgemeiner Rechtsgedanke, der auch im Zivilrecht eine Normierung erfahren hat (§ 138 I BGB; vgl. auch §§ 242, 817 S. 1, 826 BGB; vgl. für öffentlich-rechtliche Verträge ebenso §59 I VwVfG, dazu ausführlich in $\S 5$ Rn. 97), sodass eine Auslegung und Anwendung von $§ 44$ II Nr. 6 VwVfG im Rahmen des methodisch Vertretbaren Inspiration aus der Rechtsprechung und der rechtswissenschaftlichen Literatur zu besagten Vorschriften ziehen kann. ${ }^{225}$ Dabei ist jedoch stets der grundverschiedene regulatorische Kontext der Normen $\mathrm{zu}$ berücksichtigen. ${ }^{226}$

Laut Bundesverwaltungsgericht ist der Begriff der guten Sitten ein unbestimmter, ausfüllungsbedürftiger Rechtsbegriff, dessen Anwendung jedoch in vollem Umfang gerichtlicher Nachprüfung unterliegt. Mit ihm verweise das Gesetz auf die dem geschichtlichen Wandel unterworfenen sozialethischen Wertvorstellungen, die in der Rechtsgemeinschaft als Ordnungsvoraussetzungen anerkannt seien. Maßgeblich sei die vorherrschende sozialethische Überzeugung. ${ }^{227}$ Dabei ist vornehmlich auf die der geltenden Rechtsordnung, insbesondere dem Grundgesetz ${ }^{228}$ zugrundeliegenden Wertentscheidungen abzustellen. ${ }^{229}$ Dementsprechend sucht das Bundesverwaltungsgericht nach relevanten Indizien für eine in der Rechtsgemeinschaft vorherrschende Überzeugung in der

225 Vgl. Ramsauer, in: Kopp/Ramsauer, VwVfG, 20. Aufl. 2019, § 44 Rn. 48.

226 Dabei ist insbesondere zu bedenken, dass es Wertungsunterschiede im Verhältnis der Verwaltung zum Bürger und der Bürger untereinander geben kann, s. Peuker, in: Knack/Henneke, VwVfG, 10. Aufl. 2014, § 44 Rn. 44.

227 BVerwG, Urt. v. 30.1.1990, Az.: 1 C 26.87 = BVerwGE 84, 314 (317f.); vgl. auch Beschl. v. 21.4. 1998, Az.: 1 B 43.98 = GewArch 1998, 419. Vielerorts wird auch auf das „Anstandsgefühl aller billig und gerecht Denkenden“, abgestellt, s. nur Ramsauer, in: Kopp/Ramsauer, VwVfG, 20. Aufl. 2019, $\S 44$ Rn. 48 m.w. N., ohne dass es dadurch zu einem Erkenntnisgewinn käme.

228 Ramsauer, in: Kopp/Ramsauer, VwVfG, 20. Aufl. 2019, § 44 Rn. 48; Sachs, in: Stelkens/Bonk/ Sachs, VwVfG, 9. Aufl. 2018, § 44 Rn. 152; Schemmer, in: Bader/Ronellenfitsch, VwfG, 44. Ed., Stand: 1.7.2019, § 44 Rn. 59; Schwarz, in: Fehling/Kastner/Störmer, Verwaltungsrecht, 4. Aufl. 2016, § 44 VwVfG Rn. 22; Will/Rathgeber, JuS 2012, 1057 (1060).

229 Wobei zu berücksichtigen ist, dass der Gesetzgeber durchaus einen differenzierten Ansatz im Umgang mit sozialethisch zu missbilligenden Phänomenen wählen kann, s. diesbezüglich anschaulich zum § 4 I 1 Nr. 1 GastG BVerwG, Urt. v. 29.1.1985, Az.: 1 C 27.83 = BVerwGE 71, 34 (35ff.). Allgemein wird man berücksichtigen müssen, dass das Vedikt der Sittenwidrigkeit nicht bedeuten muss, dass ein Verhalten nicht in gewissen Grenzen hingenommen wird, s. BVerwG, Urt. v. 30.1. 1990, Az.: 1 C 26.87 = BVerwGE 84, 314 (319f.). 
Behördenpraxis, ${ }^{230}$ in der Rechtsprechung und in der von ihnen ausgelösten Reaktionen der Öffentlichkeit, insbesondere in der juristischen und allgemeinen Presse. ${ }^{231}$ Darüber hinaus ist jedoch auch die in der (Durchschnitts-)Bevölkerung herrschende Einstellung zu den jeweiligen Phänomenen entscheidend. ${ }^{232}$ Diese muss sich nicht lautstark äußern, ${ }^{233}$ sehr wohl aber hinreichend klar in eine Richtung weisen ${ }^{234}$. Relevant ist bei all dem zwar auch die sozialethische Bewertung vergleichbarer Phänomene, letztlich kommt es jedoch auf die Umstände des konkreten Einzelfalls an ${ }^{235}$.

Das Verdikt der Sittenwidrigkeit eines Verwaltungsakts kann verschiedene 140 Ursachen haben. Unumstritten ist, dass sich die Sittenwidrigkeit aus Inhalt und Zweck des Verwaltungsakts selbst ergeben kann. ${ }^{236}$ Dazu gehört nach herrschender Meinung auch, dass ein Verwaltungsakt etwas Sittenwidriges anordnet oder auch nur erlaubt. ${ }^{237}$ Bis heute umstritten ist, wie sich sittenwidriges Verhalten im Entstehungsprozess des Verwaltungsakts auswirkt. ${ }^{238}$ Weitgehend Einigkeit besteht darüber, dass subjektive Vorwerfbarkeit keine Voraussetzung für die Annahme der Sittenwidrigkeit ist. ${ }^{239}$ Umgekehrt soll diese allein auch keine Sittenwidrigkeit begründen können. ${ }^{240}$ Ein sittenwidriges Verhalten auf Seiten der Bürger, wie beispielsweise die Erwirkung eines Verwaltungsakts durch Täu-

230 Für nicht relevant hat das BVerwG, Urt. v. 30.1.1990, Az.: 1 C 26.87 = BVerwGE 84, 314 (316f.), indes gehalten, dass die zuständige Behörde noch im Rahmen ihrer Erlaubniserteilung die Sittenwidrigkeit des Verhaltens verkannt hat.

231 BVerwG, Urt. v. 30.1.1990, Az.: 1 C 26.87 = BVerwGE 84, 314 (318).

232 BVerwG, Urt. v. 30.1.1990, Az.: 1 C 26.87 = BVerwGE 84, 314 (319).

233 BVerwG, Urt. v. 30.1.1990, Az.: 1 C 26.87 = BVerwGE 84, 314 (319).

234 Der VGH Kassel, Urt. v. 4.3.1985, Az.: VIII OE 85/80 = NVwZ 1985, 764, lehnte die Sittenwidrigkeit einer Betriebsgenehmigung für ein Kernkraftwerk ab, weil es diesbezüglich keine einheitliche Auffassung in der Bevölkerung erkannte.

235 BVerwG, Beschl. v. 16.7.1997, Az.: 1 B 138.97 = NVwZ 1998, 411.

236 Ramsauer, in: Kopp/Ramsauer, VwVfG, 20. Aufl. 2019, § 44 Rn. 47; Will/Rathgeber, JuS 2012, 1057 (1060).

237 BVerwG, Beschl.v. 11.2.1987, Az.: 1 B 129.86 = NVwZ 1987, 411; Urt.v. 30.1.1990, Az.: 1 C 26.87 = BVerwGE 84, 314 (316); Ramsauer, in: Kopp/Ramsauer, VwVfG, 20. Aufl. 2019, § 44 Rn. 47 m.w. N. Kritisch dazu Peuker, in: Knack/Henneke, VwVfG, 10. Aufl. 2014, § 44 Rn. 46 f.

238 Der Verwaltungsakt als Ergebnis des Verwaltungsverfahrens mag dann für sich genommen gar nicht sittenwidrig sein, er könnte aber durch ein sittenwidriges Verhalten eines Beteiligten „infiziert“ werden.

239 BVerwG, Beschl.v. 11.2.1987, Az.: 1 B 129.86 = NVwZ 1987, 411; so bereits VGH München, Urt.v. 5.6.1986, Az.: 22 B 83 A.2512 u. 2707 = NVwZ 1986, 1034 (1035); Sachs, in: Stelkens/Bonk/Sachs, VwVfG, 9. Aufl. 2018, § 44 Rn. 156; a. A. aber wohl Ramsauer, in: Kopp/Ramsauer, VwVfG, 20. Aufl. 2019, § 44 Rn. 49.

240 Vgl. OVG Magedburg, Beschl.v. 10.2.2012, Az.: 1 L 3/12 = juris, Rn. 11; offengelassen, weil über § 44 I VwVfG gelöst von OVG Lüneburg, Urt.v. 13.9. 2012, Az.: 7 LB 84/11 = NVwZ-RR 2013, 129 (130).

Tobias Brings-Wiesen 
schung, Drohung oder Bestechung, wird vereinzelt für relevant erachtet, ${ }^{241}$ dem wird man angesichts der Rechtsprechung des Bundesverwaltungsgerichts zum systematischen Verhältnis von $\S 44$ und $\S 48$ II 3 Nr. 1 VwVfG (s. dazu Rn. 155) jedoch nur noch in extremen Ausnahmefällen folgen können.

Vor diesem Hintergrund ist davor $\mathrm{zu}$ warnen, § 44 II Nr. 6 VwVfG allzu extensiv auszulegen. Die Vorschrift ist trotz ihrer vermeintlichen Weite keine Generalklausel, sondern in ihrem Anwendungsbereich stark beschränkt. Dementsprechend ist auch die Kasuistik überschaubar. Bejaht wurde eine Sittenwidrigkeit der Erlaubnis der gewerblichen Veranstaltung sog. „Peep-Shows“,242 der Zurschaustellung von Frauen in einem Käfig ${ }^{243}$ und des Betreibens von Prostitution ${ }^{244}$. Sittenwidrig kann es im Einzelfall auch sein, eine dem Betroffenen günstige Entscheidung unter grobem Verstoß gegen das Kopplungsverbot von einem bestimmten Verhalten abhängig zu machen ${ }^{245}$ oder wenn eine Entscheidung völlig willkürlich erfolgt ${ }^{246}$. Verneint wurde demgegenüber die Sittenwidrigkeit von Striptease-Darbietungen, ${ }^{247}$ von öffentlichen Vorführungen pornographischer Fil$\mathrm{me}^{248}$ und von Genehmigungen des Betriebs eines Kernkraftwerks ${ }^{249}$. Wegen der Dynamik, die den sozialethischen Wertvorstellungen der Rechtsgemeinschaft innewohnt, ist jedoch jeder Einzelfall mit einer gewissen Zurückhaltung und stets innerhalb seines (rechts-)historischen Kontexts zu berücksichtigen.

\section{Allgemeine Nichtigkeitsgründe, § 44 I und III VwVfG}

142 Liegt kein besonderer Nichtigkeitsgrund gemäß § 44 II VwVfG vor, kann sich die Nichtigkeit eines Verwaltungsakts allein aus § 44 I VwVfG ergeben.

241 OVG Magedburg, Beschl. v. 10.2.2012, Az.: 1 L 3/12 = juris, Rn. 11; grundsätzlich auch Ramsauer, in: Kopp/Ramsauer, VwVfG, 20. Aufl. 2019, § 44 Rn. 47, 49.

242 Bereits vor dem VwVfG in der Rspr. weitgehend einheitlich bewertet; s. zu § 44 II Nr. 6 VwVfG BVerwG, Beschl. v. 11.2.1987, Az.: 1 B 129.86 = NVwZ 1987, 411; Urt. v. 30.1.1990, Az.: 1 C $26.87=$ BVerwGE 84, 314. Ablehnend demgegenüber OVG Hamburg, Beschl.v. 20.2.1985, Az.: Bs. VI 2/85 = NVwZ 1985, 841.

243 VGH München, Beschl. v. 22.3.1991, Az.: 22 CS 91.850 = NVwZ 1992, 76.

244 BVerwG, Urt. v. 30.1.1990, Az.: 1 C 26.87 = BVerwGE 84, 314 (320f.), m.w. N.

245 Bspw. die Erteilung einer Duldung von der Abgabe einer Verpflichtungserklärung, vgl. BVerwG, Beschl.v. 16.7.1997, Az.: 1 B 138.97 = NVwZ 1998, 411; allgemein auch Ramsauer, in: Kopp/ Ramsauer, VwVfG, 20. Aufl. 2019, § 44 Rn. 50.

246 Ramsauer, in: Kopp/Ramsauer, VwVfG, 20. Aufl. 2019, § 44 Rn. 50.

247 S. BVerwG, Urt. v. 29.1.1985, Az.: 1 C 10.83 = BVerwGE 71, 29.

248 Vgl. zum § 4 I 1 Nr. 1 GastG BVerwG, Urt. v. 29.1.1985, Az.: 1 C 27.83 = BVerwGE 71, 34.

249 VGH Kassel, Urt. v. 4.3.1985, Az.: VIII OE 85/80 = NVwZ 1985, 764.

Tobias Brings-Wiesen 
§ 44 I VwVfG knüpft an die vor dem Inkrafttreten des VwVfG herrschende 143 „Evidenztheorie“250 an und verlangt das Vorliegen zweier kumulativer Voraussetzungen: Danach ist ein Verwaltungsakt nichtig, soweit er an einem besonders schwerwiegenden Fehler leidet und dies bei verständiger Würdigung aller in Betracht kommenden Umstände offensichtlich ist. Selbst bei Erfüllen dieser Voraussetzungen ist jedoch $\mathrm{zu}$ berücksichtigen, dass sich eine Nichtigkeit bei Vorliegen der Konstellationen des § 44 III VwVfG nicht allein aus diesen Gründen ergibt.

\section{a) Kein Ausschlusstatbestand, § 44 III VwVfG}

Bei § 44 III VwVfG handelt es sich um einen nicht abschließenden ${ }^{251}$ „Negativ- 144 katalog“ von Rechtsfehlern, die für sich genommen (,nicht schon deshalb“) nicht zur Nichtigkeit eines Verwaltungsakts führen, selbst wenn sie als besonders schwerwiegend und offensichtlich i.S.v. § 44 I VwVfG zu erachten sind. ${ }^{252}$ Der Anwendungsbereich dieser Ausschlussgründe ist jedoch begrenzt. Er kann nur soweit gehen, wie keine weiteren Umstände vorliegen, die eine Nichtigkeit gemäß $\S 44 \mathrm{VwVfG}$ begründen. So hat § 44 III VwVfG insbesondere keinen Einfluss auf weitere, simultan bestehende Rechtsfehler, die nach Abs. 1 oder 2 zur Nichtigkeit führen. ${ }^{253}$ Darüber hinaus können jedoch auch im Hinblick auf einen von § 44 III VwVfG konkret erfassten Rechtsfehler besondere Umstände vorliegen, die in Widerspruch zu dem Zweck des jeweiligen Ausnahmetatbestands stehen und daher gegen einen Ausschluss der Nichtigkeit (aufgrund eben dieses Fehlers) sprechen. Eine vorsätzliche Verletzung der in §44 III VwVfG in Bezug genom-

250 S. dazu m.w. N. Sachs, in: Stelkens/Bonk/Sachs, VwVfG, 9. Aufl. 2018, § 44 Rn. 102.

251 So die h.M.: Ramsauer, in: Kopp/Ramsauer, VwVfG, 20. Aufl. 2019, § 44 Rn. 51; Schwarz, in: Fehling/Kastner/Störmer, Verwaltungsrecht, 4. Aufl. 2016, § 44 VwVfG Rn. 24; Peuker, in: Knack/ Henneke, VwVfG, 11. Aufl. 2014, § 44 Rn. 48; Beaucamp, JA 2007, 704 (706); Will/Rathgeber, JuS 2012, 1057 (1058). Dabei sind jedoch weitere dem § 44 III VwVfG vergleichbare Konstellationen m.E. dogmatisch nicht etwa als „ungeschriebene Ausschlusstatbestände“, sondern schlicht als Wertungsgesichtspunkte im Rahmen der Bestimmung der besonderen Schwere des Fehlers, s. dazu noch Rn. 155, zu berücksichtigen.

252 Ramsauer, in: Kopp/Ramsauer, VwVfG, 20. Aufl. 2019, § 44 Rn. 51; Sachs, in: Stelkens/Bonk/ Sachs, VwVfG, 9. Aufl. 2018, § 44 Rn. 158.

253 Sachs, in: Stelkens/Bonk/Sachs, VwVfG, 9. Aufl. 2018, § 44 Rn. 158; Schemmer, in: Bader/ Ronellenfitsch, VwVfG, 44. Ed., Stand: 1.7.2019, § 44 Rn. 61; Peuker, in: Knack/Henneke, VwVfG, 10. Aufl. 2014, § 44 Rn. 48. 
menen Vorschriften wird man regelmäßig zumindest als einen besonderen Umstand in die Bewertung mit einbeziehen müssen. ${ }^{254}$

Gemäß § 44 III Nr. 1 VwVfG ist ein Verwaltungsakt nicht schon deshalb nichtig, weil Vorschriften über die örtliche Zuständigkeit nicht eingehalten worden sind, außer wenn ein Fall des Abs. 2 Nr. 3 vorliegt (s. dazu Rn. 127 ff.). Konstellationen sachlicher ${ }^{255}$ oder instanzieller Unzuständigkeit richten sich ausschließlich nach §44 I VwVfG. Diese Differenzierung ist der Tatsache geschuldet, dass im Falle örtlicher Unzuständigkeit „die Gefahr eines ,Durchschlagens' der formellen Unzuständigkeit auch auf den Inhalt des [Verwaltungsakts] typischerweise geringer ist“. ${ }^{256}$ Dementsprechend kann die Verletzung von Vorschriften über die örtliche Zuständigkeit gemäß § 46 VwVfG gar unbeachtlich sein, wenn offensichtlich ist, dass sie die Entscheidung in der Sache nicht beeinflusst hat (s. dazu bereits in $\S 2 \mathrm{Rn} .617,701$ ).

Gemäß § 44 III Nr. 2 VwVfG ist ein Verwaltungsakt nicht schon deshalb nichtig, weil eine nach $\S 20$ I 1 Nr. 2 bis 6 VwVfG ausgeschlossene Person mitgewirkt ${ }^{257}$ hat. ${ }^{258}$ Dies ist der Tatsache geschuldet, dass entgegen der in $\S 20$ I 1 Nr. 2 bis 6 VwVfG fixierten unwiderlegbaren Vermutung der Befangenheit in Bezug auf die Sachentscheidung diese gleichwohl materiell fehlerfrei erfolgen kann. ${ }^{259}$ Bewusst ausgenommen wurde die Mitwirkung „in eigenen Angelegenheiten“ gemäß § 20 I 1 Nr. 1 VwVfG. Der Begriff der „Mitwirkung“ ist dem Zweck der Norm entsprechend weit zu verstehen: Er soll nicht nur die Mitwirkung an der finalen Entscheidung über den Erlass des Verwaltungsakts selbst, sondern - in Anlehnung an den Begriff des „Tätigwerdens“ i.S.v. § 20 I 1 VwVfG - auch einen tendenziell weiten Kreis an die Entscheidung vorbereitenden und diese potentiell

254 Dafür Peine/Siegel, Allgemeines Verwaltungsrecht, 12. Aufl. 2018, Rn. 555; Sachs, in: Stelkens/Bonk/Sachs, VwVfG, 9. Aufl. 2018, § 44 Rn. 158; vgl. OVG Lüneburg, Urt.v. 13.9. 2012, Az.: 7 LB 84/11 = NVwZ-RR 2013, 129 (130 f.); vgl. auch AG Magdeburg, Urt. v. 23.4.1999, Az.: 30 OWi-779 Js 29597/98a = NJW 2000, 374. Dagegen Schemmer, in: Bader/Ronellenfitsch, VwVfG, 44. Ed., Stand: 1.7.2019, § 44 Rn. 61. Wiederum anderes mag bei sog. kollusivem Zusammenwirken gelten, s. Wolff, in: Wolff/Decker, VwGO/VwVfG, 3. Aufl. 2012, § 44 VwVfG Rn. 10.

255 Worunter auch die sog. „Verbandszuständigkeit“ fällt, Sachs, in: Stelkens/Bonk/Sachs, VwVfG, 9. Aufl. 2018, § 44 Rn. 169, auch m.w. N. und Ausführungen zum (früher) umstrittenen Umgang damit, a.a.O., Rn. $161 \mathrm{ff}$.

256 Will/Rathgeber, JuS 2012, 1057 (1058).

257 S. zu ausgeschlossenen Personen und der damit verbundenen Besorgnis der Befangenheit nach den $\S \S 20,21$ VwVfG ausführlich unter $\S 2$ Rn. $642 \mathrm{ff}$.

258 S. dazu auch den Fall 12 in: Eisentraut, Fälle zum Verwaltungsrecht, 2020.

259 So auch die Gesetzesmaterialien, BT-Drucks. 7/910, S. 64. Es wird die Befangenheit der ausgeschlossenen Person, nicht aber die Kausalität zwischen einer unzulässigen Betätigung in einem Verwaltungsverfahren und der Verwaltungsentscheidung unwiderleglich vermutet, BVerwG, Urt. v. 30.5.1984, Az.: 4 C 58.81 = BVerwGE 69, 256 (269). 
beeinflussenden Verfahrensverhaltensweisen erfassen. ${ }^{260}$ So können je nach Einzelfall bereits schriftliche oder mündliche Äußerungen ausgeschlossener Personen einer Aufsichtsbehörde gegenüber der entscheidenden Behörde erfasst sein. ${ }^{261}$ Der Ausschluss der Nichtigkeit gemäß § 44 III Nr. 2 VwVfG greift nicht mehr, wenn als weiterer besonderer Umstand hinzutritt, dass die Mitwirkung zu einer offensichtlich parteilichen Entscheidung geführt hat. ${ }^{262}$ Denn dann hat sich im konkreten Einzelfall gerade die Gefahr verwirklicht, vor der die Vorschrift des § 20 I 1 VwVfG unter Anknüpfung an die persönliche Nähebeziehung abstrakt schützen soll. Ob es zu einer entsprechenden wesentlichen Beeinflussung gekommen ist, ${ }^{263}$ wird im Einzelfall nach Art, Stadium und Effekt der Mitwirkung zu bestimmen sein. Entsprechend differenziert wird damit auch die Frage einer potentiellen Nichtigkeit nach § 44 I VwVfG zu beurteilen sein. ${ }^{264}$ Fehlt demgegenüber jegliche Beeinflussung, kommt sogar eine Unbeachtlichkeit gemäß §46 VwVfG in Frage. Expressis verbis ist der Anwendungsbereich der Vorschrift beschränkt auf ipso iure ausgeschlossene Personen nach § 20 I $1^{265} \mathrm{Nr} .2$ bis 6 VwVfG. Sie ist jedoch aufgrund teleologischer Erwägungen entsprechend anzuwenden auf spezialgesetzliche Ausschlussgründe, ${ }^{266}$ auf Verstöße gegen Anordnungen über den Enthalt der Mitwirkung wegen Befangenheit gemäß § 21 I VwVfG ${ }^{267}$ sowie

260 Für ein grundsätzlich weites Verständnis Peine/Siegel, Allgemeines Verwaltungsrecht, 12. Aufl. 2018, Rn. 557; Ramsauer, in: Kopp/Ramsauer,VwVfG, 20. Aufl. 2019, § 44 Rn. 54; Sachs, in: Stelkens/Bonk/Sachs, VwVfG, 9. Aufl. 2018, § 44, Rn. 180.

261 S. BVerwG, Urt. v. 30.5.1984, Az.: 4 C 58.81 = BVerwGE 69, 256 (263ff.).

262 Ramsauer, in: Kopp/Ramsauer, VwVfG, 20. Aufl. 2019, § 44 Rn. 53f.; Sachs, in: Stelkens/ Bonk/Sachs, VwVfG, 9. Aufl. 2018, § 44, Rn. 180; Schemmer, in: Bader/Ronellenfitsch, VwVfG, 44. Ed., Stand: 1.7.2019, § 44 Rn. 63; Will/Rathgeber, JuS 2012, 1057 (1059).

263 Ramsauer, in: Kopp/Ramsauer, VwVfG, 20. Aufl. 2019, § 44 Rn. 54; Schemmer, in: Bader/ Ronellenfitsch, VwVfG, 44. Ed., Stand: 1.7.2019, § 44 Rn. 63.

264 S. für eine derartige Einzelfallbetrachtung im Hinblick auf $\S 20$ I 1 Nr. 1 VwVfG BVerwG, Beschl. v. 19.10.2015, Az.: 5 P 11.14 = NZA-RR 2016, 166 (168, Rn. 22). Eine Nichtigkeit nach Abs. 1 aufgrund offensichtlich parteilicher Entscheidung grundsätzlich in Betracht ziehend Ramsauer, in: Kopp/Ramsauer, VwVfG, 20. Aufl. 2019, § 44 Rn. 54; Sachs, in: Stelkens/Bonk/Sachs, VwVfG, 9. Aufl. 2018, § 44 Rn. 178. S. zu diesem Problem auch den Fall 12 in: Eisentraut, Fälle zum Verwaltungsrecht, 2020.

265 Zweifellos muss die Vorschrift jedoch aus systematisch-teleologischen Erwägungen auch für Konstellationen betreffend die nach § 20 I 2 VwVfG den Beteiligten gleichgestellten Personen gelten.

266 Ramsauer, in: Kopp/Ramsauer, VwVfG, 20. Aufl. 2019, § 44 Rn. 53; Schwarz, in: Fehling/ Kastner/Störmer, Verwaltungsrecht, 4. Aufl. 2016, § 44 VwVfG, Rn. 26.

267 Ramsauer, in: Kopp/Ramsauer, VwVfG, 20. Aufl. 2019, § 44 Rn. 53; Peuker, in: Knack/Henneke, VwVfG, 10. Aufl. 2014, § 44 Rn. 50; Will/Rathgeber, JuS 2012, 1057 (1059); a. A. aber LeisnerEgensperger, in: Mann/Sennekamp/Uechtritz, VwVfG, 2. Aufl. 2019, § 44 Rn. 45. 
auf Verstöße gegen Entscheidungen über Ausschlüsse und Ablehnungen von Ausschüssen (§§ 20 IV, 21 II und 71 III VwVfG) ${ }^{268}{ }^{269}$

Gemäß § 44 III Nr. 3 VwVfG ist ein Verwaltungsakt nicht schon deshalb nichtig, weil ein durch Rechtsvorschrift zur Mitwirkung berufener Ausschuss den für den Erlass des Verwaltungsakts vorgeschriebenen Beschluss nicht gefasst hat oder nicht beschlussfähig war. Die Überlegung hinter diesem Ausschlussgrund ist, dass ein entsprechender Mitwirkungsmangel als interner Vorgang den Betroffenen häufig verborgen bleiben wird und eine ipso iure eintretende Unwirksamkeit des sie betreffenden Verwaltungsakts ihrem Interesse nach Rechtssicherheit und Vertrauensschutz entgegensteht. ${ }^{270}$ „Ausschuss“ ist i.S.v. $§ 88$ VwVfG jede kollegiale Einrichtung, die in einem Verwaltungsverfahren tätig wird. ${ }^{271}$ Hat ein Ausschuss selbst Behördeneigenschaft, greift $\S 44$ III Nr. 4 VwVfG. ${ }^{272}$ Die Mitwirkung muss gesetzlich in Form eines Beschlusses vorgeschrieben sein, ${ }^{273}$ dessen Erlass im konkreten Fall unterblieben ist oder für den die erforderliche Beschlussfähigkeit gefehlt hat ${ }^{274}$. Stadium und Qualität der Mitwirkung sind nicht ausschlaggebend: Sie kann als Form der Anhörung bereits im Rahmen der Sachverhaltsermittlung oder aber erst als intensiver mitwirkende Zustimmung zur Entscheidung ${ }^{275}$ über den Erlass des Verwaltungsakts ergehen. ${ }^{276}$

$268 \mathrm{Zu} \S 20 \mathrm{IV}$ VwVfG wird bereits eine unmittelbare Anwendung diskutiert: bejahend Ramsauer, in: Kopp/Ramsauer, VwVfG, 20. Aufl. 2019, § 44 Rn. 54. Zumindest wird man aber eine entsprechende Anwendung bejahen können. Zu § 71 III VwVfG: Ramsauer, a. a. O., § 44 Rn. 53; Peuker, in: Knack/Henneke, VwVfG, 10. Aufl. 2014, § 44 Rn. 50; Will/Rathgeber, JuS 2012, 1057 (1059).

269 Auch bezüglich der letztgenannten Konstellationen ist eine entsprechende Anwendung auf spezialgesetzliche Vorschriften zu erwägen.

270 Ramsauer, in: Kopp/Ramsauer, VwVfG, 20. Aufl. 2019, § 44 Rn. 55.

271 Sachs, in: Stelkens/Bonk/Sachs, VwVfG, 9. Aufl. 2018, § 44 Rn. 183; Schemmer, in: Bader/ Ronellenfitsch, VwVfG, 44. Ed., Stand: 1.7.2019, § 44 Rn. 67; Leisner-Egensperger, in: Mann/Sennekamp/Uechtritz, VwVfG, 2. Aufl. 2019, § 44 Rn. 47.

272 Ramsauer, in: Kopp/Ramsauer, VwVfG, 20. Aufl. 2019, § 44 Rn. 55; Sachs, in: Stelkens/Bonk/ Sachs, VwVfG, 9. Aufl. 2018, § 44 Rn. 183; Schwarz, in: Fehling/Kastner/Störmer, Verwaltungsrecht, 4. Aufl. 2016, § 44 VwVfG, Rn. 28; Peuker, in: Knack/Henneke, VwVfG, 10. Aufl. 2014, § 44 Rn. 53;

273 Peine/Siegel, Allgemeines Verwaltungsrecht, 12. Aufl. 2018, Rn. 558.

274 Ramsauer, in: Kopp/Ramsauer, VwVfG, 20. Aufl. 2019, § 44 Rn. 56, setzt dem die Konstellationen der Nichtigkeit und der vor dem Erlass des Verwaltungsakts erfolgten Aufhebung des Beschlusses, Sachs, in: Stelkens/Bonk/Sachs, VwVfG, 9. Aufl. 2018, §44, Rn. 186, die der nicht ordnungsgemäßen Besetzung gleich.

275 Die Vorschrift ist nicht anwendbar auf (intern) abschließend entscheidende Kollegialorgane wie bspw. die Gemeindevertretungen, da es sich in diesem Fall nicht mehr um eine bloße „Mitwirkung“ am Erlass eines Verwaltungsaktes handelt, Sachs, in: Stelkens/Bonk/Sachs, VwVfG, 9. Aufl. 2018, § 44 Rn. 184; § 45 Rn. 92 m.w. N.; a. A. wohl OVG Lüneburg, Beschl.v. 31.1.2013, Az.: 7 LA 160/11 = BeckRS 2013, 46796.

Tobias Brings-Wiesen 
Treten keine weiteren besonderen Umstände hinzu, die gleichwohl für eine Nichtigkeit sprechen, ${ }^{277}$ ist $\mathrm{zu}$ bedenken, dass ein solcher Rechtsfehler gemäß $\S 45$ I Nr. 4 VwVfG heilbar ist sowie unbeachtlich gemäß § 46 VwVfG sein kann.

Zuletzt ist ein Verwaltungsakt gemäß § 44 III Nr. 4 VwVfG nicht schon des- 148 halb nichtig, weil die nach einer Rechtsvorschrift erforderliche Mitwirkung einer anderen Behörde unterblieben ist. Auch wegen solcher Rechtsfehler soll die Nichtigkeit grundsätzlich ausgeschlossen sein, weil sie im Innenverhältnis zweier Behörden zueinander auftreten, während den Betroffenen gegenüber der Rechtsschein eines ordnungsgemäß erlassenen Verwaltungsakts entsteht. ${ }^{278}$ „Behörden“ sind alle Stellen i.S.v. § 1 IV VwVfG (s. dazu in § 2 Rn. 52ff.). Der Begriff der „Mitwirkung“ ist wie bei § 44 III Nr. 3 VwVfG weit zu verstehen; erfasst sind somit insbesondere Konstellationen sog. „mehrstufiger Verwaltungsakte“ (s. dazu $§ 2$ Rn. 90). Auch im Übrigen gelten die Darstellungen zu Nr. 3 entsprechend. ${ }^{279}$ Der Rechtsfehler ist gemäß § 45 I Nr. 5 VwVfG heilbar sowie potentiell unbeachtlich gemäß § 46 VwVfG.

\section{b) Besonders schwerwiegender Fehler}

Ist eine Nichtigkeit nicht bereits gemäß § 44 III VwVfG ausgeschlossen, bedarf es der Prüfung einer Nichtigkeit am Maßstab von § 44 I VwVfG. Dies setzt zunächst voraus, dass es sich bei dem identifizierten Rechtsverstoß um einen besonders schwerwiegenden Fehler handelt.

Die Prüfung des Vorliegens eines Rechtsfehlers ist in der verwaltungsrechtlichen Klausur eine „every-day-task“. Größere Probleme bereitet den Student`innen demgegenüber speziell die Beurteilung der besonderen Schwere eines identifizierten Rechtsfehlers. Dies ist der Tatsache geschuldet, dass es sich dabei nicht um einen exakten, sondern einen ,gleitenden Maßstab“280 handelt. Es handelt sich um eine Wertungsentscheidung, die von allen rechtlich relevanten

276 Ramsauer, in: Kopp/Ramsauer, VwVfG, 20. Aufl. 2019, § 44 Rn. 57; Will/Rathgeber, JuS 2012, 1057 (1059).

277 S. das Beispiel bei Ramsauer, in: Kopp/Ramsauer, VwVfG, 20. Aufl. 2019, § 44 Rn. 57. Theoretisch denkbar ist auch, dass die verfassungsrechtlich zwingend gebotene Mitwirkung bestimmter Ausschüsse - wie bspw. pluralistisch besetzter Gremien - als besonderer Umstand auftritt.

278 So die Gesetzesmaterialien, BT-Drucks. 7/910, S. 64 f.

279 Entsprechend vorgehend Ramsauer, in: Kopp/Ramsauer, VwVfG, 20. Aufl. 2019, § 44 Rn. 58; Sachs, in: Stelkens/Bonk/Sachs, VwVfG, 9. Aufl. 2018, § 44 Rn. 188; Schemmer, in: Bader/Ronellenfitsch, VwVfG, 44. Ed., Stand: 1.7.2019, § 44 Rn. 70; Leisner-Egensperger, in: Mann/Sennekamp/Uechtritz, VwVfG, 2. Aufl. 2019, § 44 Rn. 50.

280 Vgl. Larenz, Methodenlehre der Rechtswissenschaft, 5. Aufl. 1983, S. 207. 
Umständen des Einzelfalls abhängt. Insofern ist es notwendig, sich zum einen der Definition und Interpretation (entsprechend juristischer Auslegungscanones) des Terminus auf einer abstrakten Ebene in Rechtsprechung und Literatur zu widmen. Zum anderen bedarf es einer Orientierung an der existierenden Kasuistik und weitgehend anerkannten Beispielsfällen zu § $44 \mathrm{I} \mathrm{VwVfG}^{281}$.

Laut Bundesverwaltungsgericht ist ein Fehler dann besonders schwerwiegend, wenn er den Verwaltungsakt als schlechterdings unerträglich, d.h. mit tragenden Verfassungsprinzipien oder der Rechtsordnung immanenten wesentlichen Wertvorstellungen unvereinbar erscheinen lässt. ${ }^{282}$ Die an eine ordnungsgemäße Verwaltung zu stellenden Anforderungen müssten in einem so hohen Maße verletzt sein, dass von niemandem erwartet werden kann, den Verwaltungsakt als verbindlich anzuerkennen. ${ }^{283}$ Wann dies der Fall ist, lasse sich nicht rechtsgrundsätzlich, sondern nur unter maßgebender Heranziehung und Würdigung der konkreten Umstände des Einzelfalls bestimmen. ${ }^{284}$ Dabei sei grundsätzlich auf den Erlasszeitpunkt abzustellen. ${ }^{285}$

Diese Begriffsbestimmung des Bundesverwaltungsgerichts sollte in einer Klausur zwar genannt werden. Sie hilft jedoch in ihrer Schlichtheit - gerade Anfänger`innen - kaum dabei, die folgende, durchaus komplexe Prüfung mit Leben und Argumenten zu füllen. Dafür ist es bedeutend wichtiger, die notwendige methodische Herangehensweise bei der Bestimmung der besonderen Schwere des Fehlers zu verstehen. Dies kann auch nicht allein durch eine breite wie tiefe Kenntnis der Kasuistik und anerkannter Beispielsfälle kompensiert werden, da anders liegende Umstände des Einzelfalls eine Beurteilung jederzeit grundlegend verändern können.

Es bedarf insofern einer Gesamtschau aller rechtlich relevanten Umstände des Einzelfalls. Deren Auswertung ist bisweilen hochanspruchsvoll und kann daher in komplexen Konstellationen sinnvoll nur von fortgeschrittenen Student ${ }^{\star}$ innen mit umfassenderen Kenntnissen im allgemeinen und besonderen

281 S. dazu die - zum Teil nicht speziell zum Merkmal des ,besonders schwerwiegenden Fehlers“ erfolgenden - systematisierenden Darstellungen bei Ramsauer, in: Kopp/Ramsauer, VwVfG, 20. Aufl. 2019, § 44 Rn. 14 ff; Sachs, in: Stelkens/Bonk/Sachs, VwVfG, 9. Aufl. 2018, § 44 Rn. 111 ff.; Peuker, in: Knack/Henneke, VwVfG, 10. Aufl. 2014, § 44 Rn. 17 ff.; Leisner-Egensperger, in: Mann/ Sennekamp/Uechtritz, VwVfG, 2. Aufl. 2019, § 44 Rn. $12 \mathrm{ff}$.

282 St. Rspr. des BVerwG unter dem VwVfG, Urt. v. 22.2.1985, Az.: 8 C 107.83 = NJW 1985, 2658 (2659); zuletzt Beschl. v. 9.7.2019, Az.: 9 B 29.18 = juris, Rn. 10.

283 St. Rspr. des BVerwG unter dem VwVfG, Urt. v. 17.10.1997, Az.: 8 C 1.96 = NVwZ 1998, 1061 (1062); zuletzt Beschl.v. 8.7.2016, Az.: 2 B 125.15 = juris, Rn. 15.

284 BVerwG, Beschl. v. 10.4.1991, Az.: 2 B 115.90 = juris, Rn. 5.

285 BVerwG, Beschl. v. 5.4.2011, Az.: 6 B 41.10 = BeckRS 2011, 50438 (Rn. 4); Urt. v. 9.9. 2014, Az.: 1 C 10.14 = NVwZ 2014, 1679 (1680, Rn. 16). 
Verwaltungsrecht erwartet werden. ${ }^{286}$ Auch Anfänger^innen sollten jedoch zumindest das folgende Grundwissen um die rechtlich relevanten Umstände haben.

Ausgangspunkt der Prüfung ist stets die den $\S \S 43 \mathrm{ff}$. VwVfG zugrundelie153 gende Wertung des Gesetzgebers, dass die Rechtswidrigkeit eines Verwaltungsakts dessen Wirksamkeit im Regelfall nicht in Frage stellt. ${ }^{287}$ Ob diese Annahme erschüttert werden kann, ist sodann anhand der Umstände des Einzelfalls zu bewerten. Kategorisierungen können Orientierung bieten, sollten jedoch stets mit der gebotenen Zurückhaltung genutzt werden. Denn bestimmte Umstände sprechen nicht per se für eine Nichtigkeit. ${ }^{288}$ So mahnt das Bundesverwaltungsgericht, die Verletzung selbst einer wichtigen Rechtsbestimmung lasse den Fehler allein noch nicht als besonders schwerwiegend erscheinen. ${ }^{289}$ Dies gilt selbst für normhierarchisch leicht zu identifizierende Fälle ,wichtiger Rechtsbestimmungen“: Weder eine Verletzung von Verfassungsrecht noch eine Verletzung von Unionsrecht ${ }^{290}$ führen für sich genommen ${ }^{291}$ zur Annahme eines besonders schwerwiegenden Fehlers. Auch das Fehlen einer eigentlich erforderlichen Ermächtigungsgrundlage (sog. „gesetzloser Verwaltungsakt“) ist nicht bereits für sich besonders schwerwiegend. ${ }^{292}$ Gleiches gilt für die Fälle von verfassungs-

286 S. für eine Anwendung der nun folgenden Hinweise die zahlreichen Beispiele in Fall 12 in: Eisentraut, Fälle zum Verwaltungsrecht, 2020.

287 Treffend Peuker, in: Knack/Henneke, VwVfG, 10. Aufl. 2014, § 44 Rn. 33: „Das Gebot der Rechtssicherheit und die Notwendigkeit der Handlungsfähigeit der Verwaltung machen die Rechtsfolge der Nichtigkeit als Folge der Rechtswidrigkeit eines Verwaltungsakts zur Ausnahme. Im Zweifelsfall ist von der Wirksamkeit auch des fehlerhaften Verwaltungsakt auszugehen“.

288 So auch Leisner-Egensperger, in: Mann/Sennekamp/Uechtritz, VwVfG, 2. Aufl. 2019, § 44 Rn. $6 \mathrm{ff}$.

289 BVerwG, Urt. v. 22.2.1985, Az.: 8 C 107.83 = NJW 1985, 2658 (2659); Urt. v. 18.4.1997, Az.: 3 C 3.95 = BVerwGE 104, 289 (296). So auch Sachs, in: Stelkens/Bonk/Sachs, VwVfG, 9. Aufl. 2018, $\S 44$ Rn. 103 m.w.N.

290 BVerwG, Beschl. v. 11.5.2000, Az.: 11 B 26.00 = NVwZ 2000, 1039 (1040); Urt. v. 16.12.2010, Az.: 3 C 44.09 = BVerwGE 138, 322 (326f., Rn. 16). Umstritten ist die Frage, ob in der Abweichung von der ständigen Rechtsprechung des EuGH ein besonders schwerwiegender Fehler liegt, für den Regelfall dagegen Leisner-Egensperger, in: Mann/Sennekamp/Uechtritz, VwVfG, 2. Aufl. 2019, $\S 44$ Rn. 9.

291 In der Gesamtschau kann jedoch durchaus von Bedeutung sein, ob gegen solche oder bloß untergesetzliche Vorschriften verstoßen wurde, so auch Leisner-Egensperger, in: Mann/Sennekamp/Uechtritz, VwVfG, 2. Aufl. 2019, § 44 Rn. 8.

292 BVerwG, Urt. v. 17.10.1997, Az.: 8 C 1.96 = NVwZ 1998, 1061 (1062). Sachs, in: Stelkens/Bonk/ Sachs, VwVfG, 9. Aufl. 2018, § 44 Rn. 105; Schemmer, in: Bader/Ronellenfitsch, VwVfG, 44. Ed., Stand: 1.7.2019, § 44 Rn. 39. Anders aber in Fällen sog. ,absoluter Gesetzlosigkeit“, vgl. instruktiv OVG Lüneburg, Urt. v. 31.1.2019, Az.: 13 LC 211/16 = juris, Rn. 83 ff. m.w. N.

Tobias Brings-Wiesen 
oder anderweitig rechtswidrigen und damit (grundsätzlich) nichtigen Ermächtigungsgrundlagen. ${ }^{293}$

Relevant ist vielmehr eine Analyse (1) der gesetzlich vorgesehenen Fehlerfolgeregelungen für den konkret in Rede stehenden und die ihm vergleichbaren Rechtsfehler sowie (2) der konkret verletzten Vorschrift, ihrer systematischen Zusammenhänge und der ihr zugrundeliegenden Zweck- und Wertvorstellungen. Formelle und materielle Rechtsfehler werden dabei gleichwertig erfasst. ${ }^{294}$

(1) Besondere systematische Anhaltspunkte bieten die Vorschriften von Teil III des VwVfG betreffend den Verwaltungsakt ( $\S \S 35 \mathrm{ff}$. VwVfG) - insbesondere jene, die dessen Wirksamkeit und Rechtswidrigkeit determinieren, da in ihnen die differenzierten gesetzgeberischen Wertvorstellungen zum Umgang mit fehlerhaften Verwaltungsakten zum Ausdruck kommen. Spezialgesetzliche Fehlerfolgenregelungen können diese modifizieren und sind dann vorrangig zu berücksichtigen. Soweit sie auf den in Rede stehenden Rechtsfehler nicht unmittelbar anwendbar sind, haben all diese Vorschriften jedoch lediglich eine Indizwirkung, die je nach den weiteren Umständen des Einzelfalls widerlegt werden kann.

- \$ 44 II und III VwVfG wurden vom Gesetzgeber bewusst geschaffen, um die Handhabung der Generalklausel in Abs. 1 zu erleichtern. ${ }^{295}$ Sie liefern entsprechend wichtige Anhaltspunkte für die Beurteilung der besonderen Schwere eines Rechtsfehlers. ${ }^{296}$ Eine Vergleichbarkeit wird regelmäßig für, das Fehlen jeglicher vergleichbarer Konstellationen in Abs. $2^{297}$ regelmäßig gegen eine besondere Schwere sprechen. Dabei muss der Fehler auch schwerer als die in Abs. 3 genannten Fallgruppen wiegen. ${ }^{298}$

- Darüber hinaus können maßstabsbildend auch die Vorschriften der \$\$ 45, 46 VwVfG berücksichtigt werden, die die Folgen von Verfahrens- und

293 S. dazu Sachs, in: Stelkens/Bonk/Sachs, VwVfG, 9. Aufl. 2018, § 44 Rn. 105 m.w. N.

294 Sachs, in: Stelkens/Bonk/Sachs, VwVfG, 9. Aufl. 2018, § 44 Rn. 103; Leisner-Egensperger, in: Mann/Sennekamp/Uechtritz, VwVfG, 2. Aufl. 2019, § 44 Rn. 6.

295 S. dazu die Gesetzesmaterialien, BT-Drucks. 7/910, S. 64. Daran ändert auch der in eine andere Richtung deutende einleitende Satzteil zu § 44 II VwVfG nichts, Sachs, in: Stelkens/Bonk/ Sachs, VwVfG, 9. Aufl. 2018, § 44 Rn. 110.

296 Sachs, in: Stelkens/Bonk/Sachs, VwVfG, 9. Aufl. 2018, § 44 Rn. 110; für Abs. 2 ausdrücklich auch BVerwG, Urt. v. 22.2.1985, Az.: 8 C 107.83 = NJW 1985, 2658 (2659); vgl. auch für die entsprechende Anwendung auf Beschlüsse der Personalvertretung BVerwG, Urt. v. 13.10.1986, Az.: 6 P 14.84 = BVerwGE 75, 62 (65); Beschl. v. 19.10.2015 Az.: 5 P 11.14 = NZA-RR 2016, 166 (167). 297 Vgl. zu § 44 I LVwVfG BW VGH Mannheim, Urt. v. 3.12.2013, Az.: 1 S 49/13 = juris, Rn. 34, zu Fällen der Täuschung oder sonstiger betrügerischer Handlungen.

298 Ramsauer, in: Kopp/Ramsauer, VwVfG, 20. Aufl. 2019, § 44 Rn. 9; Schwarz, in: Fehling/ Kastner/Störmer, Verwaltungsrecht, 4. Aufl. 2016, § 44 VwVfG Rn. 8. 
Formfehlern regeln (s. dazu bereits unter $\S 2$ Rn. 652ff., $693 \mathrm{ff}$.). Beide Vorschriften formulieren Voraussetzungen, unter denen bestimmte Rechtsfehler im Ergebnis ohne weitere Auswirkungen bleiben sollen. Zugleich gehen jedoch beide Vorschriften von der Möglichkeit aus, dass auch die ihren Anwendungsbereichen unterfallenden Fehler im Einzelfall durchaus zur Nichtigkeit führen können. ${ }^{299}$ So wird beispielsweise das Unterbleiben einer erforderlichen Anhörung regelmäßig nicht derart schwer wiegen, dass es zur Nichtigkeit führt (vgl. §45 I Nr. 3 VwVfG). ${ }^{300}$ Etwas anderes kann jedoch gelten, wenn die Behörde das Anhörungsgebot bewusst missachtet hat, um dem Betroffenen die Möglichkeit rechtzeitigen Rechtsschutzes zu nehmen und vollendete Tatsachen $\mathrm{zu}$ schaffen, sie also rechtsmissbräuchlich handelt. $^{301}$

- Von gleicher Bedeutung sind auch die Vorschriften zu Rücknahme und Widerruf von Verwaltungsakten (\$§ 48, 49 VwVfG). So hat das Bundesverwaltungsgericht festgestellt, dass bereits die Regelung in § 48 II 3 Nr. 1 VwVfG erkennen lasse, dass der Gesetzgeber selbst durch arglistige Täuschung erwirkte Verwaltungsakte in der Regel nicht als nichtig, sondern nur als rücknehmbar ansehe. ${ }^{302}$ Nichts anderes ist für Fälle der Drohung ${ }^{303}$ und Bestechung ${ }^{304}$ und die übrigen Konstellationen des § 48 II 3 VwVfG anzunehmen. Für eine Nichtigkeit kann wiederum sprechen, dass dabei gegen ein gesetzliches Verbot, insbesondere auch eine Norm des StGB verstoßen wird. Nicht abschließend geklärt ist demgegenüber die Frage, ob und gege-

299 Vgl. den Wortlaut: „Eine Verletzung von Verfahrens- oder Formvorschriften, die nicht den Verwaltungsakt nach §44 nichtig macht, [...]“, §45 I VwVfG; „Die Aufhebung eines Verwaltungsakts, der nicht nach $\S 44$ nichtig ist, [...]“, § $46 \mathrm{VwVfG}$.

300 Sachs, in: Stelkens/Bonk/Sachs, VwVfG, 9. Aufl. 2018, § 44 Rn. 118; Peuker, in Knack/Henneke, VwVfG, 10. Aufl. 2014, § 44 Rn. 19.

301 OVG Münster, Beschl. v. 13.10.2011, Az.: 1 A 1925/09 = BeckRS 2011, 55218; befürwortend Peuker, in: Knack/Henneke, VwVfG, 10. Aufl. 2014, § $44 \mathrm{Rn}$. 19; für § $45 \mathrm{VwVfG}$ grundlegend Ramsauer, in: Kopp/Ramsauer, VwVfG, 20. Aufl. 2019, § 44 Rn. 9.

302 BVerwG, Urt. v. 22.2.1985, Az.: 8 C 107.83 = NJW 1985, 2658 (2659); Urt. v. 9.9.2014, Az.: 1 C 10.14 = NVwZ 2014, 1679 (1680, Rn. 18) (betr. eine Identitätstäuschung im Rahmen der Einbürgerung).

303 Anders werden vielerorts die Konstellationen des unmittelbaren Zwangs bewertet, Ramsauer, in: Kopp/Ramsauer, VwVfG, 20. Aufl. 2019, § 44 Rn. 19; Schemmer, in: Bader/Ronellenfitsch, VwVfG, 44. Ed., Stand: 1.7.2019, § 44 Rn. 33.

304 Sachs, in: Stelkens/Bonk/Sachs, VwVfG, 9. Aufl. 2018, § 44 Rn. 117; Peuker, in: Knack/Henneke, VwVfG, 10. Aufl. 2014, § 44 Rn. 19.

Tobias Brings-Wiesen 
benenfalls inwiefern ein Verschulden auf Seiten der Behörde zu berücksichtigen ist. ${ }^{305}$

156 (2) Darüber hinaus bedarf es einer genauen Analyse der konkret verletzten Vorschrift in systematischer wie teleologischer Hinsicht. So wird man beispielsweise im Falle einer offensichtlich parteilichen Entscheidung, die eine nach $\S 20$ VwVfG ausgeschlossene Person getroffen hat, die besondere Schwere des Fehlers gerade darin begründet sehen können, dass sich in teleologischer Hinsicht genau die Gefahr der Befangenheit realisiert hat, vor der die verletzte Vorschrift eigentlich schützen sollte. Der erlassene Verwaltungsakt wäre dann mit der der Norm zugrundeliegenden wesentlichen Wertvorstellung des Schutzes der Verfahrensgerechtigkeit unvereinbar. ${ }^{306}$ Vor dem Hintergrund der vom Gesetzgeber bewusst vorgenommenen Kompetenzzuweisung und -abgrenzung kann auch eine fehlende sachliche Zuständigkeit besonders schwer wiegen, wenn der durch den Verwaltungsakt geregelte Sachverhalt „unter keinem sachlichen Gesichtspunkt Bezug zum Aufgabenbereich der handelnden Behörde hat“ ${ }^{307}$ Besonders relevant wird diese methodische Herangehensweise jedoch regelmäßig für materielle Fehler von Verwaltungsakten sein, da derer bezüglich kaum konkrete Fehlerfolgenregelungen existieren. So hat beispielsweise das Bundesverwaltungsgericht eine durch Identitätstäuschung erschlichene Einbürgerung auch deshalb nicht als besonders schwerwiegenden Fehler erachtet, weil die betroffene Person die für eine Einbürgerung im Übrigen erforderlichen Voraussetzungen wie einen längerfristigen Aufenthalt in Deutschland und das Erbringen notwendiger Integrationsleistungen persönlich erfüllt hatte. ${ }^{308}$

305 Eine Vorwerfbarkeit grundsätzlich ablehnend, weil die besondere Schwere sich auf den Verwaltungsakt, nicht aber auf das Verhalten der Behörde beziehe, BVerwG, Urt. v. 22. 2.1985, Az.: 8 C 107.83 = NJW 1985, 2658 (2659); a. A. aber hinsichtlich vorsätzlich rechtswidrigem Verhalten OVG Lüneburg, Urt. v. 13.9. 2012, Az.: 7 LB 84/11 = NVwZ-RR 2013, 129 (130); wohl auch Sachs, in: Stelkens/Bonk/Sachs, VwVfG, 9. Aufl. 2018, § 44 Rn. 158.

306 S. dazu den Fall 12 in: Eisentraut, Fälle zum Verwaltungsrecht, 2020.

307 Ramsauer, in: Kopp/Ramsauer, VwVfG, 20. Aufl. 2019, § 44 Rn. 15; OVG Bautzen, Urt. v. 24.1. 2005, Az.: 2 B 644/04 = juris, Rn. 32.

308 BVerwG, Urt. v. 9.9.2014, Az.: 1 C 10.14 = NVwZ 2014, 1679 (1680, Rn. 18). 


\section{c) Offensichtlichkeit des Fehlers und seiner besonderen Schwere}

Der besonders schwerwiegende Fehler muss darüber hinaus auch offensicht- 157 lich $^{309}$ sein. ${ }^{310}$ Dabei sind der Fehler und seine besondere Schwere Bezugspunkt der Offensichtlichkeit. ${ }^{311}$

„Offensichtlich“ sind der Fehler und seine besondere Schwere laut Bundes-

verwaltungsgericht nur dann, wenn sie für einen unvoreingenommenen, mit den in Betracht kommenden Umständen vertrauten, verständigen Beobachter ${ }^{312}$ ohne weiteres ersichtlich sind. ${ }^{313}$ Weitergehend wird gar gefordert, die besonders schwere Fehlerhaftigkeit müsse sich aufdrängen, ${ }^{314}$ dem Verwaltungsakt gewissermaßen ,auf die Stirn geschrieben sein““. ${ }^{315}$ Auch diese Definition bedarf einer weiteren Präzisierung.

Die Unterstellung der Kenntnis der „in Betracht kommenden Umstände“ darf 159 nicht dazu verleiten, die Referenzperson des „verständigen Beobachters“ allwissend $\mathrm{zu}$ machen. Diesem Beobachter dürfen grundsätzlich weder besondere Rechts- noch Fachkenntnisse unterstellt werden. Insbesondere darf nicht von einer Kenntnis der Rechtslage im Einzelfall ausgegangen werden, da dies dazu führte, dass schwerwiegende Rechtsfehler letztlich immer als offenkundig anzusehen wären ${ }^{316}$ und dem Kriterium der Offensichtlichkeit keine eigenständige

309 Der Begriff „offensichtlich“ wurde mit dem 2. VwVfÄndG (BGBl. I 1998, S. 2022) eingeführt und ersetzte den Begriff „offenkundig“, ohne dass damit eine inhaltliche Änderung intendiert gewesen wäre, s. die Gesetzesmaterialien, BT-Drucks. 13/8884, S. 5. Eine entsprechend abweichende Terminologie in den VwVfGen der Länder (vgl. bspw. § 44 I VwVfG NRW: „offenkundig“) ist daher gleichsam ohne Relevanz.

310 Dieses zusätzliche Merkmal dient dem Interesse der Rechtssicherheit: Die besondere Ausnahmekonstellation der Nichtigkeit soll nur dann in Frage kommen, wenn der nicht näher bestimmte (§ 44 II VwVfG) Rechtsfehler auch als solcher klar erkennbar ist, Ramsauer, in: Kopp/ Ramsauer, VwVfG, 20. Aufl. 2019, § 44 Rn. 12; Peuker, in: Knack/Henneke, VwVfG, 10. Aufl. 2014, $\S 44 \mathrm{Rn}$. 30. Kritisch zu diesem Merkmal Leisner-Egensperger, in: Mann/Sennekamp/Uechtritz, VwVfG, 2. Aufl. 2019, § 44 Rn. 23 ff.; grundlegend Leisner, DÖV 2007, 669.

311 BVerwG, Urt. v. 9.9.2014, Az.: 1 C 10.14 = NVwZ 2014, 1679 (1680, Rn. 16); Sachs, in: Stelkens/ Bonk/Sachs, VwVfG, 9. Aufl. 2018, § 44 Rn. 123 m.w. N.

312 Bisweilen zeigen sich leichte Modifikationen in der Bezeichnung der Referenzperson (,verständiger durchschnittlicher Beobachter“, „urteilsfähiger Bürger“), ohne dass damit jedoch Änderungen im Prüfungsmaßstab verbunden scheinen.

313 BVerwG, Beschl.v. 28.11.1997, Az.: 7 B 171.97 = juris, Rn. 5; Beschl.v. 6.6.2005, Az.: 2 B $10.05=$ juris, Rn. 9.

314 Vgl. BVerwG, Beschl. v. 12.4.2013, Az.: 1 WDS-VR 1.13 = juris, Rn. 36.

315 Ramsauer, in: Kopp/Ramsauer, VwVfG, 20 Aufl. 2019, § 44 Rn. 12; OVG Lüneburg, Urt. v. 31.1. 2019, Az.: 13 LC 211/16 = juris, Rn. 81.

316 OVG Lüneburg, Urt. v. 31.1.2019, Az.: 13 LC 211/16 = juris, Rn. 81; vgl. zu § 125 I AO bereits BVerwG, Urt. v. 17.10.1997, Az.: 8 C 1.96 = NVwZ 1998, 1061 (1062f.). 
Wirkung mehr zukäme ${ }^{317}$. Der Beobachter muss für die rechtlichen Zusammenhänge aufgeschlossen sein, ${ }^{318}$ aber ohne weitere Ermittlungen oder besondere (rechtliche) Überlegungen zu dem Schluss kommen, dass der Verwaltungsakt unmöglich rechtens sein $\mathrm{kann}^{319} \cdot{ }^{320}$ Es kommt demnach grundsätzlich $\mathrm{zu}$ der auch anderweitig oft bemühten „Parallelwertung in der Laiensphäre“. ${ }^{321}$ Etwas anderes kann jedoch dann gelten, wenn der Verwaltungsakt eine besondere Sachmaterie und somit auch einen besonderen Personenkreis betrifft. Möglich ist dann der Rekurs auf den zu erwartenden durchschnittlichen Einblick eines Angehörigen desjenigen Personenkreises, dem der Betroffene angehört, also auch die Würdigung von Umständen, die nicht für alle offensichtlich sind. ${ }^{322}$

Ernsthafte Zweifel, dass der Verwaltungsakt doch rechtmäßig sein könnte, dürfen nicht bestehen. ${ }^{323}$ Offensichtlichkeit ist entsprechend abzulehnen, wenn die Rechtslage in Rechtsprechung ${ }^{324}$ und Wissenschaft unterschiedlich beurteilt wird. Da maßgeblicher Beurteilungszeitpunkt für die Beurteilung der besonderen

317 Die Offensichtlichkeit soll aber nach h.M. ein zusätzliches Kriterium sein und nicht bereits aus der besonderen Schwere des Fehlers folgen, Peine/Siegel, Allgemeines Verwaltungsrecht, 12. Aufl. 2018, Rn. 562; Sachs, in: Stelkens/Bonk/Sachs, VwVfG, 9. Aufl. 2018, § 44 Rn. 124 m. N. zur Gegenmeinung aus der Rspr., der Leisner-Egensperger, in: Mann/Sennekamp/Uechtritz, VwVfG, 2. Aufl. 2019, § 44 Rn. 25, zustimmt.

318 OVG Münster, Urt. v. 14.3.2011, Az.: 19 A 3006/06 = BeckRS 2011, 49617. Zu weitgehend daher OVG Bautzen, Beschl.v. 24. 8. 2018, Az.: 5 A 82/17 = juris, Rn. 29; VGH München, Urt. v. 23.10.2003, Az.: 13 A 01.2848 = juris, Rn. 15; OVG Saarlouis, Urt. v. 31.5.2005, Az.: 1 R 29/04 = juris, Rn. 98, die nicht einmal Kenntnis der verletzten Rechtsvorschriften unterstellen wollen.

319 Ramsauer, in: Kopp/Ramsauer, VwVfG, 20. Aufl. 2019, § 44 Rn. 12.

320 Wo es einer Auslegung oder gar vertieften juristischen Prüfung der verletzten Vorschrift bedarf, kann nicht mehr von Offensichtlichkeit ausgegangen werden, s. dazu anschaulich VGH Kassel, Urt. v. 23.11.1988, Az.: 5 UE 1040/84 = NVwZ 1989, 484 (491). Andernorts formuliert das VGH Kassel treffend, „dass der angebliche Fehler, wenn schon nicht für mit der Streitsache vertraute Juristen, dann erst recht nicht für einen Durchschnittsbetrachter offenkundig ist“, Beschl. v. 24.11.1999, Az.: 8 UZ 993/99 = juris, Rn. 13.

321 OVG Koblenz, Urt. v. 24.6.1992, Az.: 11 A 10189/92 = juris, Rn. 18; VGH München, Urt. v. 23.10. 2003, Az.: 13 A 01.2848 = juris, Rn. 15; OVG Saarlouis, Urt.v. 31.5. 2005, Az.: 1 R 29/04 = juris, Rn. 98; Ramsauer, in: Kopp/Ramsauer, VwVfG, 20. Aufl. 2019, § 44 Rn. 12.

322 OVG Lüneburg, Urt. v. 31.1.2019, Az.: 13 LC 211/16 = juris, Rn. 81; Peuker, in: Knack/Henneke, VwVfG, 10. Aufl. 2014, § 44 Rn. 31; in diese Richtung auch Schemmer, in: Bader/Ronellenfitsch, VwVfG, 44. Ed., Stand: 1.7.2019, § 44 Rn. 17.1.

323 OVG Lüneburg, Urt. v. 27.6.2007, Az.: 15 KF 14/06 = juris, Rn. 20; OVG Bautzen, Beschl.v. 24. 8. 2018, Az.: 5 A 82/17 = juris, Rn. 29; Ramsauer, in: Kopp/Ramsauer, VwVfG, 20. Aufl. 2019, § 44 Rn. 12.

324 S. dazu VGH Mannheim, Urt. v. 31.10.1991, Az.: 4 S 1597/91 = juris, Rn. 25; Sachs, in: Stelkens/ Bonk/Sachs, VwVfG, 9. Aufl. 2018, § 44 Rn. 125; Peuker, in: Knack/Henneke, VwVfG, 10. Aufl. 2014, $\S 44$ Rn. 31.

Tobias Brings-Wiesen 
Schwere des Fehlers grundsätzlich der Zeitpunkt des Erlasses des Verwaltungsakts ist (s. dazu Rn. 150), kann insbesondere die spätere Klärung einer zuvor in Rechtsprechung und Literatur umstritten gewesenen Rechtsfrage nicht nachträglich zur Nichtigkeit eines bereits erlassenen Verwaltungsakts führen. ${ }^{325}$

Vor diesem Hintergrund wurde beispielsweise der besonders schwerwiegende Fehler des Erlasses einer Prüfungsentscheidung ohne persönliche Anmeldung des Prüflings als offensichtlich erachtet. ${ }^{326}$ Auch die Entscheidung eines Personalrats über die Besetzung einer Stelle, an der ein Mitglied mitgewirkt hat, das sich selbst um diese Stelle beworben hatte, aber nicht ausgewählt wurde, wurde in seinem Widerspruch zu dem in § 20 I 1 Nr. 1 VwVfG zugrunde liegenden Gebot der Unbefangenheit als offensichtlich bewertet. ${ }^{327}$ Die teilweise Rücknahme einer Baugenehmigung wurde als nichtig erachtet, weil der verbleibende Verwaltungsakt einen Hotelbetrieb ohne Treppenraum und ohne Sicherstellung eines ersten Rettungsweges genehmigt hätte. ${ }^{328}$ Auch hier gilt jedoch: Das Studium von Kasuistik und anerkannten Beispielen kann eine erste Orientierung bieten, ${ }^{329}$ für die Klausurlösung ist es jedoch weitaus bedeutsamer, die allgemeinen Maßstäbe $\mathrm{zu}$ verinnerlichen.

\section{Teilnichtigkeit, § 44 IV VwVfG}

So wie sich für einen Verwaltungsakt die Frage einer bloß teilweisen Rechtswid- 162 rigkeit stellen kann (s. dazu bereits in $\S 2$ Rn. 259), können dem zugrundeliegende Rechtsfehler gar zu einer teilweisen Nichtigkeit führen. § 44 IV VwVfG geht von der grundsätzlichen Möglichkeit einer solchen Teilnichtigkeit aus. Von Interesse ist sodann jedoch die Frage, wie sich diese auf den verbleibenden, nicht nichtigen Teil des Verwaltungsakts auswirkt.

Anders als im Falle gleichgeordneter Rechtsverhältnisse (§ 139 BGB, § 59 III 163 $\mathrm{VwVfG}^{330}$ ) geht die Vorschrift vom Grundsatz der bloßen Teilnichtigkeit aus:

325 BVerwG, Beschl.v. 5.4.2011, Az.: 6 B 41.10 = BeckRS 2011, 50439, Rn. 4; Sachs, in: Stelkens/ Bonk/Sachs, VwVfG, 9. Aufl. 2018, § 44 Rn. 125 m.w. N.

326 OVG Koblenz, Urt. v. 24.6.1992, Az.: 11 A 10189/92 = juris, Rn. 18; die Anmeldung erfolgte durch die Mutter.

327 BVerwG, Beschl. v. 19.10.2015, Az.: 5 P 11.14 = NZA-RR 2016, 166 (168); für Beschlüsse von Personalvertretungen knüpft das BVerwG an $§ 44$ VwVfG als Ausdruck eines allgemeinen Rechtsgrundsatzes an.

328 OVG Münster, Urt. v. 12.7.2012, Az.: 10 A 1769/10 = NVwZ-RR 2012, 953 (954).

329 S. insofern für weitere Beispiele speziell zur Offensichtlichkeit Peuker, in: Knack/Henneke, VwVfG, 10. Aufl. 2014, § 44 Rn. 32, sowie allgemein die bereits in der Fn. am Ende von Rn. 149 aufgeführten Fundstellen.

330 S. zu Fragen der Teilnichtigkeit beim öffentlich-rechtlichen Vertrag in $\S 5$ Rn. $120 \mathrm{f}$. 
Betrifft die Nichtigkeit nur einen Teil des Verwaltungsakts, so ist er nur dann im Ganzen nichtig, wenn der nichtige Teil so wesentlich ist, dass die Behörde den Verwaltungsakt ohne den nichtigen Teil nicht erlassen hätte. Die für den Verwaltungsakt als Hoheitsakt allgemein geltende Vermutung der Richtigkeit und Gültigkeit wirkt somit bei der Beurteilung der Teilnichtigkeit fort. ${ }^{331}$ Maßgeblich für die Beurteilung der Wesentlichkeit ist prima facie der Behördenwille. Allerdings soll es nach ganz herrschender Meinung - zumindest vorrangig - nicht auf den subjektiven, gar nur hypothetischen Willen der den konkreten Verwaltungsakt erlassenden Behörde, sondern auf eine objektive Betrachtungsweise ankommen. ${ }^{332}$ Vielerorts wird insofern illustrativ auf den Willen einer in Kenntnis der richtigen Rechts- und Sachlage vernünftig entscheidenden Idealbehörde abgestellt. ${ }^{33}$ Materiell kommt es auf die dem Verwaltungsakt im Einzelfall zugrundeliegenden Rechtsvorschriften und insbesondere deren Sinn und Zweck an. Somit stellen sich auch hier ${ }^{334}$ primär Grundfragen der Teilbarkeit eines Verwaltungsakts. $^{335}$

164 Wesentlich ist ein nichtiger Teil demnach, „wenn der verbleibende Teil für sich allein einen anderen Sinn erhalten und dadurch den Zweck verfehlen würde, den der Verwaltungsakt insgesamt erfüllen soll“. ${ }^{336}$ Gleiches gilt, wenn der verbleibende Teil für sich rechtswidrig wäre. ${ }^{337}$ Umgekehrt ist nicht von einer Wesentlichkeit auszugehen, wenn eine Rechtspflicht zum Erlass des verbleibenden Teils bestünde - sowohl bei gebundenen Entscheidungen als auch im Falle einer

331 So die Gesetzesmaterialien, BT-Drucks. 7/910, S. 65, 82. Somit entspricht die Regelung in ihrer Grundtendenz auch eher den Vorgaben zur Nichtigkeit von Gesetzen (vgl. nur § 78 BVerfGG). 332 Peine/Siegel, Allgemeines Verwaltungsrecht, 12. Aufl. 2018, Rn. 565; Ramsauer, in: Kopp/ Ramsauer, VwVfG, 20. Aufl. 2019, § 44 Rn. 61; Sachs, in: Stelkens/Bonk/Sachs, VwVfG, 9. Aufl. 2018, § 44 Rn. 192; Will/Rathgeber, JuS 2012, 1057 (1061).

333 Peine/Siegel, Allgemeines Verwaltungsrecht, 12. Aufl. 2018, Rn. 565; Sachs, in: Stelkens/ Bonk/Sachs, VwVfG, 9. Aufl. 2018, § 44 Rn. 192; Peuker, in: Knack/Henneke, VwVfG, 10. Aufl. 2014, $\S 44 \mathrm{Rn} .58$.

334 Wie auch hinsichtlich der Teilaufhebung eines Verwaltungsakts gemäß § 113 I 1 VwGO, s. dazu in $\S 2$ Rn. 260.

335 Ramsauer, in: Kopp/Ramsauer, VwVfG, 20. Aufl. 2019, § 44 Rn. 62, und Schwarz, in: Fehling/ Kastner/Störmer, Verwaltungsrecht, 4. Aufl. 2016, § 44 VwVfG Rn. 31, gehen somit zu Recht davon aus, dass fehlende Teilbarkeit für eine „Wesentlichkeit“ des nichtigen Teils i.S.d. Norm spricht. 336 OVG Münster, Beschl.v. 16.3.2005, Az.: 19 B 374/05 = BeckRS 2005, 25927, dort auch bejaht für eine bloß teilweise Nichtigkeit der Titelführung. Nicht angenommen bei VGH Kassel, Beschl. v. 29.10.2007, Az.: 7 TG 2891/06 = juris, Rn. 17. So auch Ramsauer, in: Kopp/Ramsauer, VwVfG, 20. Aufl. 2019, § 44 Rn. 62.

337 So bspw. im Falle der Nichtigkeit einer die Erfüllung der Voraussetzungen des Verwaltungsakts sicherstellenden Nebenbestimmung gemäß § 36 I Var. 2 VwVfG, s. VGH Kassel, Beschl. v. 20.3.1991, Az.: 4 TH 977/90 = juris, Rn. 57. 
Ermessensreduktion auf Null ${ }^{338} \cdot{ }^{339}$ In diesem Fall ist nach überwiegender Meinung auch ein dem erkennbar entgegenstehender Wille der Behörde unbeachtlich. ${ }^{340}$

Die Grenze der Objektivierbarkeit ist indes dort erreicht, wo Spielräume der 165 Behörde fortbestehen. Steht die Entscheidung beispielsweise im Ermessen der Behörde und ist dieses nicht auf Null reduziert, kann es nur auf den subjektiven Willen der erlassenden Behörde ankommen. ${ }^{341}$ Ist ein Wille der Behörde, den Verwaltungsakt ohne den nichtigen Teil nicht zu erlassen, nicht zum Ausdruck gekommen, greift der Grundsatz der Teilnichtigkeit. ${ }^{342}$

\section{Behördliche Feststellung der Nichtigkeit gemäß § 44 V VwVfG}

Als besondere Maßnahmen wider den Rechtsschein der Wirksamkeit eines Ver- 166 waltungsakts hat der Bundesgesetzgeber die behördliche Feststellung der Nichtigkeit gemäß §44 V VwVfG geschaffen. Die Entscheidung der zuständigen Behörde in dieser Frage stellt selbst einen feststellenden Verwaltungsakt (s. dazu $\S 2$ Rn. 64) dar. ${ }^{343}$

Die Entscheidung der Behörde kann auf zwei verschiedenen Wegen initiiert 167 werden, die auch den Aufbau der Prüfung beeinflussen.

Gemäß $\S 44$ V Hs. 1 VwVfG kann die Nichtigkeit jederzeit von Amts wegen 168 festgestellt werden. Die Vorschrift ermächtigt die zuständige Behörde, eigeninitiativ die Nichtigkeit eines Verwaltungsakts festzustellen. Sie fungiert als - vor dem Hintergrund des Grundsatzes des Vorbehalts des Gesetzes (s. dazu § 2 Rn. $554 \mathrm{ff}$.) notwendige - Ermächtigungsgrundlage, da die verbindliche Fest-

338 OLG Köln, Urt. v. 10.1.1992, Az.: 19 U 198/91 = BeckRS 1992, 5397, Rn. 11.

339 Detterbeck, Allgemeines Verwaltungsrecht, 17. Aufl. 2019, Rn. 619; Ramsauer, in: Kopp/ Ramsauer, VwVfG, 20. Aufl. 2019, § 44 Rn. 63; Schwarz, in: Fehling/Kastner/Störmer, Verwaltungsrecht, 4. Aufl. 2016, § 44 VwVfG Rn. 32; Peuker, in: Knack/Henneke, VwVfG, 10. Aufl. 2014, $\S 44$ Rn. 58.

340 OLG Köln, Urt. v. 10.1.1992, Az.: 19 U 198/91 = BeckRS 1992, 5397, Rn. 11; Ruffert, in: Ehlers/ Pünder, Allgemeines Verwaltungsrecht, 15. Aufl. 2016, § 22 Rn. 11; Sachs, in: Stelkens/Bonk/Sachs, VwVfG, 9. Aufl. 2018, § 44 Rn. 193; Will/Rathgeber, JuS 2012, 1057 (1061); a. A. aber OVG Münster, Urt. v. 4.6.1991, Az.: 5 A 125/90 = NVwZ-RR 1992, 525 (526).

341 Sachs, in: Stelkens/Bonk/Sachs, VwVfG, 9. Aufl. 2018, § 44 Rn. 194; Leisner-Egensperger, in: Mann/Sennekamp/Uechtritz, VwVfG, 2. Aufl. 2019, § 44 Rn. 52.

342 Sachs, in: Stelkens/Bonk/Sachs, VwVfG, 9. Aufl. 2018, § 44 Rn. 194.

343 Detterbeck, Allgemeines Verwaltungsrecht, 17. Aufl. 2019, Rn. 620; Maurer/Waldhoff, Allgemeines Verwaltungsrecht, 19. Aufl. 2017, § 10 Rn. 93; davon ausgehend auch BVerwG, Urt. v. 30.1. 1990, Az.: 1 C 26.87 = BVerwGE 84, 314; VGH Mannheim, Urt. v. 31.3. 2006, Az.: 1 S 2115/05 = BeckRS 2006, 23996, Rn. 25. 
stellung der Nichtigkeit für sich in die Rechte der von diesem Verwaltungsakt Betroffenen eingreift. ${ }^{344}$

169 Examenswissen: Vor diesem Hintergrund ist umstritten, ob auf Grundlage von § $44 \mathrm{~V}$ VwVfG analog auch das Fehlen von Nichtigkeitsgründen und somit positiv die Wirksamkeit eines Verwaltungsakts festgestellt werden kann. Die wohl herrschende Meinung lehnt dieses Vorgehen grundsätzlich mit dem Argument ab, es fehle eine entsprechende Ermächtigungsgrundlage. ${ }^{345}$ Ausnahmen werden insofern nur dort akzeptiert, wo es nach dem Grundsatz des Vorbehalts des Gesetzes keiner Ermächtigungsgrundlage bedarf. ${ }^{346}$ Anderer Auffassung ist indes Schenke mit der Begründung, dass die Feststellung der Wirksamkeit nur actus contrarius zur ausdrücklich normierten Feststellung der Nichtigkeit sei und ein Bedürfnis nach Schließung dieser verwaltungsverfahrensrechtlichen Rechtsschutzlücke bestehe. ${ }^{347}$

170 Die Vorschrift bleibt zwar im Hinblick auf die Zuständigkeit unergiebig und weist die Entscheidung schlicht „[der] Behörde“ zu. Da es sich bei der Entscheidung jedoch um einen Verwaltungsakt handelt, gelten - mangels spezialgesetzlicher Vorschriften - zumindest die allgemeinen Rechtmäßigkeitsvoraussetzungen (s. dazu $§ 2$ Rn. 580 ff.). Dies bedeutet, dass sich die Zuständigkeit im Zeitpunkt der Feststellungsentscheidung nach den Vorschriften des einschlägigen Fachrechts, subsidiär nach $\S 3$ VwVfG bestimmt, sodass regelmäßig die den ursprünglichen Verwaltungsakt erlassende Behörde, bei relevanter Änderung der die Zuständigkeit begründenden Umstände aber auch eine andere Behörde zuständig sein kann. ${ }^{348}$ Laut Ramsauer soll daneben immer auch die Behörde, die den nichtigen Verwaltungsakt erlassen hat, zuständig sein. ${ }^{349}$ Dem ist jedoch nicht $\mathrm{zu}$ folgen, da es einer klaren Zuständigkeitsverteilung bedarf. ${ }^{350}$

344 Schenke, JuS 2016, 97 (101).

345 Ramsauer, in: Kopp/Ramsauer, VwVfG, 20. Aufl. 2019, § 44 Rn. 65; Sachs, in: Stelkens/Bonk/ Sachs, VwVfG, 9. Aufl. 2018, § 44 Rn. 203; Schemmer, in: Bader/Ronellenfitsch, VwVfG, 44. Ed., Stand: 1.7.2019, § 44 Rn. 77; Will/Rathgeber, JuS 2012, 1057 (1062).

346 Sachs, in: Stelkens/Bonk/Sachs, VwVfG, 9. Aufl. 2018, § 44 Rn. 203; Schemmer, in: Bader/ Ronellenfitsch, VwVfG, 44. Ed., Stand: 1.7.2019, § 44 Rn. 77; in diese Richtung wohl auch Ramsauer, in: Kopp/Ramsauer, VwVfG, 20. Aufl. 2019, § 44 Rn. 65 m.w. N. zur Rspr. betreffend das Erfordernis einer gesetzlichen Grundlage für den Erlass feststellender Verwaltungsakte.

347 Dazu ausführlich Schenke, JuS 2016, 97 (98f.).

348 So auch Ramsauer, in: Kopp/Ramsauer, VwVfG, 20. Aufl. 2019, § 44 Rn. 67; Peuker, in: Knack/ Henneke, VwVfG, 10. Aufl. 2014, § 44 Rn. 60; Schenke, JuS 2016, 97 (98). S. zu diesen Konstellationen bereits im Kontext von §§ 48, 49 VwVfG § 2 Rn. $849 \mathrm{ff}$.

349 Ramsauer, in: Kopp/Ramsauer, VwVfG, 20. Aufl. 2019, § 44 Rn. 67.

350 So wohl auch Schemmer, in: Bader/Ronellenfitsch, VwVfG, 44. Ed., Stand: 1.7.2019, § 44 Rn. 76, der einen Zuständigkeitswechsel indes unter Zustimmung der nunmehr zuständigen Behörde zulässt.

Tobias Brings-Wiesen 
Examenswissen: Überwiegend wird auch vertreten, dass ab dem Zeitpunkt der Anhängigkeit eines Widerspruchsverfahrens auch die Widerspruchsbehörde für die Feststellung der Nichtigkeit zuständig sein soll. ${ }^{351}$ Dem hält Schenke entgegen, dass die Widerspruchsbehörde - zumindest im Rahmen eines Anfechtungswiderspruchs - nur über die Aufhebung des nichtigen Verwaltungsakts zu entscheiden habe. ${ }^{352}$

Soweit die Feststellungsentscheidung in die Rechte von Beteiligten eingreift, 172 bedarf es gemäß § 28 I VwVfG auch deren Anhörung (s. dazu § 2 Rn. 631 ff.). Einer besonderen Form bedarf die Entscheidung entsprechend § 37 II 1 VwVfG grundsätzlich nicht.

In materieller Hinsicht muss die Feststellungsentscheidung - neben den 173 allgemeinen Voraussetzungen - den Tatbestand von § 44 V Hs. 1 VwVfG erfüllen. Demnach muss der der Feststellungsentscheidung zugrundeliegende Verwaltungsakt gemäß § 44 I bis III VwVfG tatsächlich nichtig sein. Ist dies der Fall, steht die Entscheidung über die Feststellung der Nichtigkeit von Amts wegen im Ermessen der Behörde. ${ }^{353}$

$\S 44$ V Hs. 2 VwVfG bietet darüber hinaus all jenen, die ein berechtigtes In- 174 teresse daran haben, die Möglichkeit, einen Antrag auf Feststellung der Nichtigkeit eines Verwaltungsakts zu stellen.

Anders als der Widerspruch (s. dazu $\S 2$ Rn. 319 ff.) ist der Antrag auf Fest- 175 stellung der Nichtigkeit gemäß $§ 44$ V Hs. 2 VwVfG nicht fristgebunden. Er kann insbesondere auch über die Fristen von Widerspruch (§ 70 I 1 VwGO) und Anfechtungsklage ( $\$ 74$ VwGO) hinaus jederzeit gestellt werden. Eine Verwirkung des subjektiven Rechts ist zwar denkbar, verlangt jedoch das Vorliegen besonderer Umstände. ${ }^{354}$

Abweichend von den bereits dargestellten Voraussetzungen bedarf es für die $\mathbf{1 7 6}$ Annahme der Rechtmäßigkeit der Feststellungsentscheidung gemäß § 44 V Hs. 2 VwVfG des Vorliegens eines berechtigten Interesses des Antragsstellers. Über den Kreis der rechtlichen Interessen ${ }^{355}$ hinaus sind damit insbesondere auch

351 Ramsauer, in: Kopp/Ramsauer, VwVfG, 20. Aufl. 2019, § 44 Rn. 67; Peuker, in: Knack/Henneke, VwVfG, 10. Aufl. 2014, § 44 Rn. 60; Will/Rathgeber, JuS 2012, 1057 (1062, Fn. 56).

352 Schenke, JuS 2016, 97 (98, Fn. 2).

353 Schenke, JuS 2016, 97 (98).

354 Sachs, in: Stelkens/Bonk/Sachs, VwVfG, 9. Aufl. 2018, § 44 Rn. 202; Schemmer, in: Bader/ Ronellenfitsch, VwVfG, 44. Ed., Stand: 1.7.2019, § 44 Rn. 80; Leisner-Egensperger, in: Mann/ Sennekamp/Uechtritz, VwVfG, 2. Aufl. 2019, § 44 Rn. 57, allesamt unter Rekurs auf die Rspr. zur Nichtigkeitsfeststellungsklage; zur Verwirkung bereits in § 2 Rn. $399 \mathrm{ff}$.

355 Für eine Begrenzung auf das rechtliche Interesse entsprechend des eingeschränkten Verständnisses des „berechtigten Interesses“ i. S.v. § 43 I VwGO (s. dazu ausführlich Rn. 93 ff.) VGH Mannheim, Urt. v. 31.3.2006, Az.: 1 S 2115/05 = BeckRS 2006, 23996, Rn. 29 f. 
wirtschaftliche und ideelle Interessen (s. dazu Rn. 94) erfasst. ${ }^{356}$ Der Kreis der antragsberechtigten Personen ist entsprechend weit. ${ }^{357}$

177 Examenswissen: Nach herrschender Meinung kann auch im Falle der Erledigung (s. dazu § 2 Rn. $182 \mathrm{ff}$. sowie § 4 Rn. $11 \mathrm{ff}$.) des Verwaltungsakts ausnahmsweise ein § 43 und § 113 I 4 VwGO ([doppelt] analog; s. dazu in $\S 4 \mathrm{Rn}$. 15ff.) entsprechendes fortgesetztes Interesse an der behördlichen Feststellung der Nichtigkeit bestehen. ${ }^{358}$

178 Examenswissen: Die bloße Anhängigkeit anderer Rechtsschutzverfahren soll den Antrag gemäß $\S 44 \mathrm{~V}$ Hs. 2 VwVfG nach herrschender Meinung nicht unzulässig machen; ${ }^{359}$ anderes soll indes gelten, wenn ein Antrag nach $\S 44$ V Hs. 2 VwVfG bereits bestandskräftig abgelehnt wurde oder eine rechtskräftige gerichtliche Entscheidung vorliegt. ${ }^{360}$

179 Liegen die Tatbestandsvoraussetzungen von $\S 44$ V Hs. 2 VwVfG, ist die zuständige Behörde - anders als im Rahmen des $§ 44$ V Hs. 1 VwVfG - gebunden, die Nichtigkeit festzustellen. Kehrseitig haben die Antragssteller ein subjektives Recht auf eine entsprechende Entscheidung. ${ }^{361}$

180 Die Entscheidung der Behörde hat als feststellender Verwaltungsakt (s. dazu bereits in $\S 2$ Rn. 64) anders als die verschiedenen Aufhebungsentscheidungen (§ 72 VwGO; §§ 49, 49, $51 \mathrm{VwVfG)} \mathrm{keine} \mathrm{rechtsgestaltende} \mathrm{Wirkung;} \mathrm{sie} \mathrm{wirkt} \mathrm{ent-}$

356 Peine/Siegel, Allgemeines Verwaltungsrecht, 12. Aufl. 2018, Rn. 566; Ramsauer, in: Kopp/ Ramsauer, VwVfG, 20. Aufl. 2019, § 44 Rn. 68; Sachs, in: Stelkens/Bonk/Sachs, VwVfG, 9. Aufl. 2018, § 44 Rn. 200; Baumeister, in: Obermayer/Funke-Kaiser, VwVfG, 5. Aufl. 2018, § 44 Rn. 64; Will/Rathgeber, JuS 2012, 1057 (1062); Schenke, JuS 2016, 97 (98).

357 Insbesondere muss die Person vormals kein Verfahrensbeteiligter gewesen sein, Sachs, in: Stelkens/Bonk/Sachs, VwVfG, 9. Aufl. 2018, § 44 Rn. 200; Schenke, JuS 2016, 97 (98).

358 Ramsauer, in: Kopp/Ramsauer, VwVfG, 20. Aufl. 2019, § 44 Rn. 68; Sachs, in: Stelkens/Bonk/ Sachs, VwVfG, 9. Aufl. 2018, § 44 Rn. 202; Will/Rathgeber, JuS 2012, 1057 (1062); Schenke, JuS 2016, 97 (98); von der grundsätzlichen Möglichkeit ausgehend auch BVerwG, Beschl. v. 13.10.1999, Az.: 6 B 122.98 = NVwZ-RR 2000, 324 (324f.).

359 Ramsauer, in: Kopp/Ramsauer, VwVfG, 20. Aufl. 2019, § 44 Rn. 66; Peuker, in: Knack/Henneke, VwVfG, 10. Aufl. 2014, § 44 Rn. 64; Will/Rathgeber, JuS 2012, 1057 (1062).

360 Ramsauer, in: Kopp/Ramsauer, VwVfG, 20. Aufl. 2019, § 44 Rn. 66; Schwarz, in: Fehling/ Kastner/Störmer, Verwaltungsrecht, 4. Aufl. 2016, § 44 VwVfG Rn. 35; Peuker, in: Knack/Henneke, VwVfG, 10. Aufl. 2014, § 44 Rn. 64; Will/Rathgeber, JuS 2012, 1057 (1062); lediglich zur gerichtlichen Entscheidung Sachs, in: Stelkens/Bonk/Sachs, VwVfG, 9. Aufl. 2018, § 44 Rn. 202, Schenke, JuS 2016, 97 (98). Offenbar bereits auf den Zeitpunkt der behördlichen bzw. gerichtlichen Entscheidung abstellend Leisner-Egensperger, in: Mann/Sennekamp/Uechtritz, VwVfG, 2. Aufl. 2019, $\S 44$ Rn. 55, 57; tendenziell wohl auch Schenke, a.a.O.

361 Bull/Mehde, Allgemeines Verwaltungsrecht, 9. Aufl. 2015, Rn. 765; Schemmer, in: Bader/ Ronellenfitsch, VwVfG, 44. Ed., Stand: 1.7.2019, § 44 Rn. 79; Leisner-Egensperger, in: Mann/Sennekamp/Uechtritz, VwVfG, 2. Aufl. 2019, § 44 Rn. 57; Will/Rathgeber, JuS 2012, 1057 (1062); Schenke, JuS 2016, 97 (98).

Tobias Brings-Wiesen 
sprechend nicht erga omnes. ${ }^{362}$ Sie kann jedoch in Bestandskraft erwachsen ${ }^{363}$ und ist selbst der Aufhebung im Wege des - soweit gesetzlich vorgesehenen Widerspruchs gemäß § 68 I 1 VwGO oder der Anfechtungsklage gemäß § 42 I Var. 1 VwGO 364 bzw. gemäß den $\S \S 48,49,51$ VwVfG zugänglich. Dies ist insbesondere dort relevant, wo die behördliche Feststellung der Nichtigkeit zulasten eines durch den Verwaltungsakt begünstigten Betroffenen geht. Im Rahmen von Widerspruch und Anfechtungsklage gegen die behördliche Nichtigkeitsfeststellung kommt es dann jedoch nur darauf an, ob der in Rede stehende Verwaltungsakt tatsächlich nichtig ist. ${ }^{365}$

\section{Literaturhinweise}

Lehrbeiträge: Beaucamp, Die Nichtigkeit von Verwaltungsakten, JA 2007, 704; Schenke, Rechtsschutz gegen nichtige Verwaltungsakte, JuS 2016, 97; Schiedeck, Die Nichtigkeit von Verwaltungsakten gem. § 44 VwVfG, JA 1994, 483; Schladebach, Der nichtige Verwaltungsakt, VerwArch 2013, 188; Will/Rathgeber, Die Nichtigkeit von Verwaltungsakten gem. § 44 VwVfG, JuS 2012, 1057

Fallbearbeitungen: Fall 12 in: Eisentraut, Fälle zum Verwaltungsrecht, 2020; Beaucamp, „Bauen auf dem Campingplatz“?, JA 2014, 119; Ernst/Kämmerer, Fall 7 - Folgenschwere Ferndiagnose, in: Fälle zum Allgemeinen Verwaltungsrecht, 3. Aufl. 2016, S. 96; Heinze, Fall 18 - „Gartenzwerge, Hecken und 'ne warme Mahlzeit für das Kind...“, in: Systematisches Fallrepetitorium Allgemeines Verwaltungsrecht, 2014, S. 460; Peine, Fall 3 - Blue suede shoes, in: Klausurenkurs im Verwaltungsrecht, 6. Aufl. 2016, S. 142; Thiel/Westphal, Fortgeschrittenenklausur - Öffentliches Recht: Allgemeines Verwaltungsrecht - „Des Sängers Fluch“, JuS 2012, 618

362 Sachs, in: Stelkens/Bonk/Sachs, VwVfG, 9. Aufl. 2018, § 44 Rn. 201; Schenke, JuS 2016, 97 (98).

363 Der daraus resultierende Gleichlauf mit der Wirkung der Nichtigkeitsfeststellungsklage ist ein zentraler Grund für die Qualifkation als Verwaltungsakt, vgl. im Hinblick auf $\S 125 \mathrm{~V}$ AO und $\S 41$ I FGO BFH, Urt. v. 20.8.2014, Az.: X R 15/10 = NVwZ 2015, 163 (165f., Rn. 40 ff.).

364 Vgl. BVerwG, Urt. v. 31.1.1990, Az.: 1 C 26.87 = BVerwGE 84, 314 (317).

365 Zur Anfechtungsklage ausdrücklich BVerwG, Urt. v. 31.1.1990, Az.: 1 C 26.87 = BVerwGE 84, 314 (317). 


\section{Die Feststellungsklage im Polizei- und Ordnungsrecht (Nikolas Eisentraut)}

181 Die Feststellungsklage weist auch einen Anwendungsbereich im Polizei- und Ordnungsrecht (s. einführend zum Polizei- und Ordnungsrecht $§ 2$ Rn. 1008ff.) auf.

Die Feststellungsklage kann im allgemeinen Polizei- und Ordnungsrecht zum einen eine Rolle spielen, wenn die Feststellung der Rechtswidrigkeit eines bereits erledigten Realakts begehrt wird.

183 Weiterhin spielt sie in der Form der Nichtigkeitsfeststellungsklage eine Rolle, wenn die Nichtigkeitsfeststellung einer Ordnungsverfügung (Verwaltungsakt) begehrt wird.

184 Schließlich kann sie als „inzidente Normenkontrolle“ statthaft sein (s. dazu Rn. 26ff.), wenn eine Gefahrenabwehrverordnung auf ihre Rechtmäßigkeit geprüft werden soll (zur Rechtmäßigkeitsprüfung von Gefahrenabwehrverordnungen s. näher $\S 7$ Rn. 109ff.).

185 Literaturhinweis: Falllösung zur Feststellungsklage bei bereits erledigtem Realakt der Polizei: Tomerius, JURA 2018, 822: „You’ll ... walk alone“ - Stadionverbot auf Anregung der Polizei

\section{Die Feststellungsklage im Kommunalrecht (Sebastian Piecha)}

186 Die Feststellungsklage spielt im Kommunalrecht bei sog. Kommunalverfassungsstreitigkeiten eine klausurrelevante Rolle (zum Kommunalverfassungsstreit bereits einführend $\S 5$ Rn. 236 ff.). Eine Feststellungsklage ist immer dann statthaft, wenn das Bestehen oder Nichtbestehenden eines konkreten Rechtsverhältnisses begehrt wird. Ein Rechtsverhältnis ist dabei die sich aus einem konkreten Sachverhalt aufgrund einer öffentlich-rechtlichen Regelung ergebende rechtliche Beziehung einer Person zu einer anderen Person oder zu einer Sache (s. Rn. 12ff.).

187 Die Feststellungsklage im Kommunalverfassungsstreit ist begründet, wenn eine tatsächliche Verletzung von organschaftlichen Rechten durch die Organhandlung feststeht. Insbesondere handelt es sich im Kommunalrecht dann um Fragen, die die Rechtsstellung des Ratsmitgliedes betreffen:

188 Es kann etwa das Bestehen des Fraktionsstatus` für eine Vereinigung von Ratsmitgliedern überprüft werden. Fraktionen sind Vereinigungen politisch 
gleichgesinnter Mandatsträger. ${ }^{366}$ Statusrechtlich sind sie ein Zusammenschluss von Organteilen der Kommunalvertretung und damit selbst Organteil des jeweiligen Vertretungsorgans. ${ }^{367}$

Hausarbeitswissen: Die Rechtsnatur solcher Fraktionen ist umstritten. Teilweise werden sie privatrechtlich begründet, teilweise öffentlich-rechtlich qualifiziert oder je nach Gründung, Organisation und Handlungsbefugnissen und sonstigen Aspekten differenziert. ${ }^{368}$

Es bestehen in den Kommunalverfassungsgesetzen der Länder teilweise recht 190 unterschiedliche Anforderungen an die Voraussetzungen für die Bildung einer Fraktion, etwa Parteizugehörigkeiten, lediglich ähnliche Ziele oder die Mindestanzahl von Mitgliedern. ${ }^{369}$ Der Fraktionsstatus an sich ist von Bedeutung, denn davon hängen bestimmte Rechte und Pflichten ab (z.B. Rechte auf Einberufung der Gemeindevertretung, ${ }^{370}$ Antragsrecht auf Aufnahme bestimmter Punkte in die Tagesordnung ${ }^{371}$ oder Entsendungsrecht in Ausschüsse ${ }^{372}$ u.v.m.). ${ }^{373}$

Ferner ist oft ein Ausschluss aus der Ratsfraktion in solchen Feststel- 191 lungssituationen Gegenstand einer Prüfung. Ermächtigungsgrundlage ist das in den Mitwirkungsrechten der einzelnen zusammengeschlossenen Ratsmitglieder wurzelnde Selbstorganisationsrecht der Fraktionen. ${ }^{374}$ Formell rechtmäßig ist der Fraktionsausschluss, wenn der Punkt rechtzeitig bekanntgegeben wurde (Ladung), der Betroffene angehört worden ist (Anhörung), die (ggf. nach Fraktionsgeschäftsordnung besonders qualifizierte) Mehrheit gegeben war (Mehrheitsbeschluss) und dem Betroffenen die Ausschlussgründe mitgeteilt wurden (Begründung). Materiell rechtmäßig ist ein Ausschluss nur bei Bestehen eines wichtigen Grundes sowie der Einhaltung des Verhältnismäßigkeitsgrundsatzes. Ein wichtiger Grund liegt dabei vor, wenn das Vertrauensverhältnis zu der Fraktion in einer Weise gestört ist, die eine weitere Zusammenarbeit mit den

366 BVerwG, Urt. v. 27.3.1992, Az. 7 C 20/91 = NVwZ 1993, 375; VGH München, Urt. v. 8.1.1986, Az. 4 B 85 A. 2700 = BayVBl. 1986, 466;

367 BVerwG, Urt. v. 27.3.1992, Az. 7 C 20/91 = NVwZ 1993, 375.

368 Ausführlich zum Streitstand Gern/Brüning, Deutsches Kommunalrecht, 4. Aufl. 2019, Rn. 561.

369 Geregelt in allen Ländern mit Ausnahme Bayerns: §§ 32a GemO BW; 32 BbgKVerf; 36a HGO; 23 V KV M-V; 57 NKomVG; 56 GO NRW; 30a GemO RP; 30 V KSVG; 35a SächsGemO; 44 KVG LSA; 32a GO S-H; 25 ThürKO.

370 Z.B. $\S \S 34$ II BbgKVerf, 47 I GO NRW.

371 Z.B. $\S \S 48$ I GO NRW, 41 I KSVG.

372 Z.B. §§ 62 IV HGO, 58 I GO NRW, 71 IV NKomVG.

373 Ausführliche Liste bei Gern/Brüning, Deutsches Kommunalrecht, 4. Aufl. 2019, Rn. 563.

374 Burgi, Kommunalrecht, 6. Aufl. 2019, § 12 Rn. 17. 
übrigen Fraktionsmitgliedern nicht mehr zumutbar scheint, wobei dies einen fehlenden politischen Grundkonsens erfordert. ${ }^{375}$ Eine bloß temporäres Abweichen von einem vorgegebenen Abstimmungsverhalten oder gelegentliche politische Meinungsverschiedenheiten bzw. gar persönliche Differenzen sind zur Begründung eines Fraktionsausschlusses nicht ausreichend. ${ }^{376}$

Schließlich ist an einen Ausschluss von der Abstimmung wegen Befangenheit (Mitwirkungsverbot) $\mathrm{zu}$ denken, deren Rechtswidrigkeit festgestellt werden soll. Ermächtigungsgrundlagen hierzu finden sich in jedem Kommunalverfassungsrecht. ${ }^{377}$ Neben den jeweils unterschiedlichen formellen Rechtmäßigkeitsvoraussetzungen ist ein solcher Ausschluss normalerweise dann materiell rechtmäßig, wenn ein „unmittelbarer Vor- oder Nachteil“ (1) damit verbunden sein kann für das Ratsmitglied selbst, einen Angehörigen oder (u.a.) für eine juristische Person (z. B. Unternehmen), bei der es beschäftigt ist (2). Ein Vor- oder Nachteil ist dann unmittelbar, die ohne das Hinzutreten weiterer Umstände durch die betreffende Entscheidung selbst hervorgerufen werden. ${ }^{378}$ Ferner darf kein Ausschlussgrund vorliegen (3). Damit soll ein Ausufern dieses Tatbestandes verhindert werden. Das bloße Angehören $\mathrm{zu}$ einer Berufs- oder Bevölkerungsgruppe, deren gemeinsame Interessen durch die fragliche Angelegenheit berührt werden, genügt freilich nicht, um eine Befangenheit zu begründen. ${ }^{379}$ Gleichwohl ist in einer Klausur hier stets auf den Einzelfall einzugehen. Das OVG Münster erklärte etwa einen Vater bei der Entscheidung über die Neuordnung der Schullandschaft für befangen, weil sich dadurch der Schulweg für seine Tochter verändert hätte. ${ }^{380}$

\section{Die Feststellungsklage im Verwaltungsvollstreckungsrecht (Mariamo Katharina Ilal)}

193 Die Feststellungsklage spielt auch im Verwaltungsvollstreckungsrecht eine Rolle. Dies ist der Rechtsnatur der Zwangsmittelanwendung geschuldet. Diese ist - anders als Grundverfügung, Androhung und Festsetzung - kein Verwaltungsakt

375 Bätge, Kommunalrecht NRW, 5. Aufl. 2019, Rn. 302.

376 Burgi, Kommunalrecht, 6. Aufl. 2019, § 12 Rn. 17.

$377 \S 18$ GemO BW; Art.49 BayGO; §§ 20,22, 33 II BbgKVerf; 25 HGO; 24 KV MV; 41 NKomVG; 31 (i.V.m. 43 II) GO NRW; 22 GemO RP; 27 KSVG; 20 SächsGemO; 33 KVG LSA; 22 (i.V.m. 32 III) GO S-H; 38 ThürKO.

378 Burgi, Kommunalrecht, 6. Aufl. 2019, § 12 Rn. 50.

379 Burgi, Kommunalrecht, 6. Aufl. 2019, § 12 Rn. 50.

380 OVG Münster, Beschl.v. 8.5.2015, Az. 15 A 1523/14 = NWVBl. 2016, 72.

Sebastian Piecha/Mariamo Katharina Ilal 
(vgl. § 2 Rn. 1320) und kann daher auch nicht Gegenstand einer Anfechtungsklage sein. Statthafter Rechtsbehelf ist grundsätzlich die Feststellungsklage. Etwas anderes gilt freilich für die Zwangsmittelanwendung im Sofortvollzug, denn hier normiert $\S 18$ II VwVG die Statthaftigkeit der Anfechtungsklage (dazu bereits $\S 2$ Rn. 1347).

Gegenstand der folgenden Ausführungen ist folglich allein die Zwangsmit- 194 telanwendung im gestreckten Verfahren. Für die Zwangsmittelanwendung im Sofortvollzug wird auf $\S 2$ Rn. $1345 \mathrm{ff}$. verwiesen.

Im gestreckten Verfahren folgt die Zwangsmittelanwendung auf Androhung 195 und Festsetzung der Zwangsmittel. Anders als diese vorausgehenden Vollstreckungsmaßnahmen ist die Zwangsmittelanwendung ein Realakt. Statthafter Rechtsbehelf ist damit die Feststellungsklage, im Rahmen derer die Rechtmäßigkeit der Zwangsmittelanwendung (nachträglich) überprüft wird. Geht es dem Betroffenen einmal um die schnelle Abwendung einer drohenden Zwangsmittelanwendung, kann er Rechtsschutz nach § 123 VwGO suchen (hierzu allgemein $\S 10)$. Die Rechtmäßigkeit der Zwangsmittelanwendung kann aber auch im Rahmen der Überprüfung des Kostenbescheids eine Rolle spielen (auch dazu bereits unter $\S 2$ Rn. 1375). Im Punkt „Rechtmäßigkeit der Vollstreckungsmaßnahme, für die die Kosten erhoben werden“ sind dann die folgenden Voraussetzungen zu prüfen.

\section{Ermächtigungsgrundlage für die Zwangsmittelanwendung}

Ermächtigungsgrundlage der Zwangsmittelanwendung sind §§ 6 I, 15 VwVG. Op- 196 tional kann auch das jeweilige Zwangsmittel (§§ 9 I lit. x, 10 - 12 VwVG) mitzitiert werden.

\section{Formelle Rechtmäßigkeit der Zwangsmittelanwendung}

Nach § 7 VwVG ist zuständige Vollzugsbehörde diejenige, die den zu vollziehen- 197 den Verwaltungsakt erlassen hat (Grundsatz der Selbstvollstreckung durch die Ausgangsbehörde). Einer Anhörung des Betroffenen bedarf es vor Anwendung der Ersatzvornahme oder des unmittelbaren Zwangs mangels Verwaltungsaktqualität der Zwangsmittelanwendung nicht, vgl. § 28 I VwVfG.

\section{Materielle Rechtmäßigkeit der Zwangsmittelanwendung}

Die bereits bekannte Einteilung in allgemeine und besondere Vollstreckungs- 198 voraussetzungen (s. § 2 Rn. 1325) kann auch für die Prüfung der materiellen Rechtmäßigkeit der Zwangsmittelandrohung übernommen werden. 


\section{a) Allgemeine Vollstreckungsvoraussetzungen}

199 Zunächst müssen wie auch bei Androhung und Festsetzung die allgemeinen Vollstreckungsvoraussetzungen gegeben sein. Es muss also ein wirksamer, bestimmter und vollstreckbarer Grundverwaltungsakt vorliegen. Die Vollzugsbehörde muss das richtige Zwangsmittel gewählt haben. Es dürfen keine Vollstreckungshindernisse vorliegen und die Zwangsmittelanwendung muss ermessensfehlerfrei, insbesondere verhältnismäßig sein. Für detaillierte Ausführungen zu den jeweiligen Vollstreckungsvoraussetzungen wird auf $\S 2$ Rn. $1322 \mathrm{ff}$. verwiesen.

\section{b) Besondere Vollstreckungsvoraussetzungen}

200 Die Zwangsmittelanwendung muss sich einem ordnungsgemäßen Vollstreckungsverfahren anschließen und sich im Rahmen der vorausgegangenen Festsetzung bewegen.

\section{aa) Ordnungsgemäßes Vollstreckungsverfahren}

201 Die Rechtmäßigkeit der Zwangsmittelanwendung setzt ein ordnungsgemäßes Vollstreckungsverfahren voraus. Das Vollstreckungsverfahren setzt sich aus der Androhung und Festsetzung des Zwangsmittels zusammen, §§ 13, 14 VwVG. Beide sind ihrerseits Verwaltungsakte, die inzident zu prüfen sind. Der jeweils vorausgehende Rechtsakt ist Rechtmäßigkeitsvoraussetzung für den nachfolgenden Rechtsakt. ${ }^{381}$ Bei der Prüfung der Verfahrensschritte ist auch hier der tragende Grundsatz des Verwaltungsvollstreckungsrechts zu beachten, der besagt, dass die Rechtmäßigkeit einer Vollstreckungsmaßnahme lediglich von der Wirksamkeit und Vollstreckbarkeit, ${ }^{382}$ nicht aber von der Rechtmäßigkeit der vorausgehenden Verfahrensschritte abhängt. ${ }^{383}$ Wie beim Grundverwaltungsakt müssen also auch hier die Wirksamkeitsvoraussetzungen von Androhung und Festsetzung von deren Rechtmäßigkeitsvoraussetzungen getrennt werden.

381 Baumeister, in: Schenke/Graulich/Ruthig, Sicherheitsrecht des Bundes, VwVG, 2. Aufl. 2019, $\S 13$ Rn. 2.

382 Da § 80 II 1 Nr. 3, S. 2 VwGO i.V.m. den jeweiligen landesrechtlichen Vorschriften vorsieht, dass Rechtsbehelfe gegen Verwaltungsakte im Vollstreckungsverfahren keine aufschiebende Wirkung haben, ist das Kriterium der Vollstreckbarkeit regelmäßig gegeben, als Beispiel: §4 I AGVwGO Berlin.

383 Poscher/Rusteberg, JuS 2012, 26 (29); Deusch/Burr, in: Bader/Ronellenfitsch, VwVG, 43. Ed., Stand: 1.4. 2019, § 14 Rn. 14; Sadler, VwVG VwZG, 9. Aufl. 2014, § 14 Rn. 17 ff.; BVerwG, Urt. v. 13.4. 1984, Az.: 4 C 31/81 = NJW 1984, 2591; BVerwG, Beschl. v. 21.8.1996, Az.: 4 B 100/96 = NVwZ 1997, 381; OVG München, Beschl. v. 30.3.2005, Az.: 11 B 03.1818. 


\section{(1) Wirksame Androhung, § 13 VwVG}

Die Androhung bedarf zu ihrer Wirksamkeit (neben dem Nichtvorliegen eines 202 Nichtigkeitgrundes nach § $44 \mathrm{VwVfG}$ ) der Zustellung nach dem VwZG (§ 13 VII VwVG).

\section{(2) Wirksame Festsetzung, § 14 VwVG}

Wird die Festsetzung im Rahmen der Überprüfung der Zwangsmittelanwendung 203 relevant, so kommt es erneut allein auf ihre Wirksamkeit an. Die Festsetzung ist im Ausnahmefall einmal entbehrlich, wenn der Verpflichtete ernstlich und endgültig erklärt, dass er der Verpflichtung nicht nachkommen wird und somit auf die Schutzwirkung der Festsetzung verzichtet. ${ }^{384}$

\section{bb) Anwendung im Rahmen der Festsetzung}

Die Zwangsmittel müssen der Festsetzung gemäß angewendet werden, §15 I 204 VwVG. Wurde beispielsweise die Ersatzvornahme festgesetzt, so darf die Behörde auf Anwendungsebene nicht auf die Beitreibung eines Zwangsgeldes bestehen.

384 BVerwG, Beschl. v. 21.8.1996, Az.: 4 B 100/96 = NVwZ 1997, 381; kritisch Baumeister, in: Schenke/Graulich/Ruthig, Sicherheitsrecht des Bundes, VwVG, 2. Aufl. 2019, § 14 Rn. 13. 